\title{
The Origin of Organic Pollutants from the Combustion of Alternative Fuels: Phase V/VI Report
}

S. Sidhu, J. Graham, P. Taylor, and B. Dellinger

University of Dayton Research Institute

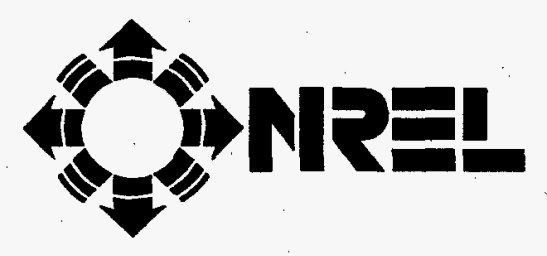

Alternative Fuels Hotline: 1-800-423-1DOE

Alternative Fuels Data Center World Wide Web Site: http://www.afdc.doe.gov

National Renewable Energy Laboratory

1617 Cole Boulevard

Golden, Colorado 80401-3393

A national laboratory of the

U.S. Department of Energy

Managed by the Midwest Research Institute

For the U.S. Department of Energy

Under Contract No. DE-AC36-83CH10093 


\section{The Origin of Organic Pollutants from the Combustion of Alternative Fuels: Phase V/VI Report}

S. Sidhu, J. Graham, P. Taylor, and B. Dellinger

University of Dayton Research Institute

NREL Technical Monitor: Paul Bergeron

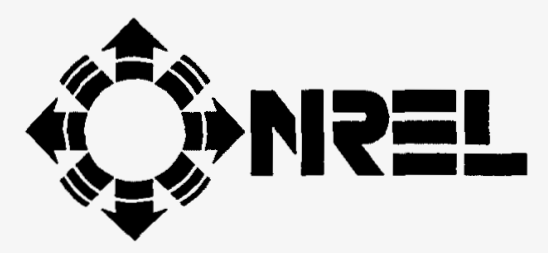

Alternative Fuels Hotline: 1-800-423-1DOE

Alternative Fuels Data Center World Wide Web Site: http://www.afdc.doe.gov

National Renewable Energy Laboratory

1617 Cole Boulevard

Golden, Colorado 80401-3393

A national laboratory of the

U.S. Department of Energy

Managed by the Midwest Research Institute

For the U.S. Department of Energy

Under Contract No. DE-AC36-83CH10093

Prepared under Subcontract Number XAU-3-12228-02

May 1998

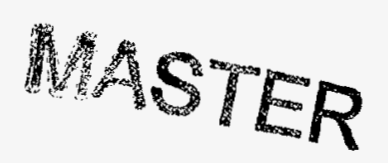




\section{NOTICE}

This report was prepared as an account of work sponsored by an agency of the United States government. Neither the United States govemment nor any agency thereof, nor any of their employees, makes any warranty, express or implied, or assumes any legal liability or responsibility for the accuracy, completeness, or usefulness of any infurmation, apparatus, product, or process disclosed, or represents that its use would not infringe privately owned rights. Reference herein to any specific commercial product, process, or service by trade name, trademark, manufacturer, or otherwise does not necessarily constitute or imply its endorsement, recommendation, or favoring by the United States government or any agency thereof. The views and opinions of authors expressed herein do not necessarily state or reflect those of the United States government or any agency thereof.

Available to DOE and DOE contractors from:

Office of Scientific and Technical Information (OSTI)

P.O. Box 62

Oak Ridge, TN 37831

Prices available by calling (423) $576-8401$

Available to the public from:

National Technical Information Service (NTIS)

U.S. Department of Commerce

5285 Port Royal Road

Springfield, VA 22161

(703) $487-4650$ 


\section{Executive Summary}

As part of the US-DOE's on-going interest in the use of alternative automotive fuels, the University of Dayton Research Institute has been conducting research on pollutant emissions resulting from the combustion of candidate fuels. This research, under the direction and sponsorship of the Department of Energy and the National Renewable Energy Laboratory (DOE/NREL), has been concerned with the combustion of compressed natural gas (CNG), liquefied petroleum gas (LPG), methanol-gasoline mix (M85), and ethanol-gasoline mix (E85).

In the first 24 months of this program, studies of the oxygen rich, stoichiometric, and fuel-rich thermal degradation of these fuels in the temperature range of 300 to $1100^{\circ} \mathrm{C}$ at atmospheric pressure and for reaction times of 1.0 and $2.0 \mathrm{~s}$ were completed. Trace organic products were identified and quantified for each fuel as a function of temperature. The results of these studies agreed well with the results of tail-pipe emission studies in that the types and quantity of emissions measured in both the laboratory and engine tests were shown to be very similar under certain operating conditions. However, some chemicals were observed in the laboratory studies that were not observed in the engine studies and vice versa. This result is important in that it has implications concerning the origin of these emissions.

As a consequence of these results, we developed a qualitative failure mode assessment of alternative fuel combustion and used it to identify additional experimental tasks to better understand the origin of organic emissions. During this contract period, these experimental tasks have focused on:

- boundary layer failure mode effects on the high pressure combustion of alternative fuels, - the effects of $\mathrm{NO}_{\mathrm{x}}$ on the oxidation of residual alcohol fuels,

- and the low temperature, surface catalyzed oxidation of residual alcohol fuels.

High pressure combustion of alternative fuels suggests that benzene, formaldehyde, acetaldehyde (except from CNG), and ethylene can form in cylinder engine under thermal quenching failure conditions. These thermal quenching conditions are experienced by the fuel that is near cylinder walls (lower temperature) and does not undergo ignition combustion. It was also observed that aromatic fraction of fuels was destroyed easily during high pressure, high temperature combustion in the engine cylinder. Thus any aromatic hydrocarbon components seen in tail pipe emissions from these fuels must be from the aromatic fraction of fuel that escaped the engine cylinder high pressure combustion region. The results from the second set of experiments show that the presence of an oil layer did not change total fuel conversion. However, the hydrocarbon fraction (primarily benzene) did exhibit an increase in concentration in the presence of an oil layer. This is in contrast to the oxygenates for which no effect was observed. This is attributed to the greater solubility of hydrocarbons in the oil layer. An investigation of the effect of crevices and indentations inside the cylinder on emissions was also conducted. Repeated attempts to configure aluminum foil and mylar inserts within the existing test section were largely inconclusive. The limited experimental results and evaluation of the surface tension of oxygenates and hydrocarbons indicate that the effects of cracks and crevices would be similar for both classes of compounds. A specially designed, perforated, stainless steel test section is needed to further explore this possible effect.

Experiments concerning the NO perturbed oxidation of methanol, M85, ethanol, and E85 indicated the presence of complex oxidation chemistry. At mild temperatures, NO addition resulted in enhanced fuel conversion. At elevated temperatures, an inhibitory effect was observed through increased yields of both partial oxidation and pyrolysis-type reaction products. Comparison of flow reactor product distributions with engine test results generally indicated improved comparisons when NO was added to the fuel. This improvement is an indication of the importance 
of post-cylinder reactions of residual fuel and NO. Previous experiments were conducted in the absence of NO. These reactions result in additional conversion of residual fuel and the formation of partially oxidized intermediates and elevated levels of light hydrocarbon pyrolysis products. The addition of $\mathrm{NO}_{2}$ did not impact product distributions for methanol, ethanol, natural gas, and $\mathrm{LP}$ gas. The addition of $\mathrm{NO}_{2}$ did enhance the low temperature $\left(500^{\circ} \mathrm{C}\right)$ conversion of the hydrocarbon fraction of M85 and E85.

Laboratory-scale experiments of the conversion of neat methanol, ethanol, M85, and E85 over a commercial Degussa $\mathrm{Pd} / \mathrm{Rh}$ three-way catalyst resulted in $>99 \%$ conversion at $350^{\circ} \mathrm{C}$ for the alcohol fraction of the fuels. However, destruction of the aromatic fraction of M85 and E85 was not complete under these conditions. An additional observation of this study was that the addition of steam inhibited conversion of ethanol and promoted formation of acetaldehyde but it had no effect on methanol based fuels. Thus steam inhibition reduces the effectiveness of commercial three way catalyst to control oxygenate pollutant emissions in vehicles burning E85/ethanol fuel. From results of this study it appears that temperature of the catalyst is a more important parameter for fuel conversion and pollutant formation than oxygen concentration or fuel composition. 


\section{Table of Contents}

Page

Executive Summary . . . . . . . . . . . . . . . . . . . .

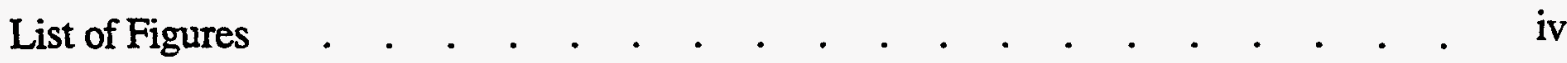

List of Tables . . . . . . . . . . . . . . . . . . . . vii

Introduction . . . . . . . . . . . . . . . . . . . . 1

Task 12 - The High Pressure Combustion of Alternative Fuels. . . . . . . $\quad 8$

Task 13 - The Effect of $\mathrm{NO}_{\mathrm{x}}$ on the Combustion of Altemative Fuels. . . . . . . 22

Task 14 - Low Temperature, Surface Catalyzed and Gas-Phase Pollutant Formation. . 34 


\section{List of Figures}

Page

1. Organic emissions from the thermal degradation of six alternative fuels. Product distributions were obtained for $50 \%$ conversion. $t_{r}=1.0 \pm 0.1 \mathrm{~s} . \phi=1.0$.

2. a) Output of conventional GC-MS of RRG effluent subjected to solid-phase extraction. b) MDGC-MS output signals for heart cuts A and B (above) and instrument blank (below).

3. MTBE Oxidation Pathways. Adapted from reference 7. . . . . . . . . . $\quad 5$

4. Schematic of high temperature, high pressure reactor (HTHP). . $\quad$. $\quad$. $\quad$. $\quad$. $\quad$. $\quad 9$

5. GC-TCD traces for the high pressure combustion of $\mathrm{M} 85 . \mathrm{T}=1230^{\circ} \mathrm{C}, \mathrm{p}=9.5 \mathrm{bar}$.

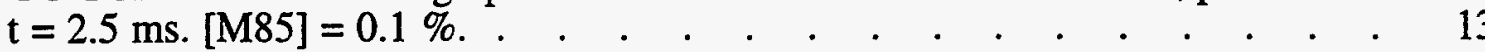

6. GC-TCD traces for the high pressure combustion of $\mathrm{E} 85 . \mathrm{T}=1220^{\circ} \mathrm{C} \cdot \mathrm{p}=9.2 \mathrm{bar}$.

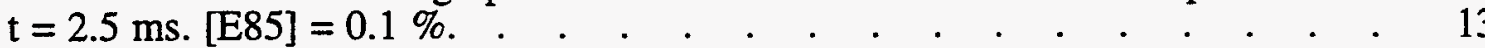

7. GC-TCD traces for the high pressure combustion of Natural Gas. $\mathrm{T}=1170^{\circ} \mathrm{C}$. $\mathrm{p}=9.2$ bar. $\mathrm{t}=2.5 \mathrm{~ms}$. [Natural Gas] $=0.1 \%$.

8. GC-TCD traces for the high pressure combustion of RFG. $\mathrm{T}=1190^{\circ} \mathrm{C} \cdot \mathrm{p}=9.3 \mathrm{bar}$. $\mathrm{t}=2.5 \mathrm{~ms} .[\mathrm{RFG}]=0.1 \%$.

9. Product distributions from the stoichiometric flow reactor oxidation of M85. Yields are reported as non-methane organic gases (NMOG). $T=800^{\circ} \mathrm{C} . t=0.75 \mathrm{~s}$.

$[\mathrm{NO}]=200 \mathrm{ppm}$.

10. Product distributions from the stoichiometric oxidation of E85. Yields are reported as non-methane organic gases $(\mathrm{MNOG}) . \mathrm{T}=800^{\circ} \mathrm{C} . \mathrm{t}=0.75 \mathrm{~s}$. $[\mathrm{NO}]=100 \mathrm{ppm}$.

11. Product distributions from the stoichiometric flow reactor oxidation of natural gas. Yields are reported as non-methane organic gases (NMOG). $\mathrm{T}=1035^{\circ} \mathrm{C} . \mathrm{t}=0.75 \mathrm{~s}$. $[\mathrm{NO}]=135 \mathrm{ppm}$.

12. Product yields from $\mathrm{M} 85$ and $\mathrm{E} 85300^{\circ} \mathrm{C}$. Fuels were passed over $\mathrm{Pd} / \mathrm{Rh}$ catalyst with a carrier gas containing $0.1 \% \mathrm{CO}, 1 \% \mathrm{O}_{2}, 10 \% \mathrm{H}_{2} \mathrm{O}$, and $1500 \mathrm{ppm} \mathrm{NO}$.

Residence time $=150 \mathrm{~ms}$. Space velocity $=24,000 \mathrm{~h}^{-1}$.

13. Molar yields of organic products from methanol oxidation as a function of [NO] and fuel/air equivalence ratio. $\mathrm{T}=923 \mathrm{~K}, \mathrm{t}_{\mathrm{r}}=0.75 \mathrm{~s}$. For $\phi=0.8,\left[\mathrm{CH}_{3} \mathrm{OH}\right]_{0}=$ $450 \mathrm{ppm},[\mathrm{NO}]_{0}=150,300 \mathrm{ppm}$. For $\phi=1.0,\left[\mathrm{CH}_{3} \mathrm{OH}\right]_{0}=565 \mathrm{ppm},[\mathrm{NO}]_{0}=$ $185,370 \mathrm{ppm}$. For $\phi=1.1,\left[\mathrm{CH}_{3} \mathrm{OH}\right]_{0}=620 \mathrm{ppm},[\mathrm{NO}]_{0}=205,410 \mathrm{ppm}$. 


\section{List of Figures \\ (Continued)}

14. Molar yields of organic products from methanol oxidation as a function of [NO] and fuel/air equivalence ratio. $\mathrm{T}=1073 \mathrm{~K}, \mathrm{t}_{\mathrm{r}}=0.75 \mathrm{~s}$. For $\phi=0.8,\left[\mathrm{CH}_{3} \mathrm{OH}\right]_{0}=$ $565 \mathrm{ppm},[\mathrm{NO}]_{0}=185,370 \mathrm{ppm}$. For $\phi=1.0,\left[\mathrm{CH}_{3} \mathrm{OH}\right]_{0}=705 \mathrm{ppm},[\mathrm{NO}]_{0}=$ $230,460 \mathrm{ppm}$. For $\phi=1.1,\left[\mathrm{CH}_{3} \mathrm{OH}\right]_{0}=775 \mathrm{ppm},[\mathrm{NO}]_{0}=255,510 \mathrm{ppm}$. . .

15. Molar yields of organic products from ethanol oxidation as a function of [NO] and fuel/air equivalence ratio. $\mathrm{T}=773 \mathrm{~K}, \mathrm{t}_{\mathrm{r}}=0.75 \mathrm{~s}$. For $\phi=0.8,\left[\mathrm{CH}_{3} \mathrm{CH}_{2} \mathrm{OH}\right]_{0}=$ $225 \mathrm{ppm},[\mathrm{NO}]_{0}=75,150 \mathrm{ppm}$. For $\phi=1.0,\left[\mathrm{CH}_{3} \mathrm{CH}_{2} \mathrm{OH}\right]_{0}=285 \mathrm{ppm},[\mathrm{NO}]_{0}=$ $95,190 \mathrm{ppm}$. For $\phi=1.1,\left[\mathrm{CH}_{3} \mathrm{CH}_{2} \mathrm{OH}\right]_{0}=310 \mathrm{ppm},[\mathrm{NO}]_{0}=105,205 \mathrm{ppm}$.

16. Molar yields of organic products from ethanol oxidation as a function of [NO] and fuel/air equivalence ratio. $\mathrm{T}=923 \mathrm{~K}, \mathrm{t}_{\mathrm{r}}=0.75 \mathrm{~s}$. For $\phi=0.8,\left[\mathrm{CH}_{3} \mathrm{CH}_{2} \mathrm{OH}\right]_{0}=$ $225 \mathrm{ppm},[\mathrm{NO}]_{0}=75,150 \mathrm{ppm}$. For $\phi=1.0,\left[\mathrm{CH}_{3} \mathrm{CH}_{2} \mathrm{OH}\right]_{0}=285 \mathrm{ppm},[\mathrm{NO}]_{0}=$ 95, $190 \mathrm{ppm}$. For $\phi=1.1,\left[\mathrm{CH}_{3} \mathrm{CH}_{2} \mathrm{OH}\right]_{0}=310 \mathrm{ppm},[\mathrm{NO}]_{0}=105,205 \mathrm{ppm}$. .

17. Molar yields of organic products from ethanol oxidation as a function of [NO] and fuel/air equivalence ratio. $\mathrm{T}=1073 \mathrm{~K}, \mathrm{t}_{\mathrm{r}}=0.75 \mathrm{~s}$. For $\phi=0.8,\left[\mathrm{CH}_{3} \mathrm{CH}_{2} \mathrm{OH}\right]_{0}=$ $280 \mathrm{ppm},[\mathrm{NO}]_{0}=90,185 \mathrm{ppm}$. For $\phi=1.0,\left[\mathrm{CH}_{3} \mathrm{CH}_{2} \mathrm{OH}\right]_{0}=355 \mathrm{ppm},[\mathrm{NO}]_{0}=$ $115,235 \mathrm{ppm}$. For $\phi=1.1,\left[\mathrm{CH}_{3} \mathrm{CH}_{2} \mathrm{OH}\right]_{0}=390 \mathrm{ppm},[\mathrm{NO}]_{0}=130,260 \mathrm{ppm}$.

18. Organic Product yields from the stoichiometric oxidation of M85 as a function of temperature and $\left[\mathrm{NO}_{2}\right] . \mathrm{t}_{\mathrm{r}}=0.75 \mathrm{~s},[\mathrm{M} 85]_{0} \sim 250 \mathrm{ppm},\left[\mathrm{NO}_{2}\right]_{0}=5,25 \mathrm{ppm}$.

19. Organic Product yields from the stoichiometric oxidation of $E 85$ as a function of temperature and $\left[\mathrm{NO}_{2}\right] . \mathrm{t}_{\mathrm{r}}=0.75 \mathrm{~s},[\mathrm{E} 85]_{0} \sim 200 \mathrm{ppm},\left[\mathrm{NO}_{2}\right]_{0}=4,20 \mathrm{ppm}$. .

20. Schematic Diagram of Advanced Thermal Reactor System. . . . . . . . 35

21. Product yields from four different fuels at 100,200 , and $300^{\circ} \mathrm{C}$. All fuels were passed over $\mathrm{Pd} / \mathrm{Rh}$ catalyst with a carrier gas containing $0.1 \% \mathrm{CO}, 1 \% \mathrm{O}_{2}, 10 \%$ $\mathrm{H}_{2} \mathrm{O}$, and $1500 \mathrm{ppm}$ NO. Residence time $=150 \mathrm{~ms}$. Space velocity $=24,000 \mathrm{~h}^{-1}$. .

22. GC-FID traces for $1000 \mathrm{ppm}$ methanol over $\mathrm{Pd} / \mathrm{Rh}$ catalyst in carrier gas containing $0.1 \% \mathrm{CO}, 1 \% \mathrm{O}_{2}, 10 \% \mathrm{H}_{2} \mathrm{O}$, and $1500 \mathrm{ppm}$ NO. Residence time $=150 \mathrm{~ms}$. Space velocity $=24,000 \mathrm{~h}^{-1}$.

23. Effect of NO concentration on conversion of methanol and ethanol over $\mathrm{Pd} / \mathrm{Rh}$ catalyst at $100^{\circ} \mathrm{C}$. Experiments with 0 and $500 \mathrm{ppm}$ NO were conducted under stoichiometric conditions; experiments with $1500 \mathrm{ppm}$ NO were conducted under8 fuel-lean conditions. 


\section{List of Figures (Continued)}

24. GC-FID traces for $1000 \mathrm{ppm}$ ethanol over $\mathrm{Pd} / \mathrm{Rh}$ catalyst in carrier gas containing $0.1 \% \mathrm{CO}, 1 \% \mathrm{O}_{2}, 10 \% \mathrm{H}_{2} \mathrm{O}$, and $1500 \mathrm{ppm}$ NO. Residence time $=150 \mathrm{~ms}$. Space velocity $=24,000 \mathrm{~h}^{-1}$.

25. GC-FID traces for $1000 \mathrm{ppm}$ M85 over Pd/Rh catalyst in carrier gas containing $0.1 \% \mathrm{CO}, 1 \% \mathrm{O}_{2}, 10 \% \mathrm{H}_{2} \mathrm{O}$, and $1500 \mathrm{ppm}$ NO. Residence time $=150 \mathrm{~ms}$. Space velocity $=24,000 \mathrm{~h}^{-1}$.

26. GC-FID traces for $1000 \mathrm{ppm} \mathrm{E} 85$ over $\mathrm{Pd} / \mathrm{Rh}$ catalyst in carrier gas containing $0.1 \% \mathrm{CO}, 1 \% \mathrm{O}_{2}, 10 \% \mathrm{H}_{2} \mathrm{O}$, and $1500 \mathrm{ppm}$ NO. Residence time $=150 \mathrm{~ms}$. Space velocity $=24,000 \mathrm{~h}^{-1}$. 


\section{List of Tables}

$\underline{\text { Page }}$

1. Spark Ignited Engine Failure Mode Analysis. . . . . . . . . . . 2

2. Semi-quantitative Product Yields from the High Pressure Combustion of M85. . . 15

3. Semi-quantitative Product Yields from the High Pressure Combustion of E85. . . 15

4. Semi-quantitative Product Yields from the High Pressure Combustion of Natural Gas. 16

5. Semi-quantitative Product Yields from the High Pressure Combustion of RFG. $\quad 16$

6. GC-MS Conditions. . . . . . . . . . . . . . . . . . 23 


\section{Introduction}

As part of the DOE/NREL program on alternative automotive fuels, the Environmental Science and Engineering Group of the University of Dayton Research Institute (UDRI) has been conducting studies on the origin and fate of organic pollutants from the combustion of alternative fuels. In phases I-III, a quantitative characterization of organic combustion by-products from natural gas [14]. LP gas [1-4] methanol [1-4], ethanol [1-4], and MTBE [5] has been conducted. In addition, detailed kinetic studies of the reaction of hydroxyl radicals with methanol [1,3], ethanol [1,3]. dimethyl ether [6,7], methyl $t$-butylether (MTBE) [6,7], and acetaldehyde [6,8] have been completed. In phase IV, we examined the effects of catalytic surfaces [9] and nitric oxide (NO) [9.10] on the post-combustion oxidation of alternative fuels. conducted a quantitative characterization of organic combustion by-products from M85 [9,11] and E85 [9.11], and initiated the development of multi-dimensional gas-chromatographic techniques for the even more detailed characterization of combustion emissions from reformulated gasoline [9]. These studies were conducted in the context of a "failure mode" model that we developed to account for pollutant emissions from automotive systems [9].

\section{Assessment of Potential Failure Modes}

Studies of conventional gasoline indicate about $91 \%$ of the fuel is consumed in the cylinder flame during the power stroke, with $9 \%$ of the fuel escaping unburned or converted to products of incomplete combustion (PICs) $[12,13]$. However about $2 \%$ of this unburned fraction is decomposed in the exhaust port or manifold following the exhaust stroke and about $5 \%$ is decomposed in the cylinder during the subsequent intake or compression strokes $[12,13]$. Of the remaining $2 \%$, about $1.5 \%$ is degraded in the exhaust pipe or catalytic converter. Key questions we are trying to address are: 1) how do these proportions change for alternative fuels? and 2) which pollutants are formed in each zone?

Table 1 presents the results of a partial assessment of these questions for spark-ignited (SI) engines. Here we have identified potential engine/exhaust port failure modes, i.e., conditions or zones where combustion may not be complete. We have also identified which fuel properties would control destruction under each failure mode. For example, oxidation kinetics would control emissions from the cylinder under conditions of thermal quenching at the cylinder wall or cooling of the cylinder gas by intake air. Consequently, the oxidizability of the fuel as represented by the temperature required for $99 \%$ destruction ( $\mathrm{T}_{99}(\mathrm{ox})$ ); the difficulty in oxidation of PICs from the fuel can be represented by the temperature of maximum PIC formation (TPIC(ox)); and buming temperature of the fuel as represented by its adiabatic flame temperature $\left(\mathrm{T}_{\mathrm{ad}}\right)$ are all fuel parameters that might control the efficiency of destruction in the cylinder under thermal quenching. In the post-cylinder regions, oxygen starved degradation may be dominant. Thus, the pyrolytic stability of the fuel (T99 (py)) and the pyrolytic stability of the PICs (TPIC(py)) may control emissions. If the fuel is dissolved in an oil layer [13] then its oil solubility as represented by its octanol-water partition coefficient $\left(\mathrm{K}_{\mathrm{o} / \mathrm{w}}\right)$ or volatility as represented by its vapor pressure (V.P.) may control emissions. If the fuel is in a cylinder groove or crevice [13], the capillary action as indicated by its surface tension $(\xi)$ may control emissions. If liquid fuel pools are formed on the cylinder head [13], then the vapor pressure of the fuel will correlate with efficiency of destruction. 
Table 1. Spark Ignited Engine Failure Mode Analysis

\begin{tabular}{|c|c|c|c|}
\hline Failure Mode & Indicator & Parameter & Correlation \\
\hline $\begin{array}{c}\text { In-cylinder thermal } \\
\text { quenching }\end{array}$ & Oxidizability & $\mathrm{T}_{99}(\mathrm{ox})^{1}$ & No \\
\hline & & $\mathrm{T}_{\mathrm{PIC}}(\mathrm{ox})^{2}$ & No \\
\hline & & $\mathrm{T}_{\mathrm{ad}}{ }^{3}$ & Yes \\
\hline $\begin{array}{c}\text { Post-cylinder } \\
\text { pyrolysis }\end{array}$ & Thermal Stability & $\mathrm{T}_{99}(\mathrm{py})^{4}$ & No \\
\hline & & $\mathrm{T}_{\mathrm{PIC}(\mathrm{py})^{5}}$ & No \\
\hline Oil layer adsorption & Oil Solubility & $\mathrm{K}_{\mathrm{o} / \mathrm{w}^{6}}$ & No \\
\hline & & V.P. $^{7}$ & Yes \\
\hline Crevice wetting & Capillary Action & $\xi^{8}$ & Yes \\
\hline Liquid fuel pooling & Vapor Pressure & V.P. & Yes \\
\hline
\end{tabular}

\section{Parameter Descriptions:}

1. Temperature for $99 \%$ destruction as determined under excess air conditions.

2. Temperature for maximum levels of PIC (product of incomplete combustion) formation as determined under excess air conditions.

3. Adiabatic flame temperature.

4. Temperature for $99 \%$ destruction as determined under fuel-rich conditions.

5. Temperature for maximum levels of PIC (product of incomplete combustion) formation as determined under fuel-rich conditions.

6. Octanol-water partition coefficient.

7. Vapor pressure.

8. Surface tension.

The various fuel properties identified in Table 1 were correlated with emissions from different alternative fuels. Positive correlations were obtained for the adiabatic flame temperature, vapor pressure as related to oil layer adsorption and liquid pool formation, and surface tension as related to capillary action in cylinder crevices. This suggests that pollutant emissions most likely result from absorption of the fuel in oil layers, wetting of crevices, and thermal quenching in the cylinder or in the exhaust manifold. These results lead us to believe that studies of the origin of emissions from alternative fuels should address these specific failure modes.

\section{Summary of Phases I-IV}

The chemical nature of organic emissions is also likely to depend upon the failure mode and zone in which the by-product is produced. Our post-combustion flow reactor [1-5.9-11] and elementary reaction kinetic studies $[1,3,6-8]$ indicate that a wide range of types of PICs can be produced. Figure 1 presents a summary of organic by-products from the stoichiometric oxidation of six alternative fueis for equal levels of fuel conversion $(-50 \%)$. The nature of the hydrocarbons is as expected and consists of alkanes, olefins, and alkynes. In addition, oxygenates, including alcohols (unburned fuel) and carbonyls were also observed. Species containing carbonyl groups can be very reactive and act as efficient ozone precursors. In addition, compounds containing multiple carbonyl groups are of largely unknown toxicity. Under fuel-rich conditions, aromatics and alkylated aromatics were also observed and are indicative of molecular growth type reactions that occur in all combustion systems. 


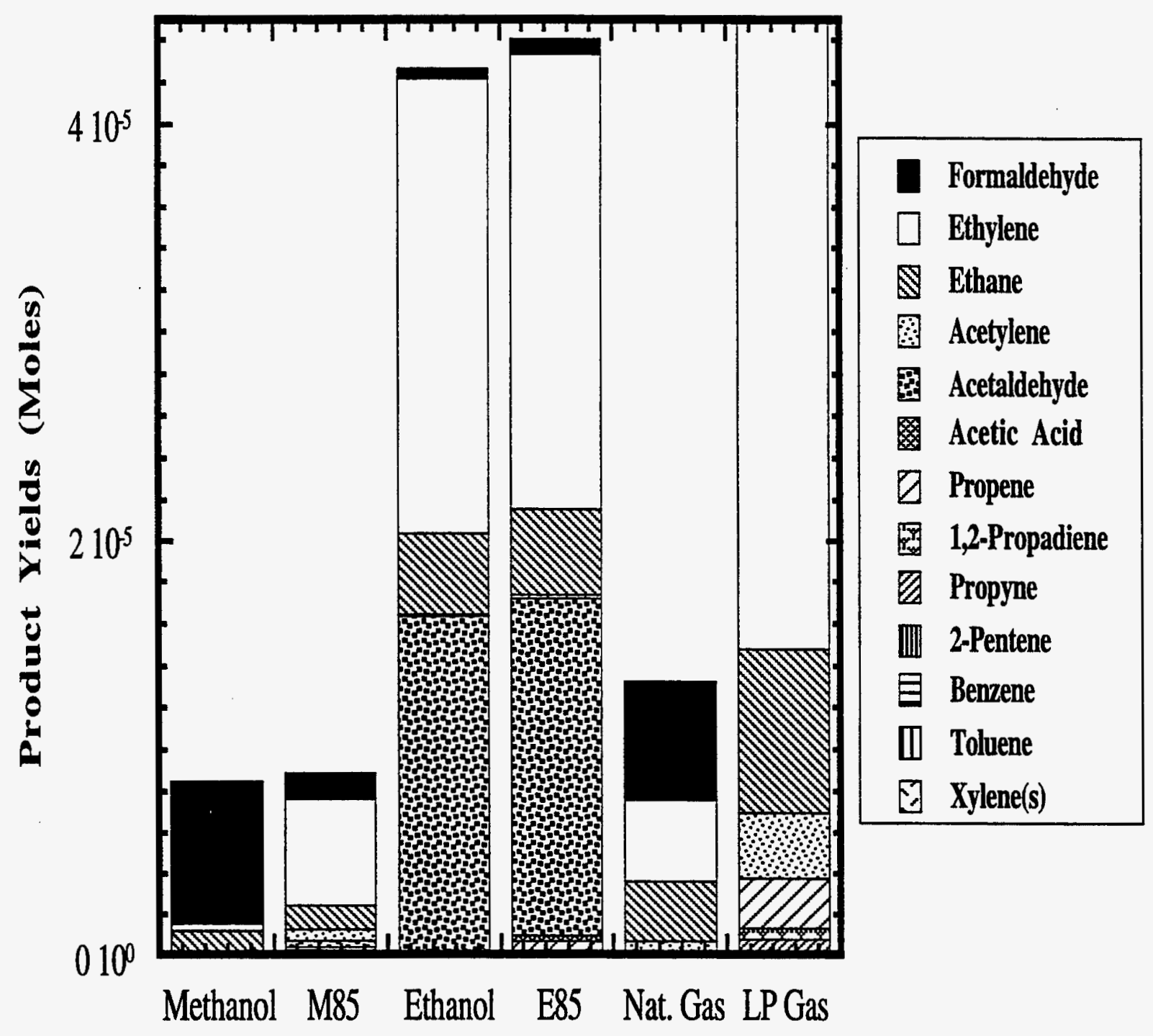

Fuel

Figure 1. Organic emissions from the thermal degradation of six alternative fuels. Product distributions were obtained for $-50 \%$ conversion. $t_{r}=1.0 \pm 0.25 \mathrm{~s}$. Fuel-air equivalence ratio $=1.0$.

Figure 2 presents a summary of the characterization of polar (largely oxygenated hydrocarbons) PICs produced from the oxidation of reformulated gasoline [9]. These chromatograms were produced by solid phase, silica gel extraction of the effluent from the $600^{\circ} \mathrm{C}$ oxidation of reformulated gasoline followed by two-dimensional GC analysis. Narrow heartcuts from the onedimension chromatogram at 16.2 and 27.2 minutes were subjected to a second dimension of analysis. The previously unidentifiable singlet peak at 16.2 minutes and the doublet at 27.2 minutes were resolved into more than 30 different solutes. MS analysis revealed that these PICs were largely singly oxygenated or doubly oxygenated hydrocarbons, e.g. 3,4-bis(methylene)- 
cyclopentanone, 2-methyl-cyclopenten-1-one, cycloheptatriene-1-one, 2H-pyran-2-one, phenol, $\mathrm{C}_{3}$-alkylphenol, trimethylbenzaldehyde, 4-ethyl-benzoic acid methyl ester, 1,4-dihydro-1,4epoxynaphthalene, and 2,3-dihydro-3-methyl-1H-indene-1-one.

(a)

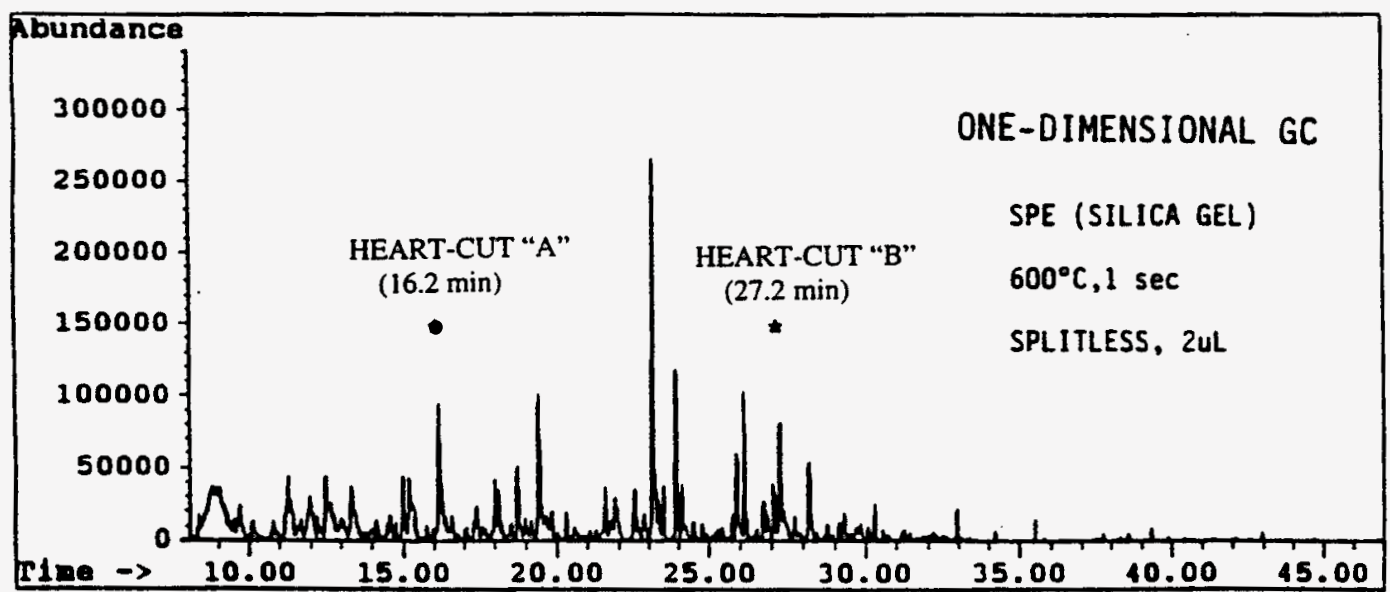

(b)
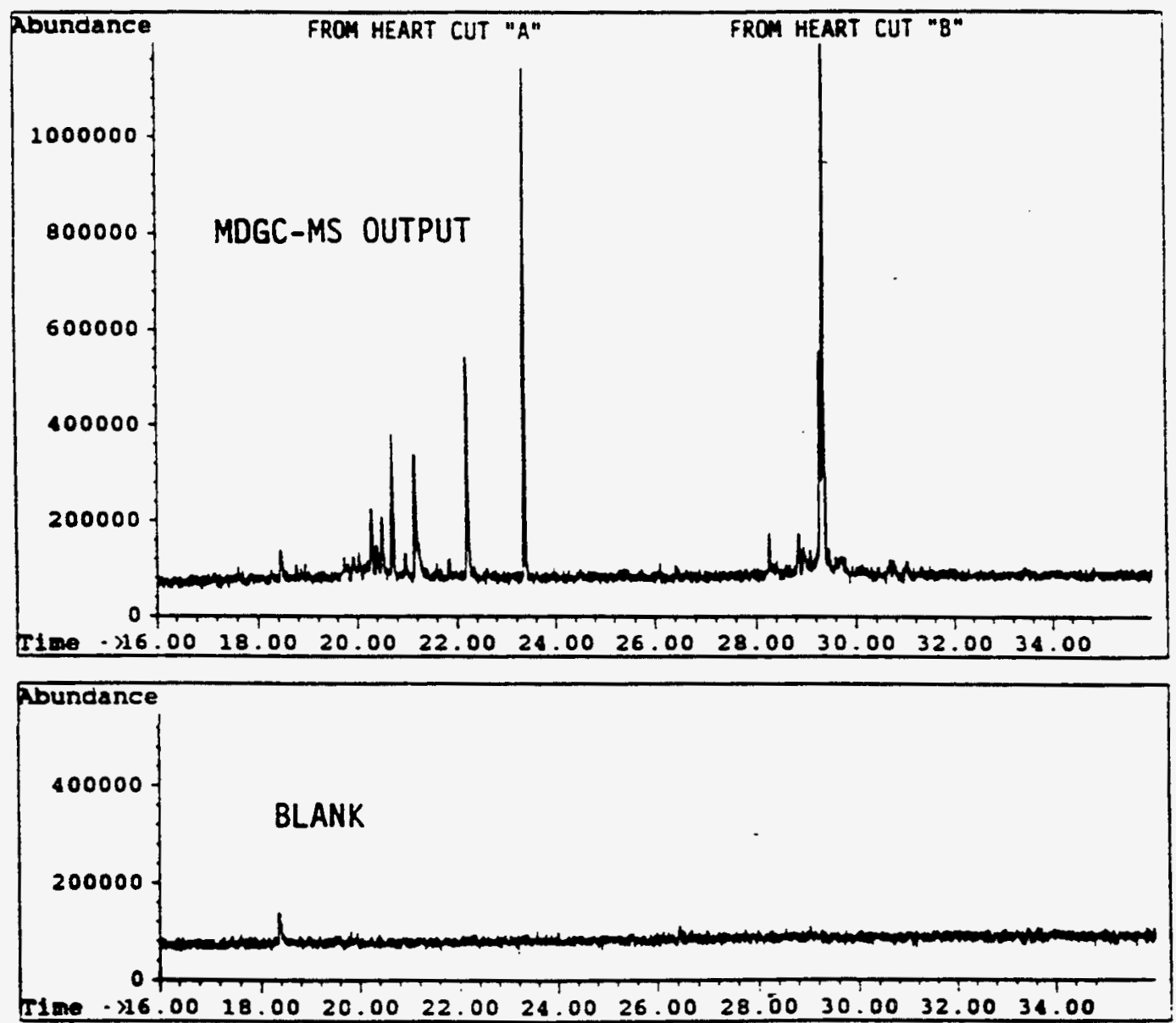

Figure 2. a) Output of conventional GC-MS of RFG effluent subjected to solid-phase extraction. b) MDGC-MS output signals for heart cuts A and B (above) and instrument blank (below). 
Analysis of the mechanism of oxidation of MTBE presents a good example of how these PICs may be produced. Figure 3 displays four routes of decomposition of MTBE following attack by hydroxyl radical $[6,7]$. Products denoted in boldface type were observed in the stoichiometric gasphase oxidation of MTBE in a tubular flow reactor [5]. Hydrogen abstraction by hydroxyl radical is expected to be the initial step in the decomposition of MTBE, as hydroxy radical is the dominant reactive radical under stoichiometric combustion conditions. The first two pathways result in formation of formaldehyde as an identifiable PIC, preceding complete oxidation to $\mathrm{CO}_{2}$. The third pathway can result in molecular growth, although many of intermediate hydrocarbon species are expected to be oxidized also. However, the fourth pathway is expected to result in formation of oxygenated alkenes that can undergo further partial oxygenation to form di-oxygenates. These types of PICs can be very effective ozone precursors. For example, methyl glyoxyl has one of the highest known MIRs. However, based on the results described in task 14. it is unlikely that methyl glyoxyl will survive transit through the catalytic converter.

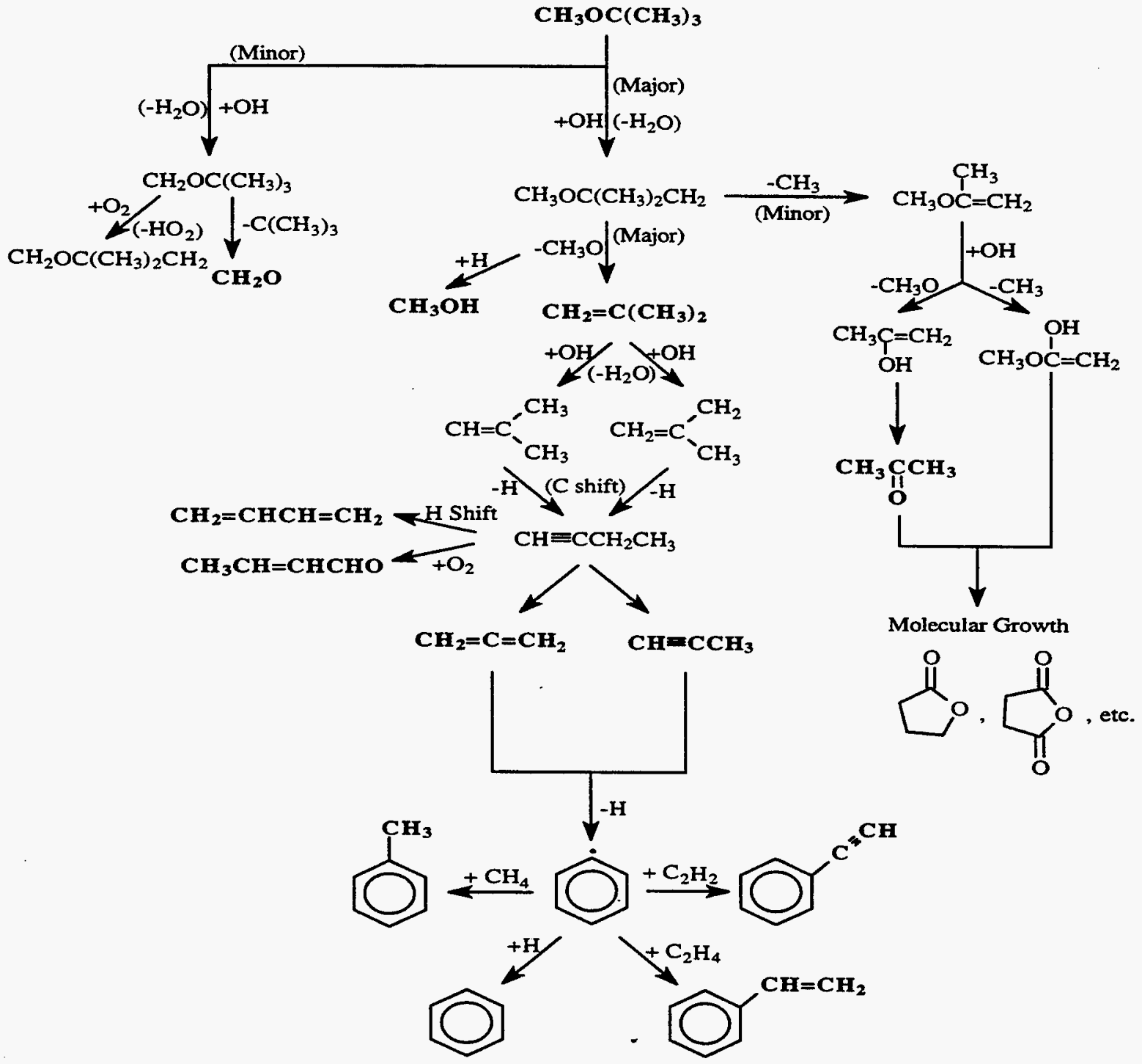

Figure 3. MTBE Oxidation Pathways. Adapted from reference 7. 
Introduction of $\mathrm{NO}_{\mathrm{x}}$ to the system is expected to further increase the formation of oxygenates. Experiments of the NO perturbed oxidation of methanol, M85, ethanol, and E85 have been completed for temperatures ranging from $500-800^{\circ} \mathrm{C}[9,10]$. Two general effects were observed for all four fuels. The addition of NO increased the conversion of each fuel to partial oxidation byproducts. The primary effect was the increased yields of formaldehyde from methanol and M85 and acetaldehyde from ethanol and E85. A second effect observed was the increased yields of a wide range of reaction by-products. For example, for ethanol, addition of NO increased yields of pyrolysis-type products such as ethene, ethane, and acetylene (at higher temperatures). Increased yields of oxygenates were also observed with NO addition. Observed by-products included formaldehyde and dimethyl ether. These oxygenates were not observed in the oxidation of ethanol in the absence of NO addition. Examination of total ion chromatograms suggests that several additional by-products were formed that appear to be related to the presence of NO.

Unfortunately, these presumably polar species could not be sufficiently resolved using conventional GC-MS analysis to permit accurate identification.

Surfaces can also result in partially oxygenated PICs as they act as a catalytic substrate for low temperature oxidation of organic species. The results from a preliminary study with ethanol and methanol has shown that most of the pollutants are formed in a temperature range of $50^{\circ} \mathrm{C}$ to $200^{\circ} \mathrm{C}$ [9]. Above $200^{\circ} \mathrm{C}$, catalyst $(\mathrm{Pd} / \mathrm{Rh})$ was very efficient in destroying unburnt fuel. Below $200^{\circ} \mathrm{C}$, methanol mainly formed methyl formate, methyl acetate and methyl carbonate, whereas, ethanol formed methyl to vinyl acetates along with acetone and acetaldehyde. NO addition also had a pronounced effect below $200^{\circ} \mathrm{C}$, it inhibited the destruction of methanol and ethanol and lead to the formation of nitrogen containing species - acetonitrile, nitrobenzaldehyde, acetylamine, nitroethane and substituted imidazole. In one aspect our results agree with engine emission data, that most of emissions are produced under cold start conditions. However, above $200^{\circ} \mathrm{C}$, unlike engine tests our study shows no emissions. This disagreement could be due to different catalyst, higher (or lower) NO concentration, or a different residence time. For example, a broad residence time distribution in the catalyst will result in lower conversion for a small fraction of the engine exhaust. This fraction can be responsible for all observed tailpipe emissions. Based on our experiments, we conclude that the effect of changes in stoichiometry on catalytic efficiency is small when compared to the effect of temperature.

Based on the results for Phases I-IV, we believe important areas of continued study include the mechanism of formation of oxygenated PICs under engine/exhaust failure mode conditions. Classes of PICs include: carbonyls, alcohols, dicarbonyls, and hydroxy carbonyls of a possibly wide range of molecular weights. Failure modes of principal interest include: 1) oxygen depleted thermal degradation of fuel released from indentations, crevices, and oil-layers in the engine cylinder; 2) oxidation of residual fuel and initially formed PICs in a $\mathrm{NO}_{\mathrm{x}}$-rich environment of the exhaust port and manifold; and 3) surface-catalyzed oxidation in the exhaust manifold, tail pipe, and catalytic converter.

In this report describing the results of Phases V and VI, we present three separate experimental studies that represent a continuation of previous studies of the origin of organic pollutants from the combustion of alternative fuels. In task 12, we present high temperature, high pressure combustion studies of M85, E85, CNG, and RFG. This study focuses on the examination of incylinder failure modes on the high temperature oxidation of these fuels. In task 13 , we present the conclusion of a previous study $[9,10]$ of the effect of NO on the oxidation of residual fuel. In this task, we present new data on the effect of traces of $\mathrm{NO}_{2}$ on the post-cylinder oxidation of residual organic by-products. In addition, the previous data for NO have been quantified and the mechanistic discussion of hydrocarbon-NO interactions is refined. In task 14, we present the conclusion of a previous study [9] that evaluated the effects of temperature on the performance of a fabricated three-way oxidation catalyst with respect to organic emissions. In this task, the results for the fabricated catalyst are compared to a commercial Degussa three-way catalyst. The effects of different exhaust gas effluent composition were also examined. 


\section{$\underline{\text { References }}$}

1. P. H. Taylor and B. Dellinger. 1994. "Impacts of Alternative Fuels on Air Quality," National Renewable Energy Laboratory TP-425-6650, Golden, CO.

2. P. H. Taylor, S. Shanbhag, and B. Dellinger. 1994. "The High-Temperature Pyrolysis and Oxidation of Methanol and Ethanol: Experimental Results and Comparison with Vehicle Emission Tests," in Progress in Emission Control Technologies (SP-1053), SAE Technical Paper Series \#941904, p. 39, Warrendale, PA.

3. P. H. Taylor, W. A. Rubey, S. Shanbhag, M. Rahman, and B. Dellinger. 1995. "The Origin and Fate of Organic Pollutants from the Combustion of Alternative Fuels," National Renewable Energy Laboratory Report TP-425-7607, Golden, CO.

4. P. H. Taylor, S. Shanbhag, W. A. Rubey, B. Dellinger, and M. Bergin. 1998. "Speciation of Organic By-Products from the Thermal Decomposition of Alternative Automotive Fuels," in press, Air and Waste Management Association Journal.

5. P. H. Taylor, S. Shanbhag, and B. Dellinger. 1998. "Benzene Formation from the Flow Reactor Oxidation of MTBE," in press, Combustion and Flame.

6. P. H. Taylor, M. Rahman, and B. Dellinger. 1996. "The Origin and Fate of Organic Pollutants from the Combustion of Alternative Fuels: Phase III Report," National Renewable Energy Laboratory Report TP-425-21082, Golden, CO.

7. M. Arif, B. Dellinger, and P. H. Taylor. 1997. "Rate Coefficients of Hydroxyl Radical Reaction with Dimethyl Ether and Methyl $t$-butyl Ether over an Extended Temperature Range," Journal of Physical Chemistry A, 101, 2436.

8. P. H. Taylor, M. Sm. Rahman, M. Arif, B. Dellinger, and P. Marshall. 1997. "Kinetic and Mechanistic Studies of the Reaction of Hydroxyl Radicals with Acetaldehyde over an Extended Temperature Range," Twenty-Sixth Combustion Symposium, p. 497, The Combustion Institute.

9. P. H. Taylor, L. Cheng, W. A. Rubey, R. C. Striebich, S. S. Sidhu, and B. Dellinger. 1997. "The Origin and Fate of Organic Pollutants from the Combustion of Alternative Fuels: Phase IV Report," National Renewable Energy Laboratory Report SR-540-23145, Golden, CO.

10. P. H. Taylor, L. Cheng, and B. Dellinger. 1998. "The Influence of Nitric Oxides on the Oxidation of Methanol and Ethanol," accepted, Combustion and Flame.

11. P. H. Taylor, L. Cheng, and B. Dellinger. 1996. "Organic Pollutants from the Thermal Degradation of Oxygenated Fuels," in Alternative Fuel: Composition. Performance, Engines, and Systems (SP-1181), SAE Technical Paper Series \#961088, p. 269, Warrendale, PA.

12. J. V. Mendillo and J. B. Heywood. 1981. SAE Technical Paper Series No. 810019 , Warrendale, PA.

13. W. K. Cheng, D. Hamrin, J. B. Heywood, S. Hochgreb, K. Min, and M. Norris. 1993. SAE Technical Paper Series No. 932708 , Warrendale; PA. 


\section{Task 12 - High Pressure Combustion of Alternative Fuels}

\section{Introduction}

In the introduction of this report, we presented a qualitative failure mode analysis of the automotive engine burning alternative fuels. The various fuel properties identified in Table 1 were correlated with emissions from different alternative fuels. Positive correlations were obtained for the adiabatic burning temperature, vapor pressure as related to oil layer adsorption and liquid pool formation, and surface tension as related to capillary action in cylinder crevices. This suggested perhaps that pollutant emissions may result from absorption of the fuel in oil layers, wetting of crevices, and thermal quenching within the engine cylinder or in the exhaust manifold. Based on these results, we decided to address these specific failure modes to better understand the origin of emissions from alternative fuels.

The objective of this task is to determine the types and yields of organic pollutants produced from in-cylinder failure modes such as absorption of fuel in oil layers and retention in cylinder cracks and crevices. A high-temperature shock tube was used to conduct these studies. Experiments were conducted at temperatures between $1200-1500^{\circ} \mathrm{C}$, absolute pressures of $9-10 \mathrm{bar}$, and a fuel/air equivalence ratio of 1.0 (stoichiometric). Reaction times were approximately 2.5-3.0 milliseconds.

Four alternative fuels were examined - M85, E85, CNG, and CA Phase 2 RFG. Baseline experiments were initially conducted to determine the nature of organic emissions under a thermal quenching failure condition. A temperature of $1200-1300^{\circ} \mathrm{C}$ was selected for these experiments. This compares with an adiabatic flame temperature for these fuels in excess of $2000^{\circ} \mathrm{C}$. In the second set of experiments, the walls of the shock tube test section were coated with Fisher mechanical pump oil (solvent refined 100\% neutral paraffinic oil), and the baseline experiments were repeated. The composition Fisher mechanical pump oil is similar to the semi-volatile fraction (branched and linear paraffins) of common engine oil. This makes it possible to evacuate the shock tube while still providing an oil layer for fuel absorption. These experiments were designed to study the influence of solubility of the various fuels in the oil layer on the reaction kinetics of organic by-product formation under a thermal quenching failure condition. In a third set of experiments, a series of simulated crevices were created within the shock tube test section These experiments were designed to determine the influence of fuel wetting of these crevices on the reaction kinetics of organic by-product formation under a thermal quenching failure condition.

The organic by-products obtained from the in-cylinder failure modes experiments are compared with previous studies in our laboratory where organic by-product distributions were measured under different post-combustion failure mode simulations. The initial work conducted under this contract simulated the reactions of unburnt fuel in the exhaust port of an automobile engine. These experiments were conducted with fused silica flow reactors coupled to in-line GC-TCD and GCMS analytical systems. These experiments explored the effects of thermal quenching and poor fuel/air mixing on organic emissions. Subsequent work explored the effects of thermal NOx generation in the engine cylinder on the reaction kinetics of organic by-product formation in the exhaust port. Another series of studies have examined the effects of failure modes during the operation of the three-way noble metal, oxidation catalyst. The effects of catalyst temperature, oxygen concentration, and the composition of the exhaust on the reaction kinetics of organic pollutant destruction on the catalytic surfaces have been studied extensively. The results of these comparisons will provide an initial indication of how the composition of organic by-products varies as a function of different failure modes throughout the automobile engine assembly. 


\section{Experimental Approach}

This study was conducted in a high temperature, high pressure (HTHP) reactor which is based on a single pulse reflective shock tube technique. The single pulse shock tube (SPST) was first described by Glick, et al. [1] in 1955. The SPST is very simple device that generates a high temperature and high pressure pulse for a brief period of time by the aerodynamic action of a shock wave. The HTHP is designed such that the initial and the final pressure and temperature of test section can be independently controlled. This feature of HTHP reactor permits investigation of reactions at various points of the engine cycle. The HTHP reactor is configured so that reactant and products can be removed for analysis after each experiment. Thus the HTHP reactor is an excellent system for the controlled simulation of combustion engines. Fuel vapors can be compressed up to 30 atmospheres and heated to temperatures up to $3000^{\circ} \mathrm{F}$ with exposure times on the order of milliseconds. By controlling the initial pressures on either side of the diaphragm (see figure 4) prior to diaphragm rupture, the full range of engine operating conditions can be generated. The HTHP reactor used in this study is similar to Glick's SPST in essential operation but is much improved in many of the details.

\section{HTHP Reactor Configuration}

The HTHP reactor can be divided into three main sections, driver, driven and test section (see Figure 4).

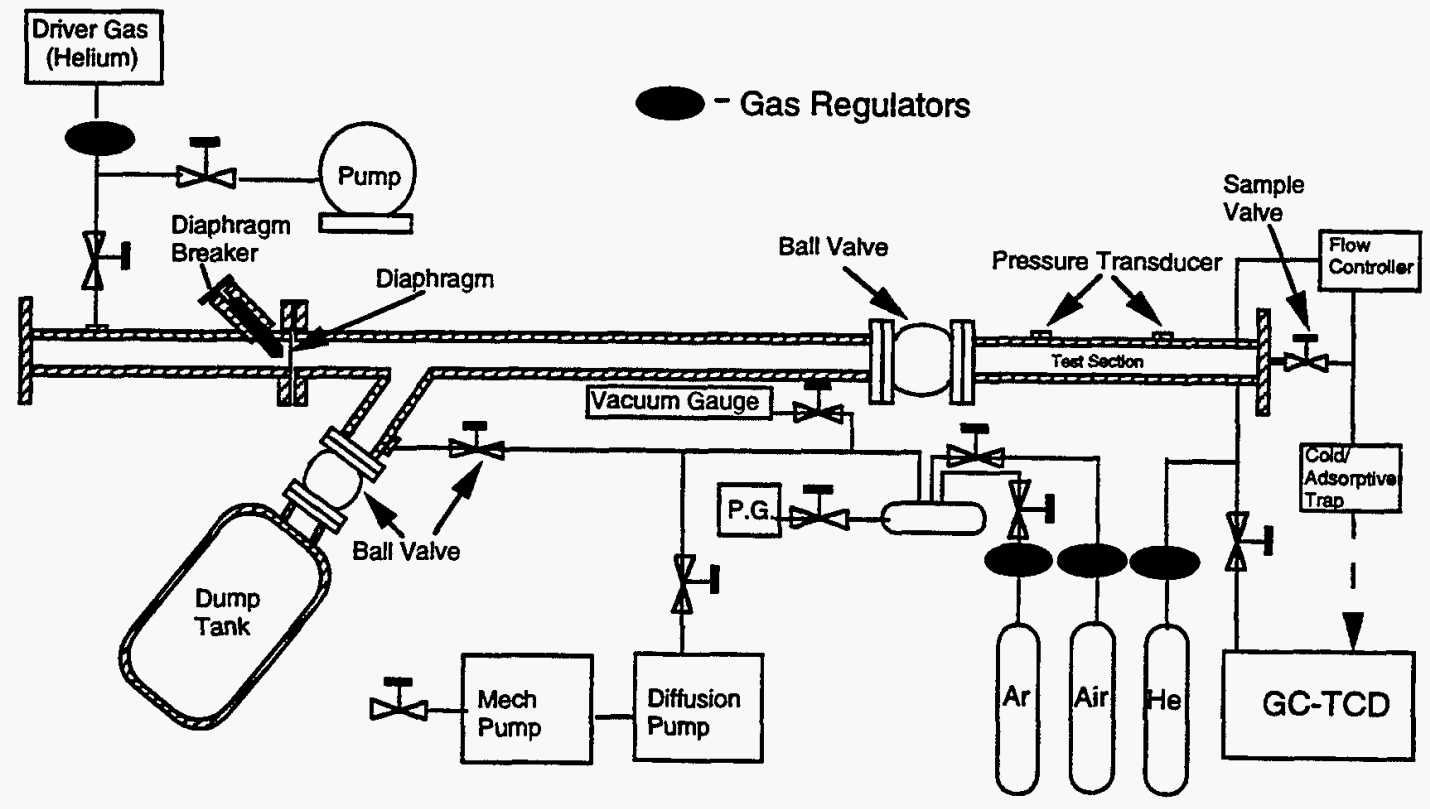

Figure 4. Schematic of high temperature, high pressure reactor (HTHP).

The driver section is the high pressure section which is made of 3 inch i.d. steel tube that is 3 feet long. This section holds the high pressure driver gas (helium) that is used to generate the shock wave and is separated from the driven section of the shock tube by a thin mylar film (diaphragm). The driven and test sections are both low pressure sections that are made of 2-inch i.d., seamless, stainless steel tubing and are 9 feet and 3 feet long, respectively. These two sections are separated by a electro-pneumatic ball valve (James Nelebury). A 40 liter dump tank is connected to driven section near the diaphragm by a 2 inch i.d. steel tube at a $45^{\circ}$ angle with the tube. The dump tank 
prevents reflection of transmitted shock waves and repetitive heating of the reaction mixture. The vacuum system used to evacuate the shock tube is attached to dump tank connecting tube by a 1.5 inch i.d. steel tube. Both dump tank and vacuum system can be isolated from shock tube individually by their respective ball valves. The vacuum system has been designed so that the shock tube may be evacuated quickly to less than 1 mtorr by a Pfeiffer (TPH100) diffusion pump backed by Edwards (Model ES200) mechanical rough pump. Vacuum is measured by a Kurt J. Lesker vacuum gauge ( $1 \mathrm{mtorr}$ to $1 \mathrm{~atm}$ ) and a MKS cold cathode gauge. Test section houses two piezoelectric transducers (P.C.B. Model 113A) that are placed $36 \mathrm{~cm}$ apart to monitor pressure changes in the test section. The output from these transducers is recorded by Lecroy $9450 \mathrm{~A}$ oscilloscope and the waveforms generated are used to calculate incident shock velocity, reflected shock velocity and reaction dwell time. The incident shock velocity is then used to calculate final temperature and pressure using ideal gas equations. The test section also has a rubber septum sealed tap for sample introduction and a tap in the end plate for product sample collection.

For each experiment, the driven and test section were evacuated to less than 1 mtorr and then filled with 100 torr of argon (Air Products, UHP). The ball valve is then shut to separate the test section from the driven section and gas or liquid fuel sample is injected into the test section along with appropriate amount of oxygen to achieve stoichiometric reaction conditions. Fuel is then allowed to $\mathrm{mix}$ and vaporize for a fixed time (10 $\mathrm{min}$ for $\mathrm{E} 85$ and $20 \mathrm{~min}$. for RFG and M85). These times for each fuel were established by thermogravimetric analysis (TGA) at $20^{\circ} \mathrm{C}$ in stagnant air. Even though M85 and RFG have higher vapor pressure than E85, the TGA showed that in stagnant media (e.g. shock tube test section) E85 goes into vapor phase before M85 and RFG. This could be due to diffusion limitations through the stagnant film, which will have higher concentration of fuel in case of M85 and RFG because of their higher vapor pressure. In any case these vaporization times were conservative estimates allowing more than enough time to vaporize fuels in the shocktube test section which is at subambient pressure ( 100 torr) under pre-shock conditions. For CNG, we waited 5 minutes to allow adequate mixing. This procedure is followed so that a known quantity of reactants can be confined to a relativity short axial location so that all reactants can experience the same reaction conditions. In all experiments, reactant mole fraction was always kept below 0.1. This dilution is required so that acoustical properties (specific heat and speed of sound) of the reactant mixture are not very different from the pure inert (ideal) gas. This property helps to prevent shock reflections at the reactant mixture/diluent gas interface and provides a sufficient heat sink so that approximately isothermal conditions are maintained during the reaction time.

As fuel is vaporizing, the driver section is flushed with helium and is filled up to 120 psi. As mentioned above, the driver section is separated from driven section by a thin mylar sheet. The mylar thickness $(0.005$ inch) was determined by the pressure difference between the high and low pressure section. Helium was used as a driver gas because a low molecular weight gas yields the strongest shock, due to its relatively high speed of sound.

To initiate an experiment, the firing sequence is engaged. This opens the ball valve and then the diaphragm is mechanically punctured. At the same instant the diaphragm ruptures, a shock front is formed by action of high pressure gas as it moves through the low pressure region. This shock wave travels along the tube causing a step function increase in temperature and pressure as it passes through the gas until it reaches the end wall, causing a reflection which results in additional step increase in temperature and pressure as it passes through the already processed gas. The arrival of rarefaction (expansion) waves rapidly cools the reaction mixture, at an approximate rate of $5 \times 10^{5}$ $\mathrm{K} / \mathrm{s}$. Due to this rapid cooling the reaction mixture is "frozen" and retains its high temperature composition and thus can be analyzed later by conventional analytical techniques. The ball valve closes immediately after arrival of rarefaction wave isolating the test section from the rest of the tube. The test section is then pressurized to 5 psi with helium and then product samples are collected through a sampling valve located at the end plate. 


\section{Analytical Procedures}

Product samples were collected by two different trapping techniques. In the first technique, product sample was collected in a U-tube cold-trap immersed in liquid nitrogen. A flow rate of approximately $150 \mathrm{ml} / \mathrm{min}$ was maintained during sample collection. The trapped sample was then transferred to a Varian (Model 3700) gas chromatograph (GC) by heating the trap. At the head of the PORAPAKQ GC column (100/120 mesh, $2 \mathrm{~mm} \mathrm{x} 2 \mathrm{~m})$, the products were cryogenically trapped at $-80^{\circ} \mathrm{C}$ using liquid nitrogen as coolant. The $\mathrm{GC}$ was then temperature programmed from $-80^{\circ} \mathrm{C}$ ( $1 \mathrm{~min}$. hold) to $240^{\circ} \mathrm{C}$ at a rate of $20^{\circ} \mathrm{C} / \mathrm{min}$. The products were detected using a thermal conductivity detector (TCD), with detector temperature of $250^{\circ} \mathrm{C}$ and a filament temperature of $270^{\circ} \mathrm{C}$ resulting in approximately $110 \mathrm{~mA}$ of current.

In second sampling technique, the sample was collected on a adsorptive trap (Carbopack B - $0.2 \mathrm{~g}$, mesh $60 / 80$ and Tenax TA- $0.2 \mathrm{~g}$, mesh $60 / 80$ ). A flowrate of $100 \mathrm{ml} / \mathrm{min}$ was maintained during trapping. After trapping was complete, the trap was removed and taken to a STDS flow reactor system where the products were thermally desorbed using oxygen free helium carrier gas at flowrates of $100 \mathrm{ml} / \mathrm{min}$. For desorption, the thermal reactor chamber was programmed from $35^{\circ} \mathrm{C}$ to $300^{\circ} \mathrm{C}$ at rate of $25^{\circ} \mathrm{C} / \mathrm{min}$ with a hold of $10 \mathrm{~min}$. at $300^{\circ} \mathrm{C}$. The desorbed products were then trapped on a DB-1 capillary column (J\&W Scientific, $30 \mathrm{~m}, 0.32 \mathrm{~mm} \mathrm{ID}, 5 \mu \mathrm{m}$ film thickness) held at $-60^{\circ} \mathrm{C}$ using liquid nitrogen as coolant. The $\mathrm{GC}$ was then temperature programmed from $-60^{\circ} \mathrm{C}$ (1 min. hold) to $265^{\circ} \mathrm{C}\left(10 \mathrm{~min}\right.$ hold) at a rate of $15^{\circ} \mathrm{C} / \mathrm{min}$. Products were analyzed by means of a mass selective detector (HP 5970B MSD) operating in the scan mode from 30-250 amu.

The MSD data was used to analyze the product distribution and also help in identification of TCD peaks. The TCD data was used to obtain fuel conversions and relative product yields. Based on MSD data, analytical standards were run on the TCD to confirm product identification and also to obtain relative product and parent yields.

In this study we examined four alternative fuels - M85, E85, CNG, and CA Phase 2 RFG - for three engine failure modes. The first set of experiments were conducted to determine the nature of organic emissions under a thermal quenching failure condition. A temperature of $1200-1300^{\circ} \mathrm{C}$ and a pressure of 9-10 atm was maintained for these experiments. The reaction dwell time for all these experiments was $2.5 \mathrm{~ms}$. In the second set of experiments, one third of the tube i.d. in test section was coated with Fisher mechanical pump oil, and the baseline experiments were repeated. The use of Fisher mechanical pump oil was justified because the solubility of fuels in oil laver is dependent on semi-volatile composition of oil, which was the same for Fisher mechanical pump oil and common engine oil. In a third set of experiments, we tried to simulate crevices within the shock tube test section by placing thin aluminum foils or mylar sheets with perforations inside the test section. These perforated mylar and aluminum sheets were placed along the shock tube walls axially and radially in various widths and configurations. In all these tests, the sheets were removed from the shock tube wall during passage of the incident wave and this resulted in causing an interference with the reflected wave thus prohibiting occurrence of isothermal reaction conditions. Some configurations were better than others and in those it was observed that the effect of crevices appeared to be negligible when compared to the effect of non-idealities in the shock front that were caused by presence of these sheets. From all these tests it was determined that the best way to do this experiment will be to custom design the test section in which crevices of a predetermined depth and length are etched on the inside wall of shock tube. This was beyond the scope of the present study. Thus in following sections we will only present data from baseline and oil layer experiments.

\section{Results}

GC-TCD traces obtained during high pressure combustion of M85, E85, CNG, and RFG, under thermal quenching failure conditions, are presented in Figs 5, 6, 7, and 8, respectively. Reaction 
products are labeled on each chromatogram. GC-TCD traces from oil layer are not shown here because the effect of oil layer on product distribution was too small to be visible in GC-TCD traces. A careful analysis of data shows that the presence of an oil layer did not change total fuel conversion. However, an overall increase in the hydrocarbon concentration was observed but not for the oxygenated fraction. This is attributed to the greater solubility of the hydrocarbons in the oil layer than the oxygenates. The parent fuel conversion and relative (semi-quantitative) yields of identified reaction products from both sets of experiments are presented in tables $2,3,4$, and 5 for M85, E85, CNG, and RFG, respectively. These relative vields were calculated by dividing the integrated response of each product by the integrated response of the primary fuel components of the unconverted fuel measured under ambient conditions. For example, in case of M85, benzene. toluene and xylene yields are relative to fraction of benzene, toluene, and xylene present in the unburnt M85 fuel sample under ambient conditions. Relative yields of all other products including remaining methanol are relative to the methanol present in unburnt M85.

Stoichiometric oxidation of M85 at a temperature of $1230^{\circ} \mathrm{C}$ resulted in $88 \%$ conversion of the methanol component. Semi-quantitative yields of ethene, ethane, formaldehyde, acetaldehyde, and butane were less than $2 \%$ of the initial methanol response. Semi-quantitative yields of aromatic hydrocarbons were larger. Toluene and the xylenes were converted by about $85-90 \%$ of their initial responses. Benzene was reduced by about $50 \%$. Ethanol was an initial component of the fuel and was degraded by $>98 \%$. The addition of an oil layer resulted in a subtle change in the organic product distributions. These experiments, conducted at a slightly lower temperature of $1170^{\circ} \mathrm{C}$, did not produce formaldehyde as a product and resulted in the formation of an unidentified product that is likely a $\mathrm{C}_{3}$ hydrocarbon or an oxygenated species. The conversion of aromatic hydrocarbon components of the gasoline was significantly reduced in these experiments. Benzene, in particular, exhibited a near three-fold increase in response in the presence of the oil layer. Unfortunately, it can not be readily discerned if this increase in concentration of aromatic hydrocarbons is due to the presence of the oil layer or due to the $60^{\circ} \mathrm{C}$ reduction in temperature.

Stoichiometric oxidation of E85 at a temperature of $1220^{\circ} \mathrm{C}$ resulted in $83 \%$ conversion of the ethanol component. Semi-quantitative yields of ethene, ethane, propene, formaldehyde, acetaldehyde, and butane were less than $10 \%$ of the initial ethanol response. Semi-quantitative yields of aromatic hydrocarbons were larger. This was especially the case for benzene which exhibited a larger response following the high-temperature exposure than in the neat unstressed sample, clearly indicating its formation as a combustion product. With the exception of benzene, yields of the hydrocarbon components reduced significantly, but not to the extent observed for M85. The addition of an oil layer $\left(1220^{\circ} \mathrm{C}\right)$ did not result in observable changes in conversion of ethanol or its partial oxidation products, with deviations less than $1 \%$ (absolute conversion). The presence of the oil layer did not influence the conversion of the hydrocarbon components of the fuel with the exception of benzene. Benzene's response increased by a factor of 1.4, once again clearly indicating its formation as a combustion product.

Stoichiometric oxidation of $\mathrm{CNG}$ at a temperature of $1170^{\circ} \mathrm{C}$ resulted in only $3 \%$ conversion of the methane component. As the temperature was increased to $1480^{\circ} \mathrm{C}$, conversion of the CNG methane component reached $84 \%$. Ethylene, ethane, propylene, formaldehyde, n-butane and benzene were the observed products. The addition of an oil layer did not result in observable changes in organic product distributions. Furthermore, the conversion of the initial CNG components was insensitive to the presence of the oil layer.

Stoichiometric oxidation of RFG at a temperature of $1190^{\circ} \mathrm{C}$ resulted in a dramatic shift of the organic constituents compared to the analysis of a neat, unstressed sample. The neat sample contains $\mathrm{C}_{4}-\mathrm{C}_{8}$ hydrocarbon constituents. The stoichiometric oxidation of $\mathrm{RFG}$ resulted in the production of large yields of ethene, ethane, propene, $n$-butane along with the formation of formaldehyde, acetaldehyde, and acetic acid. The behavior of the aromatic hydrocarbon components, i.e., benzene, toluene and xylene varied. Toluene and the xylene isomers were 
approximately $70 \%$ converted. Benzene's response increased by a factor of 1.15 , suggesting its formation as a combustion product. The presence of the oil layer had a subtle effect on organic product distributions. Yields of $n$-butane decreased by a factor of 10 . Yields of acetic acid decreased by about a factor of 3. Yields of benzene increased by a factor of 2.4. Yields of the other reaction products varied by less than a factor of 1.4 .

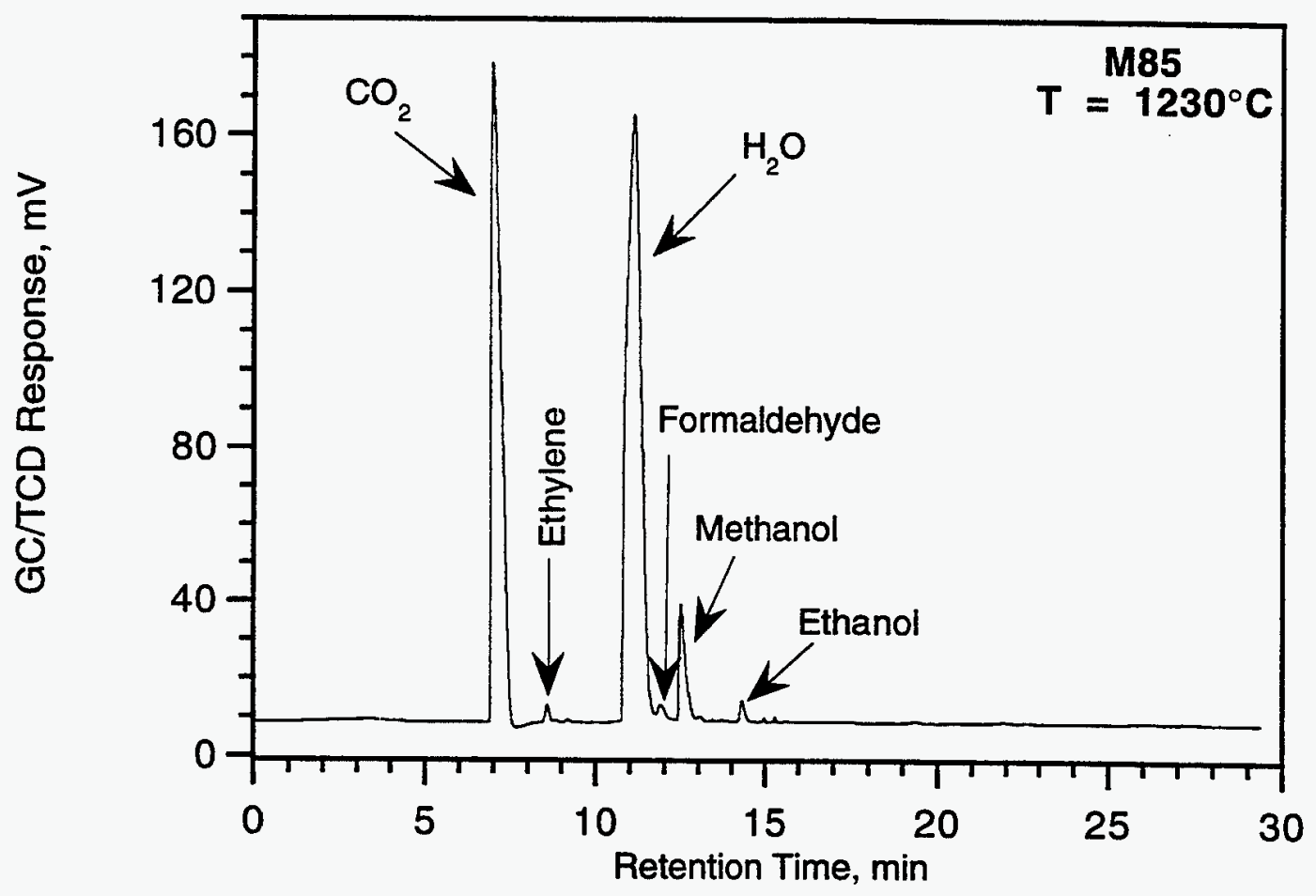

Figure 5. GC-TCD traces for the high pressure combustion of $\mathrm{M} 85 . \mathrm{T}=1230^{\circ} \mathrm{C}, \mathrm{p}=9.5 \mathrm{bar}$. $\mathrm{t}=2.5 \mathrm{~ms}$. $[\mathrm{M} 85]=0.1 \%$

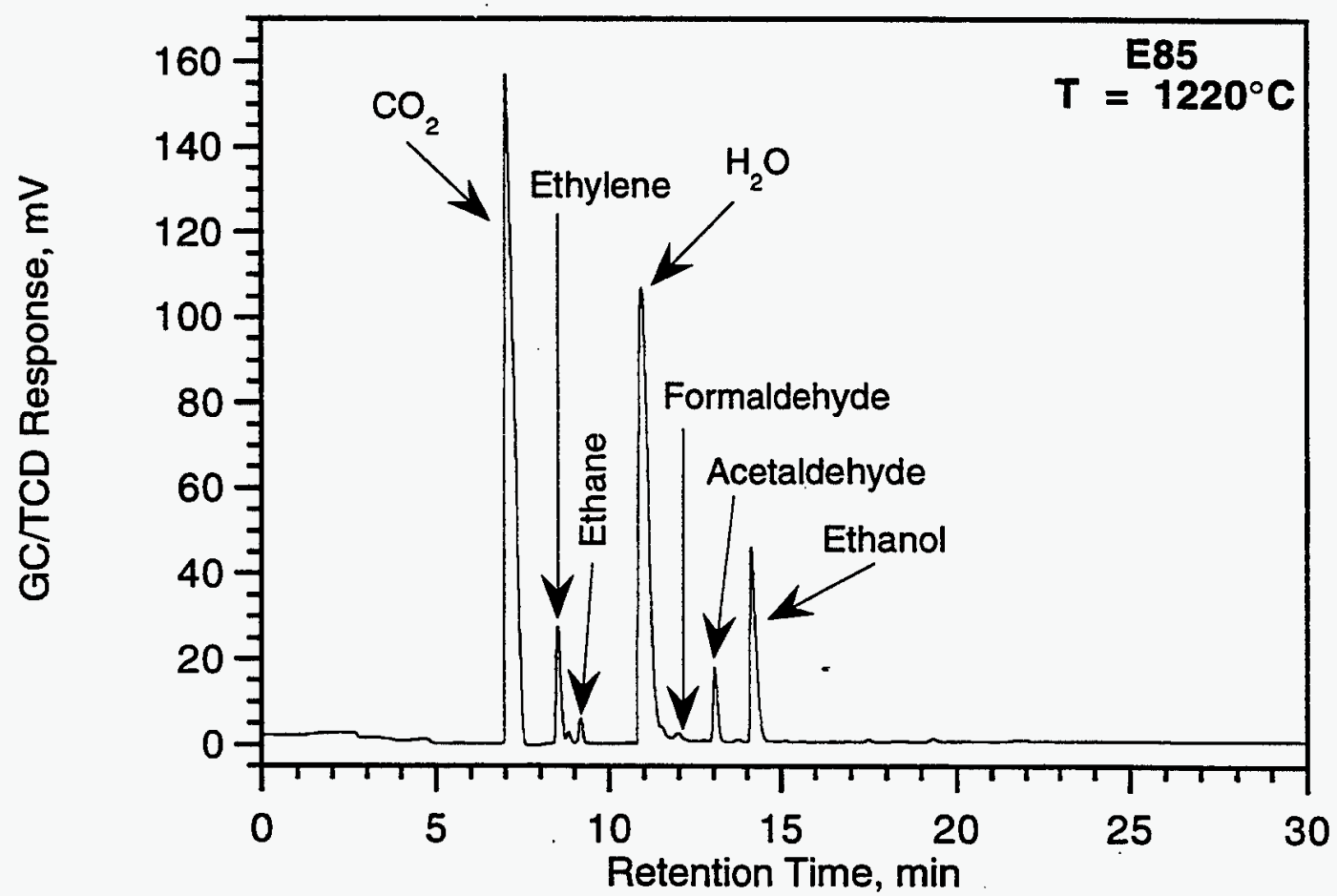

Figure 6. GC-TCD traces for the high pressure combustion of E85. T $=1220^{\circ} \mathrm{C}, \mathrm{p}=9.2 \mathrm{bar}$. $\mathrm{t}=2.5 \mathrm{~ms}$. [E85] $=0.1 \%$. 


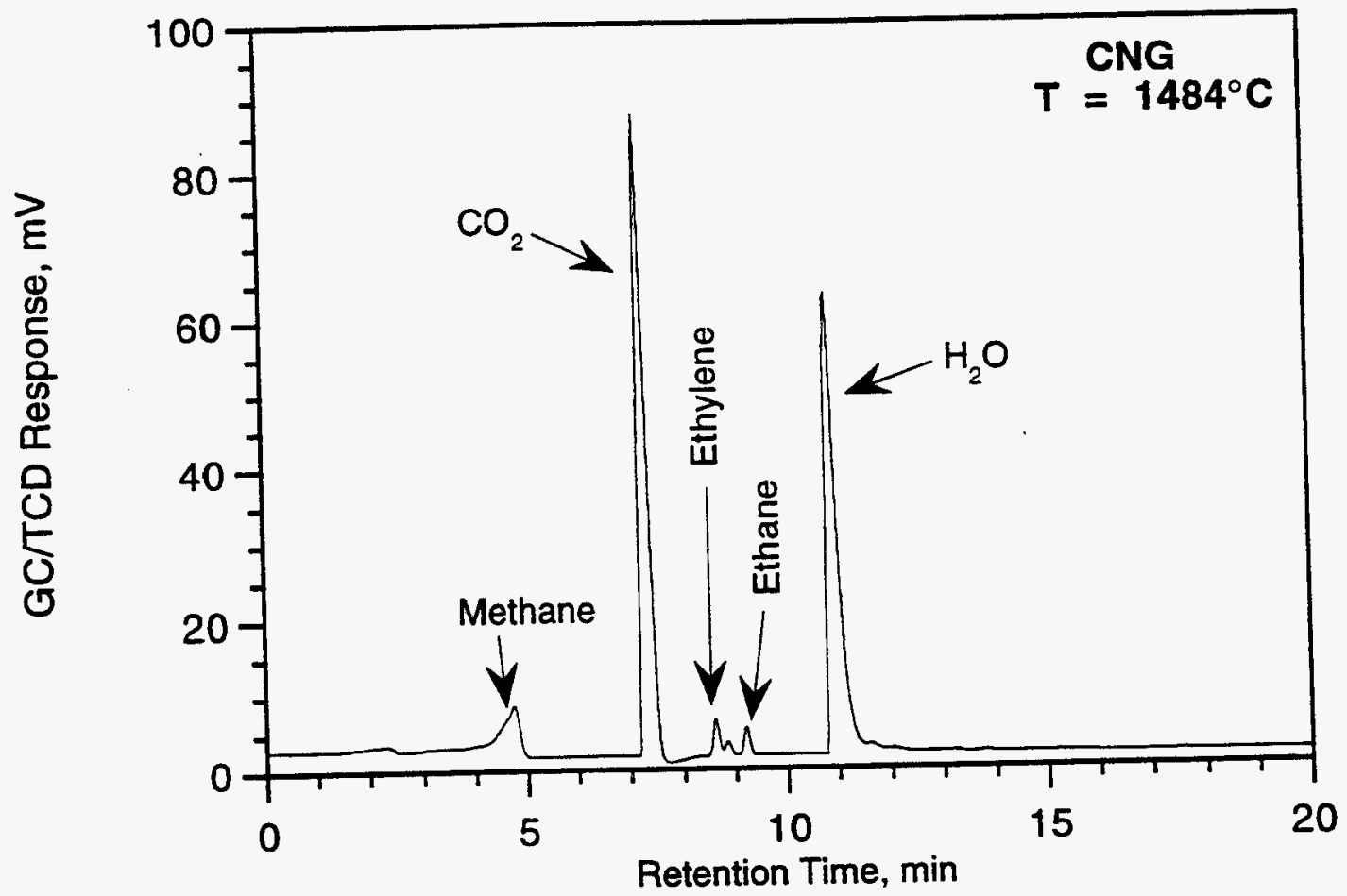

Figure 7. GC-TCD traces for the high pressure combustion of CNG. $T=1170^{\circ} \mathrm{C}, \mathrm{p}=9.2 \mathrm{bar}$. $\mathrm{t}=2.5 \mathrm{~ms}$. [Natural Gas] $=0.1 \%$

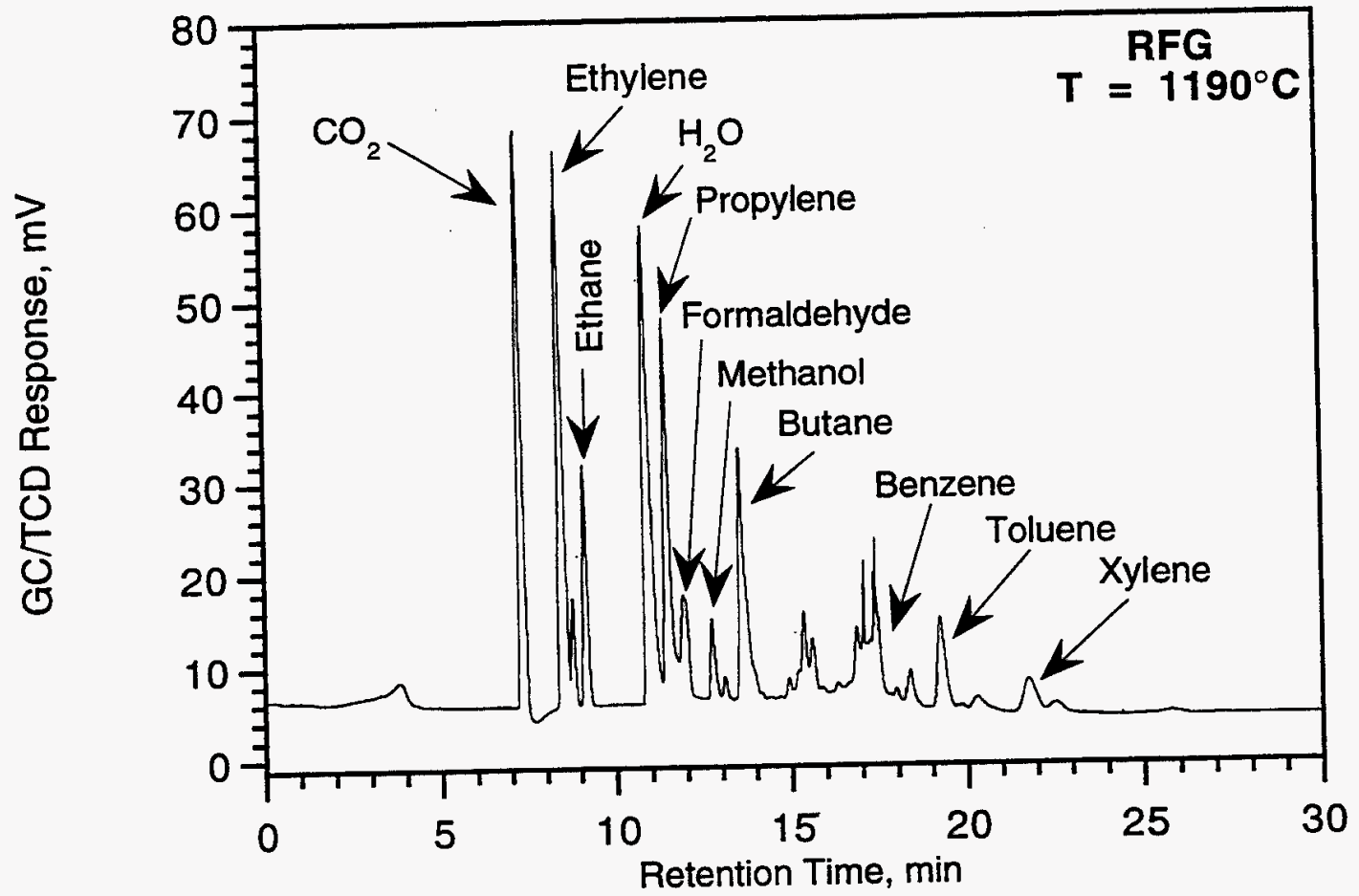

Figure 8. GC-TCD traces for the high pressure combustion of RFG. T $=1190^{\circ} \mathrm{C}, \mathrm{p}=9.3 \mathrm{bar}$. $\mathrm{t}=2.5 \mathrm{~ms}$. $[\mathrm{RFG}]=0.1 \%$. 


\section{Table 2- Semi-Quantitative Product Yields from the High Pressure Combustion of M85}

\begin{tabular}{|c|c|c|}
\hline Name & $\begin{array}{c}\text { Fraction Remaining } \\
\text { Neat }\left(1230^{\circ} \mathrm{C}\right)\end{array}$ & $\begin{array}{c}\text { Fraction Remaining } \\
\text { W/Oil Layer }\left(1170^{\circ} \mathrm{C}\right)\end{array}$ \\
\hline Methane & ND & ND \\
\hline Methanol & 12 & 31 \\
\hline Ethanol & 1.6 & 4.2 \\
\hline Ethylene & 1.1 & 1.4 \\
\hline Ethane & 0.1 & 0.1 \\
\hline Propylene & $\mathrm{ND}$ & $\mathrm{ND}$ \\
\hline Formaldehyde & 1.8 & $\mathrm{ND}$ \\
\hline Acetaldehyde & 0.4 & $\mathrm{ND}$ \\
\hline Butane & 0.1 & 0.2 \\
\hline Acetic Acid & $\mathrm{ND}$ & $\mathrm{ND}$ \\
\hline Benzene & $53^{\mathrm{b}}$ & $130^{\mathrm{b}}$ \\
\hline Toluene & $16^{\mathrm{c}}$ & $86^{\mathrm{c}}$ \\
\hline Xylene & $12^{\mathrm{d}}$ & $57^{\mathrm{d}}$ \\
\hline
\end{tabular}

$\mathrm{ND}$ - not detected

a - Fraction remaining (corrected for blank run) based on methanol response in unburnt M85 sample.

b - Fraction remaining (corrected for blank run) based on benzene response in unburnt M85 sample.

c - Fraction remaining (corrected for blank run) based on toluene response in unburnt M85 sample.

d - Fraction remaining (corrected for blank run) based on xylene response in unburnt M85 sample.

\section{Table 3- Semi-Quantitative Product Yields from the High Pressure Combustion of $\mathbf{E 8 5}$}

\begin{tabular}{|c|c|c|}
\hline Name & $\begin{array}{c}\text { Fraction Remaining } \\
\text { Neat }\left(1220^{\circ} \mathrm{C}\right)\end{array}$ & $\begin{array}{c}\text { Fraction Remaining }^{\mathrm{a}} \\
\text { W/Oil Layer }\left(1220^{\circ} \mathrm{C}\right)\end{array}$ \\
\hline Methane & $\mathrm{ND}$ & ND \\
\hline Methanol & ND & ND \\
\hline Ethanol & 17 & 18 \\
\hline Ethylene & 6.9 & 7.0 \\
\hline Ethane & 1.3 & 0.5 \\
\hline Propylene & 0.5 & 1.4 \\
\hline Formaldehyde & 0.7 & 0.9 \\
\hline Acetaldehyde & 4.6 & 5.0 \\
\hline Butane & 0.2 & 0.3 \\
\hline Acetic Acid & $\mathrm{ND}$ & ND \\
\hline Benzene & $120^{\mathrm{b}}$ & $170^{\mathrm{b}}$ \\
\hline Toluene & $25^{\mathrm{c}}$ & $24^{\mathrm{c}}$ \\
\hline Xylene & $19^{\mathrm{d}}$ & $18^{\mathrm{d}}$ \\
\hline
\end{tabular}

ND- not detected

a - Fraction remaining (corrected for blank run) based on ethanol response in unburnt E85 sample.

b - Fraction remaining (corrected for blank run) based on benzene response in unburnt E85 sample.

c - Fraction remaining (corrected for blank run) based on toluene response in unburnt E85 sample.

d - Fraction remaining (corrected for blank run) based on xylene response in unburnt E85 sample. 
Table 4- Semi-Quantitative Product Yields from the High Pressure Combustion of CNG

\begin{tabular}{|c|c|c|}
\hline Name & $\begin{array}{c}\text { Fraction Remaininga } \\
\text { Neat }\left(1480^{\circ} \mathrm{C}\right)\end{array}$ & $\begin{array}{c}\text { Fraction Remaining } \\
\text { W/Oil Layer }\left(1480^{\circ} \mathrm{C}\right)\end{array}$ \\
\hline Methane & 15.5 & 16 \\
\hline Methanol & ND & ND \\
\hline Ethanol & ND & ND \\
\hline Ethylene & 3.1 & 4.0 \\
\hline Ethane & 2.8 & 3.1 \\
\hline Propylene & 1.2 & 1.5 \\
\hline Formaldehyde & 0.5 & 0.5 \\
\hline Acetaldehyde & ND & ND \\
\hline Butane & 0.2 & 0.6 \\
\hline Acetic Acid & ND & ND \\
\hline Benzene & 0.1 & 0.1 \\
\hline
\end{tabular}

ND- not detected

a - Fraction remaining (corrected for blank run) based on methane response in unburnt CNG sample.

Table 5- Semi-Quantitative Product Yields from the High Pressure Combustion of RFG

\begin{tabular}{|c|c|c|}
\hline Name & $\begin{array}{c}\text { Fraction Remaining } \\
\text { Neat }\left(1190^{\circ} \mathrm{C}\right)\end{array}$ & $\begin{array}{c}\text { Fraction Remaining } \\
\text { W/Oil Layer }\left(1190^{\circ} \mathrm{C}\right)\end{array}$ \\
\hline Methane & ND & ND \\
\hline Methanol & 3.3 & 2.4 \\
\hline Ethanol & ND & ND \\
\hline Ethylene & 25 & 26 \\
\hline Ethane & 9.7 & 12 \\
\hline Propylene & 17 & 12 \\
\hline Formaldehyde & 6.6 & 5.7 \\
\hline Acetaldehyde & 0.8 & 0.8 \\
\hline Butane & 150 & 12 \\
\hline Acetic Acid & 0.4 & 0.1 \\
\hline Benzene & $110^{\mathrm{b}}$ & $270^{\mathrm{b}}$ \\
\hline Toluene & $34^{\mathrm{c}}$ & $29^{\mathrm{c}}$ \\
\hline Xylene & $26^{\mathrm{d}}$ & $27^{\mathrm{d}}$ \\
\hline Unknown-A & $13^{\mathrm{d}}$ & $8.7^{\mathrm{d}}$ \\
\hline Dimethyl Hexane (DMH) & $8.8^{\mathrm{e}}$ & $5.4^{\mathrm{e}}$ \\
\hline Unknown-B & $17^{\mathrm{d}}$ & $11^{\mathrm{d}}$ \\
\hline
\end{tabular}

ND- not detected

a - Fraction remaining (corrected for blank run) based on sum of responses of five major components (toluene, xylene, unknown-A, dimethyl hexane and unknown-B) in unburnt RFG sample.

b - Fraction remaining (corrected for blank run) based on benzene response in unburnt RFG sample.

c - Fraction remaining (corrected for blank run) based on toluene response in unburnt RFG sample.

d - Fraction remaining (corrected for blank run) based on xylene response in unburnt RFG sample.

e - Fraction remaining (corrected for blank run) based on DMH response in unburnt RFG sample. 


\section{Discussion}

In this section, we present a discussion of the differences in organic product distributions from the high pressure shock tube experiments, the atmospheric pressure flow reactor experiments [2] and the low temperature catalysis evaluation studies (see Task 14). This comparison provides potential indication of the sources of actual tailpipe emissions from vehicle tests.

To refamiliarize the reader, product distributions from the atmospheric pressure flow reactor experiments for M85, E85 and natural gas are presented in Figs. 9, 10, and 11, respectively [2]. Product distributions from the catalyst evaluation studies of M85 and E85 are presented in Figure 12.

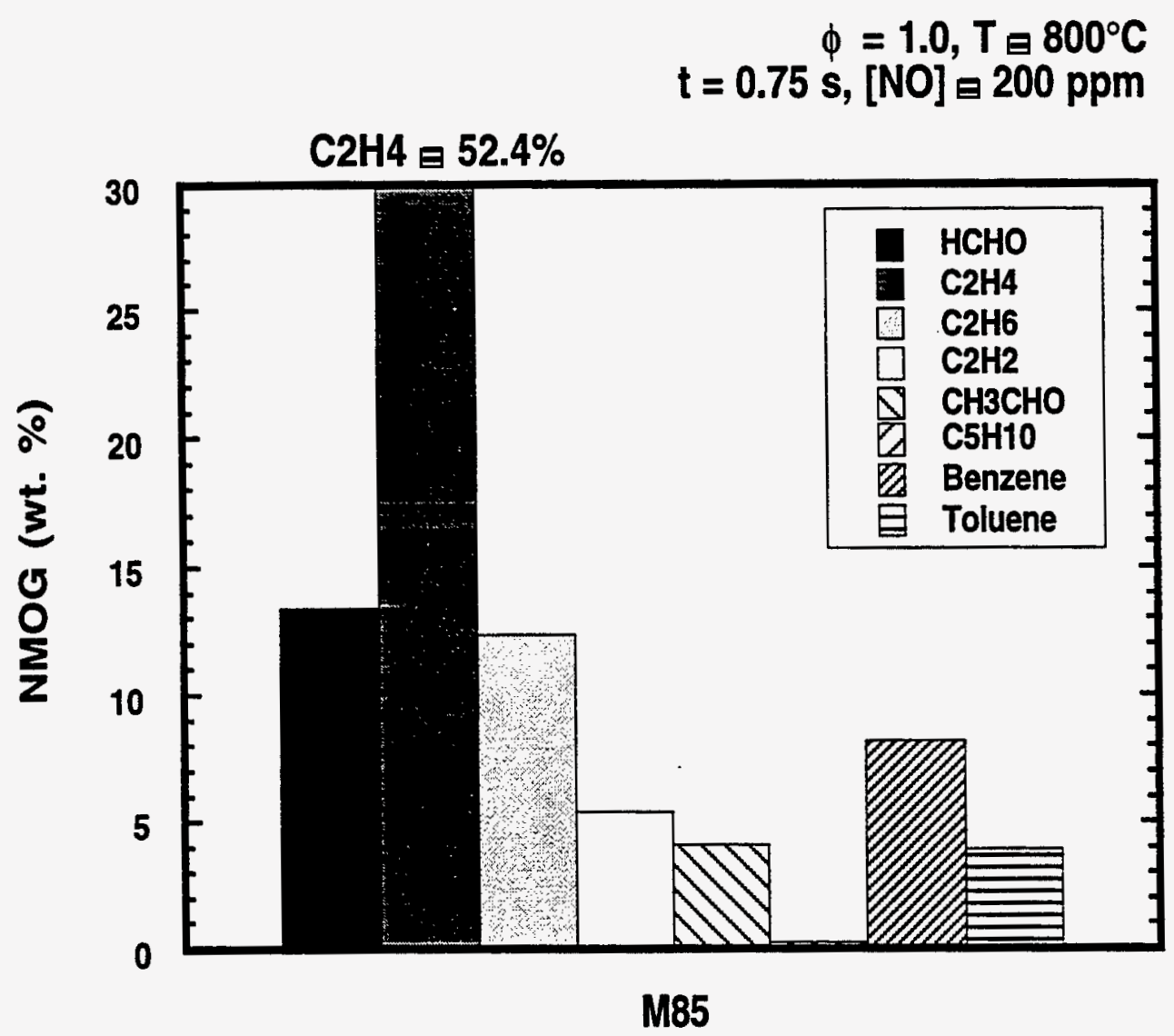

Figure 9. Product distributions from the stoichiometric flow reactor oxidation of M85. Yields are reported as non-methane organic gases (NMOG). $T=800^{\circ} \mathrm{C} . t=0.75 \mathrm{~s} .[\mathrm{NO}]=200 \mathrm{ppm}$. 


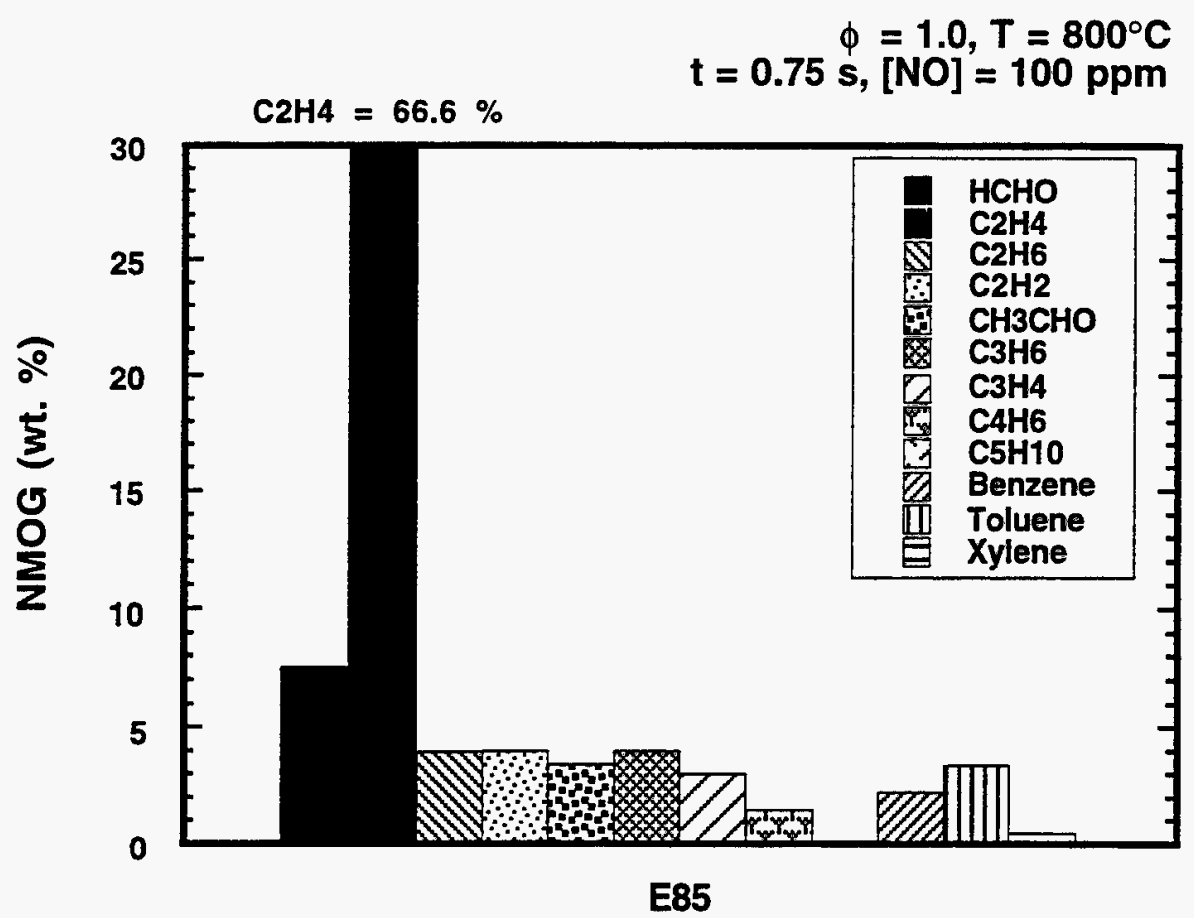

Figure 10. Product distributions from the stoichiometric oxidation of E85. Yields are reported as non-methane organic gases (MNOG). $T=800^{\circ} \mathrm{C} . t=0.75 \mathrm{~s}$. $[\mathrm{NO}]=100 \mathrm{ppm}$.

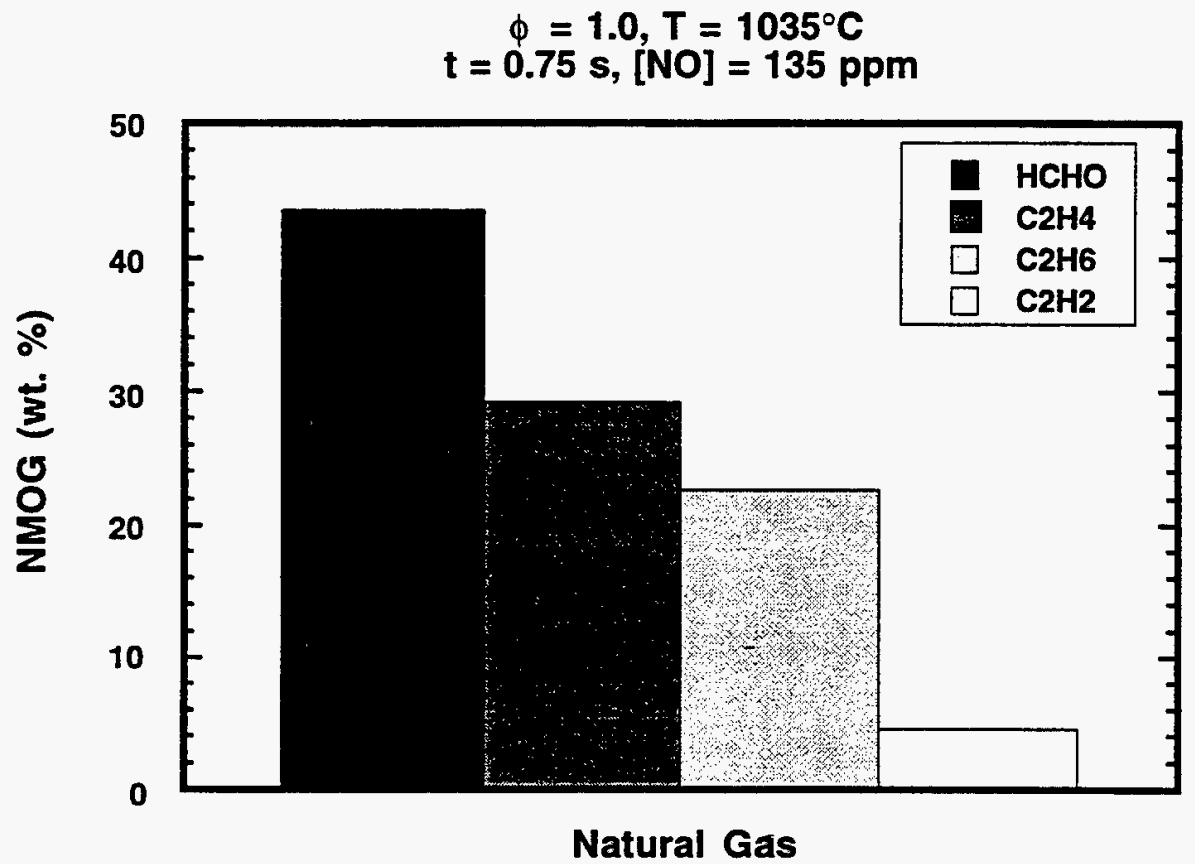

Figure 11. Product distributions from the stoichiometric flow reactor oxidation of natural gas.

Yields are reported as non-methane organic gases (NMOG). $T=1035^{\circ} \mathrm{C} . t=0.75 \mathrm{~s}$. $[\mathrm{NO}]=135$ ppm. 


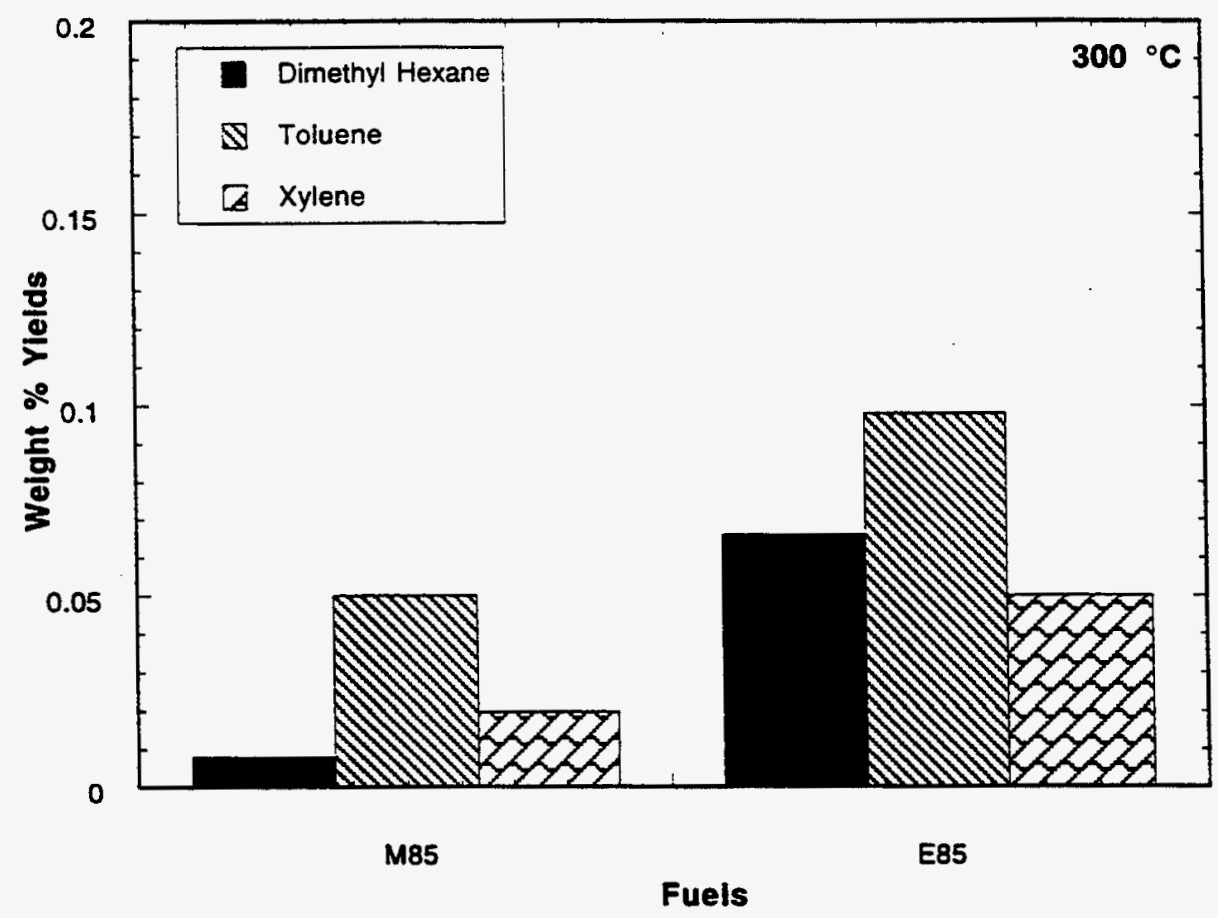

Figure 12. Product yields from M85 and E85 at $300^{\circ} \mathrm{C}$. Fuels were passed over $\mathrm{Pd} / \mathrm{Rh}$ catalyst with a carrier gas containing $0.1 \% \mathrm{CO}, 1 \% \mathrm{O}_{2}, 10 \% \mathrm{H}_{2} \mathrm{O}$, and $1500 \mathrm{ppm} \mathrm{NO}$. Residence time $=150 \mathrm{~ms}$. Space velocity $=24,000 \mathrm{~h}^{-1}$.

Comparison of the product distributions for the various M85 experiments provides some interesting observations. The largest number of reaction products were observed in the atmospheric pressure flow reactor experiments. Products observed in the flow reactor tests [2] but not in the shock tube experiments included acetylene, acetaldehyde, and a pentene isomer. Comparison of these products with those obtained in the high pressure shock tube experiments indicates that the gasoline fraction of the fuel was converted to trace levels in the shock tube tests but that the benzene and toluene components survived the flow reactor tests. The same observation was evident when comparing the shock tube data with the catalyst evaluation tests. Even at temperatures as high as $300^{\circ} \mathrm{C}$, the toluene and xylene fraction of the M85 survived the catalyst exposure.

Comparison of the organic product distributions for the various E85 experiments resulted in the same general trend. Once again, the largest number of reaction products were observed in the flow reactor experiments [2]. Products observed in the flow reactor tests but not in the shock tube experiments included acetylene, propyne ( 2 isomers), and butadiene. Comparison of these products with those obtained in the shock tube tests indicated that, with the exception of benzene, the gasoline fraction of the fuel was largely destroyed in the shock tube tests while benzene, toluene and xylene components survived the flow reactor tests. In the flow reactor tests, significant quantities of $\mathrm{C}_{3}$ and $\mathrm{C}_{4}$ products were also observed. These unsaturated, molecular growth precursors were not observed in the shock tube tests. Comparison of the product distributions of the shock tube tests and the catalyst evaluation tests once again indicated that the gasoline fraction of the E85 survived the catalyst exposure but not the high pressure shock tube test. 
Very little difference in product distributions was evident between the shock tube tests and the lower temperature flow reactor experiments for CNG [2]. With the exception of acetylene, all other flow reactor products were observed. CNG was not subjected to catalyst evaluation.

A valid comparison of product distributions between shock tube and flow reactor experiments for RFG was not possible. Our previous flow reactor studies focused on a detailed analysis of the polar fraction of the reactor effluent [3]. The high pressure shock tube tests were based on conventional GC-TCD and GC-MS detection. It would be worthwhile to compare the yields of the aromatic and alkyl-aromatic fractions to determine if the same trend observed for M85 and E85 also occurs for RFG.

Vehicle tests of M85 and E85 report significant quantities of benzene, toluene, and xylenes along with lighter hydrocarbons and partially oxidized intermediates [4]. The lighter hydrocarbons and the partially oxidized intermediate products of incomplete combustion of the fuel. The benzene, toluene, and xylenes are observed because they are thermally stable initial fuel components ae well as products from the combustion of the fuel under poor fuel/air mixing conditions. Our analysis of product distributions from high pressure shock tube measurements, atmospheric pressure flow reactor studies, and the catalyst evaluations suggest that failure modes in the cylinder and exhaust port/runner are a likely source of these aromatic products. The temperatures in the exhaust port are sufficiently high to decompose the alcohol fuel components but not the aromatic gasoline fraction. Our limited catalyst evaluation studies, further suggest that these aromatic hydrocarbon components that survive intact to the catalyst are not as readily oxidized under cold start conditions compared to residual alcohol fuel or the partially oxidized intermediates.

\section{Conclusions and Recommendations}

A comparison of product distributions arising from simulations of different conditions throughout the engine/exhaust system demonstrates the complexity of the chemistry occurring. Based on results of this study and our previous alternative fuel studies, we can conclude the following:

1. High pressure combustion of alternative fuels suggests that benzene, formaldehyde. acetaldehyde (except from CNG), and ethylene can form in the engine cylinder under thermal quenching failure conditions.

2. The aromatic fraction of the alcohol fuels was destroyed easily during high pressure, high temperature combustion in the engine cylinder. Thus, aromatic hydrocarbon components observed in tail pipe emissions from these fuels originate from the aromatic fraction of fuel that escaped high pressure engine cylinder combustion and could not be oxidized under thermal conditions downstream of the engine cylinder and during its exposure to a commercial three-way catalyst.

3. The results from the second set of experiments show that the presence of an oil layer did not change total fuel conversion. However, an overall increase in the hydrocarbon concentration was observed but not for the oxygenated fraction. This is attributed to the greater solubility of the hydrocarbons in the oil layer than the oxygenates.

Additional experiments are warranted. Variables that should be examined include the thickness of the oil film, the temperature of the fuel combustion, and the composition of the oil. A further investigation of crevices and indentations inside the cylinder is also warranted. Repeated attempts to configure aluminum foil and mylar inserts within the existing test section were inconclusive. A specially designed, perforated, stainless steel test section is needed to further explore this possible effect. However, minimal differences in surface tension of oxygenates (methanol-22.07 dynes $/ \mathrm{cm}$ and ethanol- $21.97 \mathrm{dynes} / \mathrm{cm}$ at $25^{\circ} \mathrm{C}$ ) and hydrocarbons (benzene - $28.18 \mathrm{dynes} / \mathrm{cm}$ and Toluene - 
27.93 dynes $/ \mathrm{cm}$ at $\left.25^{\circ} \mathrm{C}\right)$ when compared to surface tension of water $\left(72.14\right.$ dynes $/ \mathrm{cm}$ at $\left.25^{\circ} \mathrm{C}\right)$ suggests that differences in their emissions due to crevice wetting would be mimimal.

\section{References}

1. Glick, H.S., Squire, W., and Hertzberg, A. 1955. Fifth Syposium (International) on Combustion (Reinhold, N.Y.), p. 383.

2. Cheng, L. 1997. "The Effect of Nitric Oxides on the Atmospheric Pressure Oxidation of Methanol, Ethanol, M85, and E85," M.S. Thesis in Chemical Engineering, University of Dayton.

3. Taylor, P. H., Cheng, L., Rubey, W. A., Striebich, R. C., Sidhu, S.S. and Dellinger, B. 1997. "The Origin and Fate of Organic Pollutants from the Combustion of Alternative Fuels: Phase IV Report," National Renewable Energy Laboratory Report SR-540-23145, Golden, $\mathrm{CO}$.

4. Taylor, P. H., Cheng, L., and Dellinger, B.: in "Alternative Fuel: Composition, Performance, Engines, and Systems," \#961088, SAE Technical Paper Series, Warrendale, PA, 1996. Series \#941904, p. 39, Warrendale, PA. 


\section{Task 13 - The Effect of NOx on the Reaction of Fuel Components}

\section{Introduction}

The objective of this task was to determine the impact of $\mathrm{NO}_{\mathrm{x}}$ on organic pollutant formation from the combustion of alternative fuels. Our initial studies used mixtures of oxygen and helium as the reaction atmosphere for the oxidation of alternative fuels. In this task, we have modified this mixture with the addition of $\mathrm{NO}_{\mathrm{x}}$ at levels that would be produced in a spark ignition, internal combustion engine. This study is especially relevant to pollutant formation in the cylinder exhaust port where $\mathrm{NO}_{\mathrm{x}}$ produced in the engine cylinder and unburned fuel are mixed and can still undergo reaction at elevated temperatures. This study will also help to determine if any of the observed differences in the our flow reactor studies and dynamometer tests are due to the presence of $\mathrm{NO}_{\mathrm{x}}$ in engine tests.

\section{Background}

The oxidation of $\mathrm{NO}$ to $\mathrm{NO}_{2}$ in the presence of oxygen has been shown to be strongly promoted, at temperatures as low as $300^{\circ} \mathrm{C}$, by the presence of low concentrations of hydrocarbons, $\mathrm{CO}$ and $\mathrm{H}_{2}$ [1-6]. At the same time, the oxidation of the hydrocarbon is greatly sensitized, resulting in the formation of oxygenated species and unsaturated hydrocarbon compounds. Emissions of $\mathrm{NO}_{2}$ from combustion appliances such as gas cookers and heaters [3] and gas turbines [7] are likely the result of these reactions. It has also been demonstrated [3] that trace concentrations of NO (as little as $0.02 \mathrm{ppm}$, similar to that often found in urban air) have a profound effect on the oxidation of $n$ butane. This result suggests that hydrocarbon-NO interactions may also be important in experimental studies of low temperature ignition and in ignition phenomena in automotive engines. Hydrocarbon-NO interactions may also play a role in the formation of otherwise unstable partially oxidized intermediates in the exhaust/port runner of light and heavy duty vehicles. Some of these compounds are unlikely to survive high temperature exposure in the engine cylinder. Their observation in tailpipe emissions suggest their formation subsequent to the engine cylinder.

There are relatively few prior studies of the effect of $\mathrm{NO}$ and $\mathrm{NO}_{2}$ on the conversion of alcohol fuels. Yano and Ito $[8,9]$ have examined the reactions that can occur in the exhaust of methanolfueled automobile engines and found that NO considerably accelerates the oxidation of residual methanol. They noted that this catalysis is accompanied by some limited $\mathrm{NO}$ to $\mathrm{NO}_{2}$ conversion. In related studies, Lyon et al have examined the oxidation of $\mathrm{NO}$ to $\mathrm{NO}_{2}$ by methanol in a quartz flow reactor [10] and Zamansky et al. reported a similar study in a $300 \mathrm{~kW}$ combustor firing natural gas and coal [11]. These studies focused on the conversion of $\mathrm{NO}$ to $\mathrm{NO}_{2}$ (conversions as high as $90 \%$ were achievable under certain conditions) as related to NO removal in postcombustion gases. The influence of $\mathrm{NO}$ on the conversion of $\mathrm{CH}_{3} \mathrm{OH}$ to intermediate reaction products was not examined.

\section{Experimental Approach}

The thermal degradation behavior of alternative fuel $/ \mathrm{NO}_{\mathrm{x}} /$ air mixtures was examined using a 1.13$\mathrm{cm}$ i.d., $69 \mathrm{~cm}^{3}$ volume, fused silica flow reactor coupled to an in-line GC-MS analytical detection system. The experimental approach for these studies were described in detail in previous publications $[12,13]$. The salient features of these experiments are summarized here.

High-purity $\mathrm{CH}_{3} \mathrm{OH}$ and $\mathrm{CH}_{3} \mathrm{CH}_{2} \mathrm{OH}$ were obtained from Aldrich Chemical Company, Inc. GCMS analysis of samples confirmed a purity in excess of $99.9 \%$ with no detectable impurities. 
Natural gas and LP gas were obtained from Air Products and Chemicals, Inc. and used asreceived. M85 and E85 were obtained from Southwest Research Institute and used as-received.

Experiments were conducted under fuel-lean $(\phi=0.8)$, stoichiometric, and fuel-rich $(\phi=1.1)$ conditions. The proper ratios of fuel/ $\mathrm{NO}_{\mathrm{X}} /$ air were prepared in 1 liter light-tight Pyrex ${ }^{\circledR}$ bulbs by mixing vaporized fuels with $\mathrm{NO}\left(20.8 \%\right.$ in $\mathrm{He}$, Air Products and Chemicals, Inc.), $\mathrm{NO}_{2}(0.875 \%$ in $\mathrm{He}$, Air Products and Chemicals, Inc.), and $\mathrm{O}_{2}$ (15\% in $\mathrm{N}_{2}$, Air Products and Chemicals, Inc.). The nitric oxide standard contained $<1 \% \mathrm{NO}_{2}$ impurity. The reactants were isolated from ultraviolet radiation to ensure that no photolytic conversion occurred prior to thermal testing. A syringe pump was used to provide steady-state sample injection. High purity $(99.99+\%)$, moisture free helium was the diluent and reactor carrier gas. Data were obtained for isothermal reactor exposures ranging from 500 to $1075^{\circ} \mathrm{C}$ for mean, gas-phase residence times of $0.75 \pm 0.05 \mathrm{~s}$. Initial fuel concentrations varied with reactor temperature (total gas flow rate) and equivalence ratio. The ranges in concentrations were: $\mathrm{CH}_{3} \mathrm{OH}$ and $\mathrm{M} 85$ : $453-774 \mathrm{ppm}, \mathrm{CH}_{3} \mathrm{CH}_{2} \mathrm{OH}$ and E85: 226-312 ppm, Nat. Gas: $300-512$ ppm, and LP gas: $127-217$ ppm. Initial NO concentrations were onethird and two/thirds of the initial fuel concentration. Initial $\mathrm{NO}_{2}$ concentrations were 0.1 and 0.02 the initial fuel concentration. Total gas flow rates ranged from $2114 \mathrm{~cm} 3 / \mathrm{min}$ to $2627 \mathrm{~cm} 3 / \mathrm{min}$, depending on the reactor temperature. Input sample flow rates were $10.7 \mathrm{~cm} 3 / \mathrm{min}$. The mean absolute pressure for all experiments was $1.4 \pm 0.2 \mathrm{~atm}$.

Capillary column gas chromatography (HP 5890 Series I GC)was utilized for product separation. A porous layer open tubular (PLOT) column was used for separation of light hydrocarbons, oxygenates, and nitrogen-containing hydrocarbons. Quantitative product analysis was accomplished using a quadrapole mass spectrometer (HP 5970B) in the scanning mode. GC retention times of analytical standards (Aldrich Chemical Company, Inc.) provided confirmation of observed products. Compound quantification was achieved using prepared standards of known concentration. Quantitative transport of $\mathrm{NO}$ and $\mathrm{NO}_{2}$ throughout the reactor system was verified using off-line tedlar bag sampling and a chemiluminescent $\mathrm{NO}_{\mathrm{x}}$ analyzer. Table 6 summarizes the GC-MS conditions.

Table 6. GC-MS Conditions

\begin{tabular}{|c|c|}
\hline GC Columns: & $\begin{array}{l}\text { GS-Q (styrene-divinylbenzene polymer), } \\
30 \mathrm{~m} \text { x } 0.32 \mathrm{~mm} \text { i.d. }\end{array}$ \\
\hline GC Temperature Program: & $-60^{\circ} \mathrm{C}$ to $240^{\circ} \mathrm{C} @ 10^{\circ} \mathrm{C} / \mathrm{min}$ \\
\hline GC-MS Transfer Line Temperature: & $250^{\circ} \mathrm{C}$ \\
\hline Carrier Gas: & Helium \\
\hline Ionization Mode & Electron Impact \\
\hline Electron Energy: & $70 \mathrm{eV}$ \\
\hline Mass range Scanned: & $10-200 \mathrm{amu}$ \\
\hline Run Time: & $35 \mathrm{~min}$ \\
\hline
\end{tabular}

The focus of these studies was organic speciation and quantitation. No attempt was made to quantitate $\mathrm{O}_{2}$ or the major combustion end products $\mathrm{CO}, \mathrm{H}_{2}, \mathrm{CO}_{2}$ and $\mathrm{H}_{2} \mathrm{O}$. As such, the integrity of the data was based primarily on run-to-run reproducibility and day-to-day repeatability. Based on the multiple measurements, uncertainties in quantitative by-product yields for major and minor products were $\pm 10 \%$ and $\pm 25 \%$, respectively. Uncertainties in formaldehyde concentrations were only good to about $\pm 50 \%$ because of the abnormally large bandwidth ( $>1 \mathrm{~min}$ ) of the GC response. 


\section{Results}

Molar yields of organic byproducts for two different NO concentrations and three different fuel/air equivalence ratios centered around stoichiometric oxidation are illustrated in Figures 13, and 14 for methanol and Figs 15,16 and 17 for ethanol. At $650^{\circ} \mathrm{C}$, besides formaldehyde (cf. Fig. 13) no additional organic reaction products were observed from NO perturbed methanol oxidation. The effect of $\mathrm{NO}$ addition involved dramatic conversion of methanol to $\mathrm{CO}+\mathrm{CO}_{2}$. Yields of formaldehyde increased by only about a factor of 2 . At $800^{\circ} \mathrm{C}$ (see Figure 14), formaldehyde, ethene, acetylene, and traces of ethane were observed as low-yield products. Under these higher temperature conditions, the addition of NO resulted in slight increases in vields of all organic intermediates except ethane. Hydrogen cyanide, in yields of approximately $2 \times 10^{-7}$ moles was also observed under fuel-rich conditions with $\mathrm{NO}$ addition $(\mathrm{NO} /$ fuel ratio $=0.67)$ at these elevated temperatures. The influence of fuel/air stoichiometry appeared to be negligible compared to the initial concentration of NO and changes in reactor temperature.

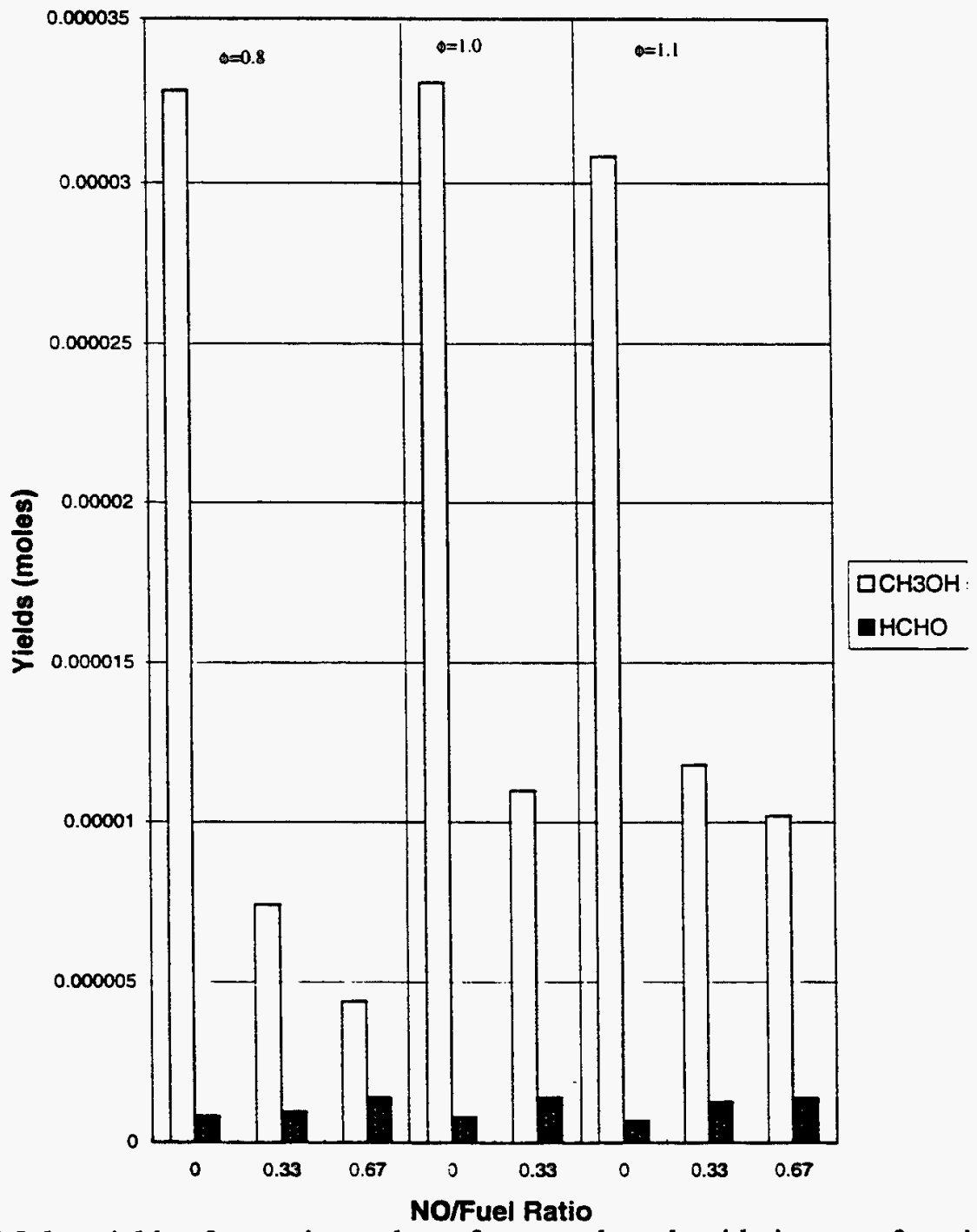

Figure 13. Molar yields of organic products from methanol oxidation as a function of [NO] and fuel/air equivalence ratio. $\mathrm{T}=650^{\circ} \mathrm{C}, \mathrm{t}_{\mathrm{r}}=0.75 \mathrm{~s}$. For $\phi=0.8,\left[\mathrm{CH}_{3} \mathrm{OH}\right]_{0}=450$ ppm, $[\mathrm{NO}]_{0}=150,300 \mathrm{ppm}$. For $\phi=1.0,\left[\mathrm{CH}_{3} \mathrm{OH}\right]_{0}=565 \mathrm{ppm},[\mathrm{NO}]_{0}=185,370$ ppm. For $\phi=1.1,\left[\mathrm{CH}_{3} \mathrm{OH}\right]_{0}=620 \mathrm{ppm},[\mathrm{NO}]_{0}=205,410 \mathrm{ppm}$. 


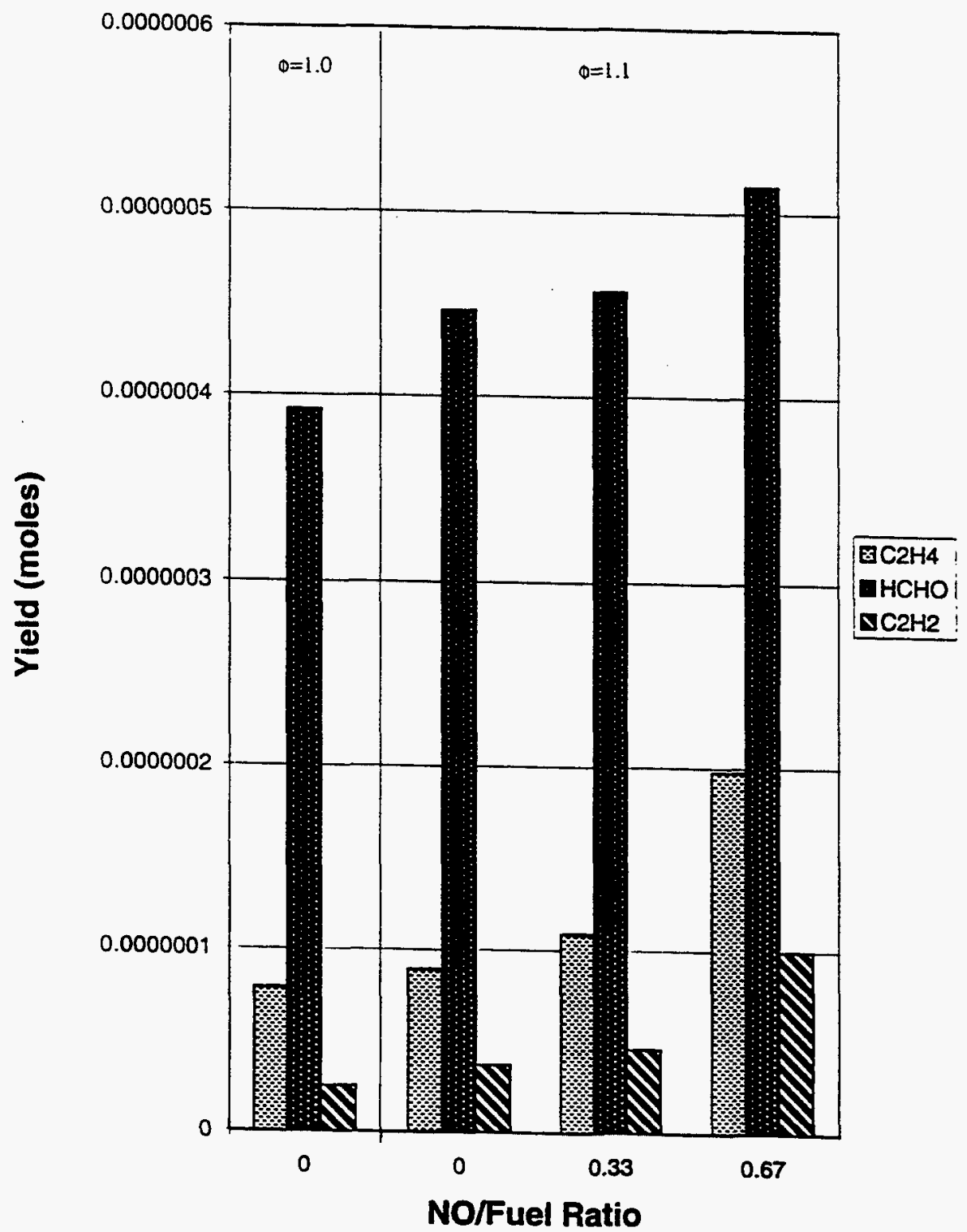

Figure 14. Molar yields of organic products from methanol oxidation as a function of [NO] and fuel/air equivalence ratio. $\mathrm{T}=800^{\circ} \mathrm{C}, \mathrm{t}_{\mathrm{r}}=0.75 \mathrm{~s}$. For $\phi=0.8,\left[\mathrm{CH}_{3} \mathrm{OH}\right]_{0}=565$ ppm, $[\mathrm{NO}]_{0}=185,370 \mathrm{ppm}$. For $\phi=1.0,\left[\mathrm{CH}_{3} \mathrm{OH}\right]_{0}=705 \mathrm{ppm},[\mathrm{NO}]_{0}=230$, $460 \mathrm{ppm}$. For $\phi=1.1,\left[\mathrm{CH}_{3} \mathrm{OH}\right]_{0}=775 \mathrm{ppm},[\mathrm{NO}]_{0}=255,510 \mathrm{ppm}$.

A more dramatic effect was observed from NO perturbed ethanol oxidation at 500 and $650^{\circ} \mathrm{C}$ (see Figures 15 and 16, respectively). At these temperatures, ethanol oxidation was promoted upon NO addition with ethene, ethane, dimethyl ether, acetaldehyde and formaldehyde the major organic intermediates. Ethane, formaldehyde, and dimethyl ether were not observed in the ethanol oxidation experiments conducted in the absence of NO. The addition of NO resulted not only in enhanced ethanol conversion but in enhanced oxidation of acetaldehyde at $650^{\circ} \mathrm{C}$. These trends were generally independent of fuel/air stoichiometry. At $800^{\circ} \mathrm{C}$ (see Figure 17), the effect of NO addition on ethanol oxidation was somewhat different. The reaction products were ethene (major), ethane, acetylene, formaldehyde and acetaldehyde. The addition of NO reduced the yields of 
acetaldehyde and ethene yet increased the yields of ethane, acetylene and formaldehyde. These trends were independent of fuel/air stoichiometry. In contrast to methanol, hydrogen cyanide was not observed in the ethanol experiments at elevated temperatures.

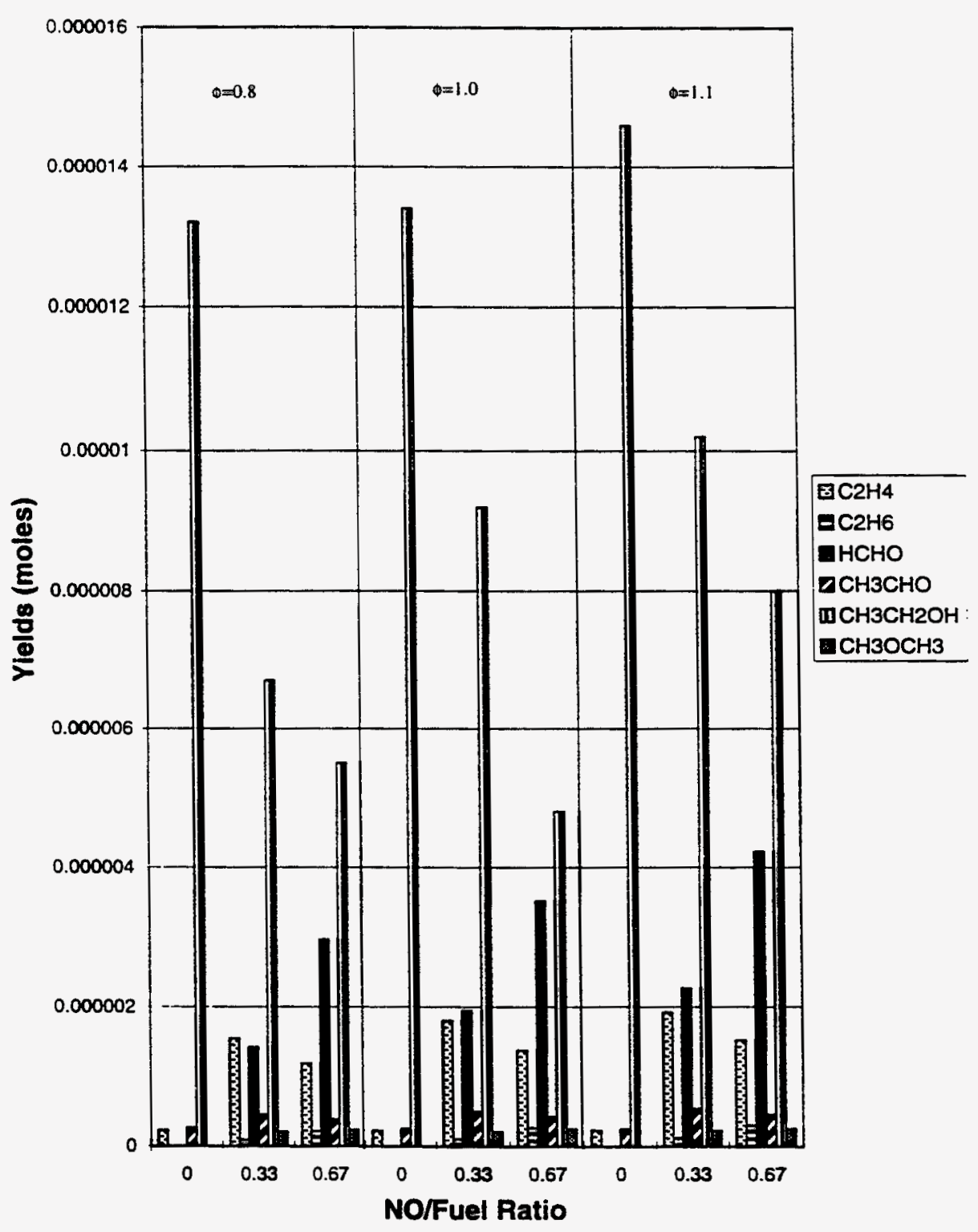

Figure 15. Molar yields of organic products from ethanol oxidation as a function of [NO] and fuel/air equivalence ratio. $\mathrm{T}=500^{\circ} \mathrm{C}, \mathrm{t}_{\mathrm{r}}=0.75 \mathrm{~s}$. For $\phi=0.8,\left[\mathrm{CH}_{3} \mathrm{CH}_{2} \mathrm{OH}\right]_{0}=$ $225 \mathrm{ppm},[\mathrm{NO}]_{0}=75,150 \mathrm{ppm}$. For $\phi=1.0,\left[\mathrm{CH}_{3} \mathrm{CH}_{2} \mathrm{OH}\right]_{0}=285 \mathrm{ppm},[\mathrm{NO}]_{0}=$ 95, 190 ppm. For $\phi=1.1,\left[\mathrm{CH}_{3} \mathrm{CH}_{2} \mathrm{OH}\right]_{0}=310 \mathrm{ppm},[\mathrm{NO}]_{0}=105,205 \mathrm{ppm}$. 


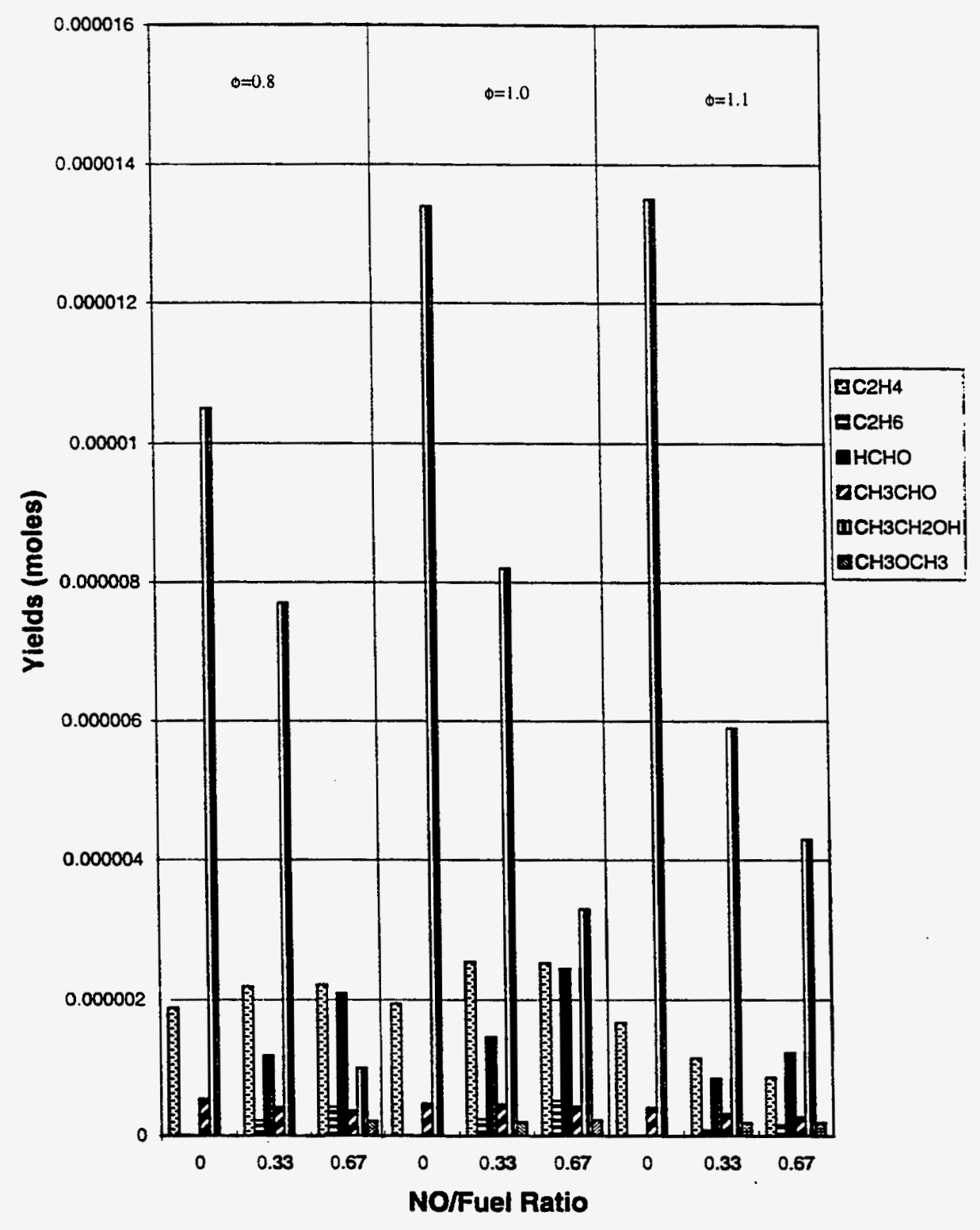

Figure 16. Molar yields of organic products from ethanol oxidation as a function of [NO] and fuel/air equivalence ratio. $\mathrm{T}=650^{\circ} \mathrm{C}, \mathrm{t}_{\mathrm{r}}=0.75 \mathrm{~s}$. For $\phi=0.8,\left[\mathrm{CH}_{3} \mathrm{CH}_{2} \mathrm{OH}\right]_{0}=225$ ppm, $[\mathrm{NO}]_{0}=75,150 \mathrm{ppm}$. For $\phi=1.0,\left[\mathrm{CH}_{3} \mathrm{CH}_{2} \mathrm{OH}\right]_{0}=285 \mathrm{ppm},[\mathrm{NO}]_{0}=95$, $190 \mathrm{ppm}$. For $\phi=1.1,\left[\mathrm{CH}_{3} \mathrm{CH}_{2} \mathrm{OH}\right]_{0}=310 \mathrm{ppm},\left[\mathrm{NO}_{0}=105,205 \mathrm{ppm}\right.$.

The addition of trace quantities of $\mathrm{NO}_{2}$ to stoichiometric mixtures of methanol and ethanol did not change the product distributions obtained for the neat fuels, within experimental error. A summary of the experimental results for M85 and E85 are given in Figures 18 and 19. A simplified notation is given in the ordinate in these graphs to relate the initial composition of the various mixtures. Conditions A-C, D-F, and G-I represent incremental addition of $\mathrm{NO}_{2}$ to the stoichiometric reaction mixtures (cases $A, D$, and $G$ are baseline cases) for reaction temperatures of 
500,650 , and $800^{\circ} \mathrm{C}$, respectively. The data indicate that $\mathrm{NO}_{2}$ does not influence the thermal degradation of either alcohol fuel component or their primary decomposition byproducts.

However, a dramatic effect was observed for both straight-chain and aryl hydrocarbon components of these fuels (cf. Figs. 18 and 19). A significant reduction in yields of these components was observed at all three temperatures investigated.

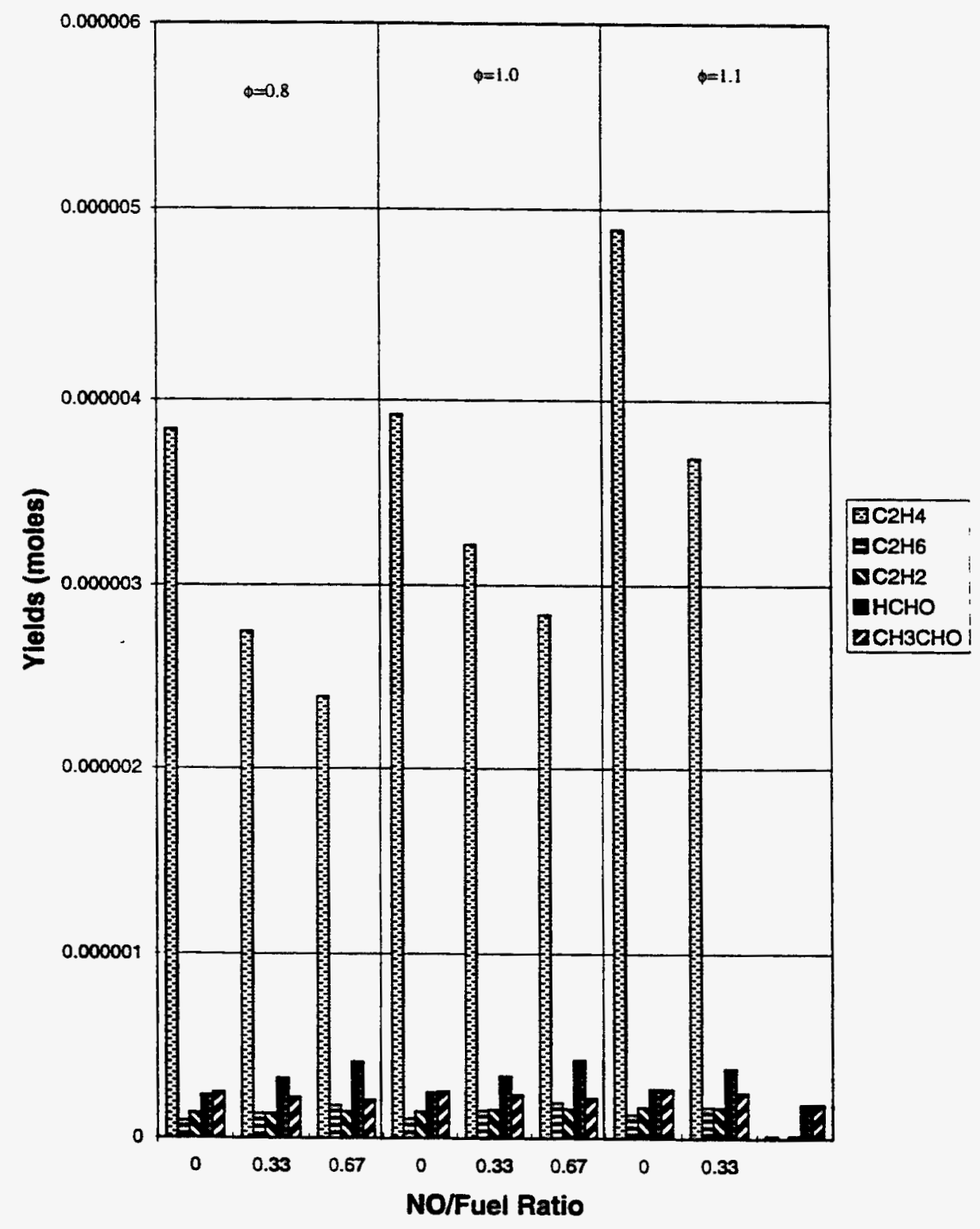

Figure 17. Molar yields of organic products from ethanol oxidation as a function of [NO] and fuel/air equivalence ratio. $\mathrm{T}=800^{\circ} \mathrm{C}, \mathrm{t}_{\mathrm{r}}=0.75 \mathrm{~s}$. For $\phi=0.8,\left[\mathrm{CH}_{3} \mathrm{CH}_{2} \mathrm{OH}\right]_{0}=280$ ppm, $[\mathrm{NO}]_{0}=90,185 \mathrm{ppm}$. For $\phi=1.0,\left[\mathrm{CH}_{3} \mathrm{CH}_{2} \mathrm{OH}\right]_{0}=355 \mathrm{ppm},[\mathrm{NO}]_{0}=115$, $235 \mathrm{ppm}$. For $\phi=1.1,\left[\mathrm{CH}_{3} \mathrm{CH}_{2} \mathrm{OH}\right]_{0}=390 \mathrm{ppm},[\mathrm{NO}]_{0}=130,260 \mathrm{ppm}$. 


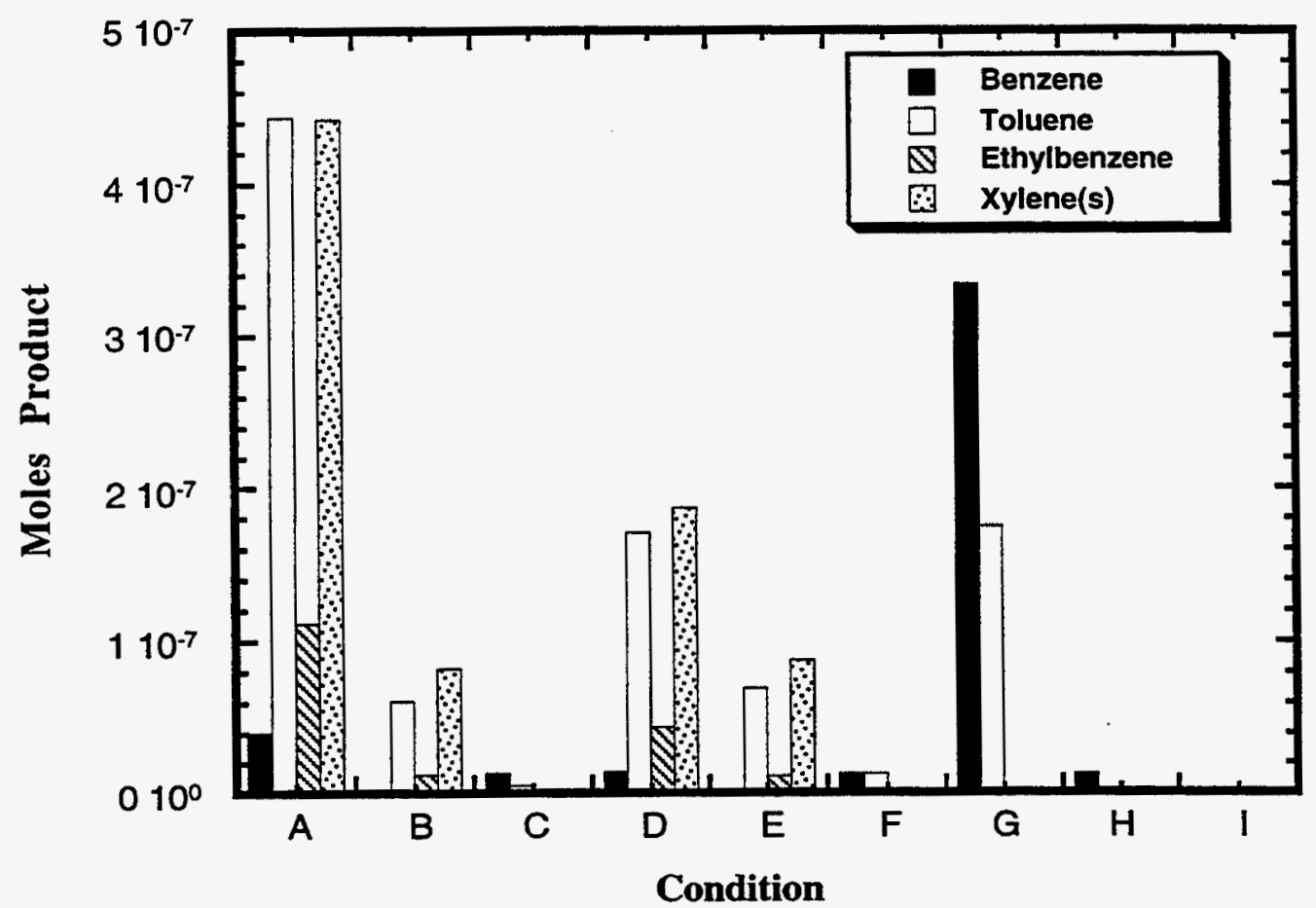

Figure 18. Organic product yields from the stoichiometric oxidation of M85 as a function of temperature and $\left[\mathrm{NO}_{2}\right] . \mathrm{t}_{\mathrm{r}}=0.75 \mathrm{~s},[\mathrm{M} 85]_{0} \sim 250 \mathrm{ppm},\left[\mathrm{NO}_{2}\right]_{0}=5,25 \mathrm{ppm}$. Conditions A-C, D$\mathrm{F}$, and $\mathrm{G}-\mathrm{I}$ represent incremental addition of $\mathrm{NO}_{2}$ to the stoichiometric reaction mixtures (cases $\mathrm{A}$. $\mathrm{D}$, and $\mathrm{G}$ are baseline cases) for reaction temperatures of 500,650 , and $800^{\circ} \mathrm{C}$, respectively.

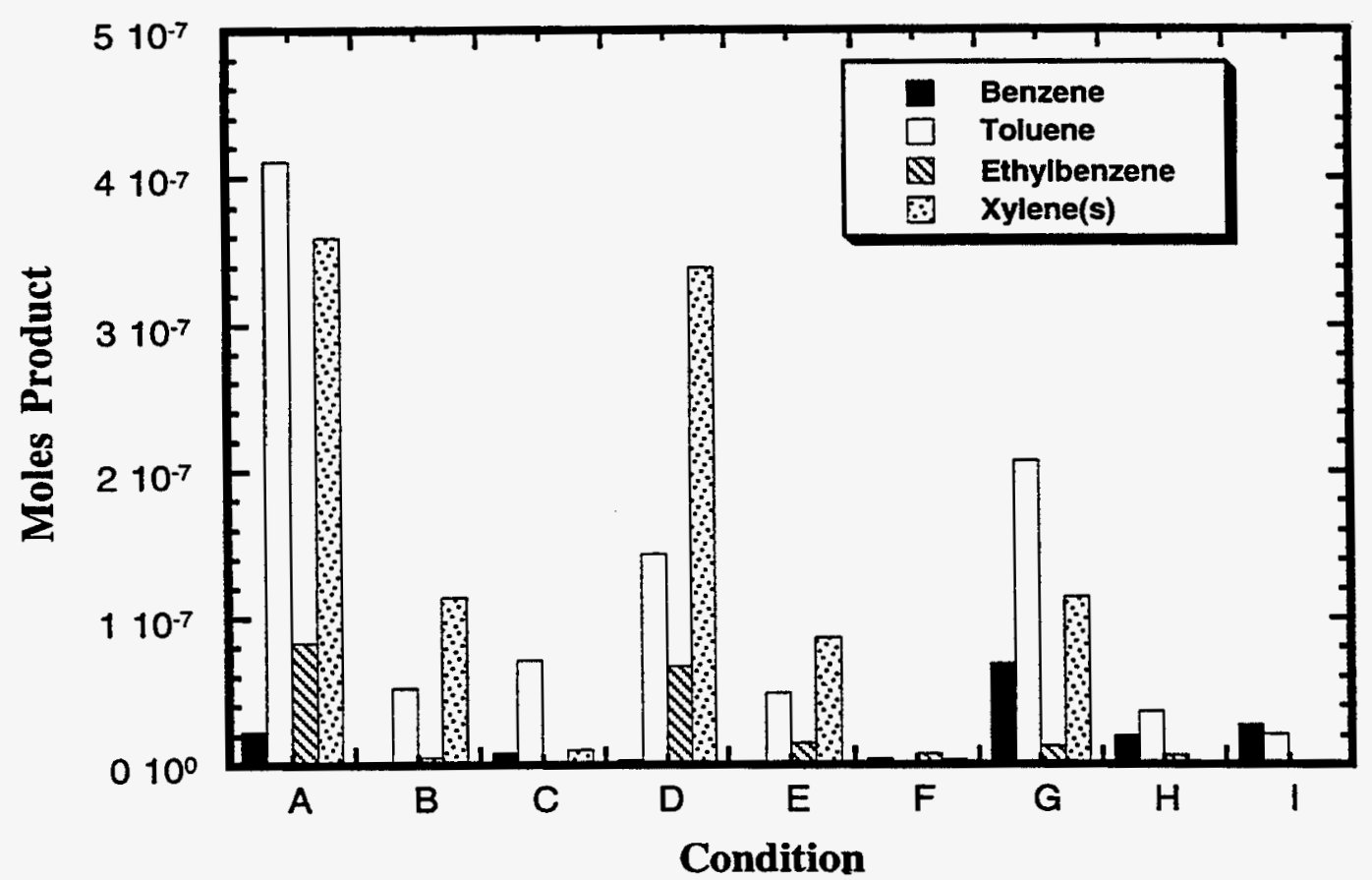

Figure 19. Organic product yields from the stoichiometric oxidation of E85 as a function of temperature and $\left[\mathrm{NO}_{2}\right] . \mathrm{t}_{\mathrm{r}}=0.75 \mathrm{~s}$, [E85 $]_{0} \sim 200 \mathrm{ppm},\left[\mathrm{NO}_{2}\right]_{0}=4,20 \mathrm{ppm}$. Conditions A-C, D$\mathrm{F}$. and $\mathrm{G}-\mathrm{I}$ represent incremental addition of $\mathrm{NO}_{2}$ to the stoichiometric reaction mixtures (cases $\mathrm{A}$. $\mathrm{D}$, and $\mathrm{G}$ are baseline cases) for reaction temperatures of 500,650 , and $800^{\circ} \mathrm{C}$, respectively. 
Studies of the addition of $\mathrm{NO}$ or $\mathrm{NO}_{2}$ to the stoichiometric oxidation of natural gas and LP gas did not show any effect on fuel conversion or formation of intermediate products. Previous studies of the interaction of $\mathrm{NO}$ and $\mathrm{NO}_{2}$ with these fuels have reported substantial effects [6,14]. However, these prior studies were conducted at low temperatures $\left(\leq 500^{\circ} \mathrm{C}\right)$ and once again point to the conversion of unreactive $\mathrm{HO}_{2}$ radicals to more reactive $\mathrm{OH}$ radicals in the cool flame oxidation of these fuels. At elevated temperatures, the perturbation on the $\mathrm{OH}$ radical concentration with $\mathrm{NO}$ or $\mathrm{NO}_{2}$ addition was insignificant under our experimental conditions.

\section{Discussion}

The distribution of observed products upon NO addition suggests that both promoting and inhibiting effects were observed for each reaction system, depending on the experimental conditions. For methanol, a significant decrease in cumulative organic by-product yields (factor of 3 to 5) was observed at $650^{\circ} \mathrm{C}$; yet at $800^{\circ} \mathrm{C}$, organic byproduct yields showed a slight increase with NO concentration. For ethanol, an opposite trend was evident. Cumulative organic byproduct yields generally increased slightly with $\mathrm{NO}$ concentration at $500^{\circ} \mathrm{C}$ and decreased with NO concentration at $650^{\circ} \mathrm{C}$ and $800^{\circ} \mathrm{C}$. The experimental results suggest that NO perturbs the oxidation chemistry of methanol and ethanol in a complex fashion, acting as a promoter with both fuels and certain intermediates and as an inhibitor with other intermediates. The manifestation of these effects appears to be dominated by temperature and NO concentration. For methanol, the results further suggest that a threshold NO concentration may exist beyond which small changes in the oxidation chemistry occur. This effect was not as evident for ethanol.

Previous researchers $[1-6,14]$ have discussed mechanisms for the conversion of low concentrations of $\mathrm{NO}$ to $\mathrm{NO}_{2}$ promoted by hydrocarbons. At high NO concentrations and low temperatures, it is generally agreed that the conversion is a result of reactions of the type:

$$
\begin{aligned}
& \mathrm{NO}+\mathrm{RO}_{2}=\Rightarrow \mathrm{NO}_{2}+\mathrm{RO} \\
& \text { where } \mathrm{R}=\mathrm{H}, \mathrm{CH}_{3}, \mathrm{C}_{2} \mathrm{H}_{5}, \ldots, \mathrm{C}_{\mathrm{n}} \mathrm{H}_{2 \mathrm{n}+1} .
\end{aligned}
$$

and that the addition of $\mathrm{NO}$ significantly perturbs the steady state concentration of the reactive $\mathrm{OH}$ radical. It is generally accepted that this class of reactions is also responsible for the conversion of $\mathrm{NO}$ to $\mathrm{NO}_{2}$ in the atmosphere, where subsequent photolysis of $\mathrm{NO}_{2}$ results in ozone production and photochemical smog formation [15].

Peroxy radicals are not considered the dominant initial radicals formed from the intermediate temperature oxidation of alcohols [16]. For instance, for methanol, under these experimental conditions, $\mathrm{CH}_{2} \mathrm{OH}$ is considered the dominant initial radical species formed following $\mathrm{H}$ abstraction. The following chemically activated reaction can be envisioned for $\mathrm{CH}_{2} \mathrm{OH}$ in the presence of NO:

$$
\mathrm{CH}_{2} \mathrm{OH}+\mathrm{NO} \Leftrightarrow=>\mathrm{CH}_{2} \mathrm{OHNO}^{\#}=\Rightarrow \mathrm{CH}_{3} \mathrm{NO}_{2} \quad \Delta \mathrm{H}_{298}=-33.5 \mathrm{kcal}^{-\mathrm{mol}^{-1}}
$$

An alternative reaction, important at higher temperatures where $\mathrm{C}-\mathrm{O}$ bond fission becomes important [10], involves:

$$
\mathrm{CH}_{3}+\mathrm{NO}_{2}+\mathrm{M}<----->\mathrm{CH}_{3} \mathrm{NO}_{2}+\mathrm{M}
$$


$\mathrm{R} 2$ is kinetically more difficult to envision than $\mathrm{R} 3$, a simple radical recombination reaction. However, since nitromethane was only observed from methanol oxidation in experiments at low temperatures $(773 \mathrm{~K})$, a reaction involving $\mathrm{CH}_{2} \mathrm{OH}$ radicals appears more plausible.

For ethanol, under these experimental conditions, the dominant initial radical species following $\mathrm{H}$ abstraction include $\mathrm{CH}_{2} \mathrm{CH}_{2} \mathrm{OH}$ and $\mathrm{CH}_{3} \mathrm{CHOH}$ [17]. Based on $\mathrm{R} 2$, one would expect nitroethane to be a product under these experimental conditions. Nitromethane, but not nitroethane was the observed nitrogenated compound at $500^{\circ} \mathrm{C}$. This result suggests that the dominant radical species derived from ethanol oxidation readily decompose, providing a source of stable $\mathrm{CH}_{3}$ and $\mathrm{CH}_{2} \mathrm{OH}$ radicals that react with $\mathrm{NO}$ and $\mathrm{NO}_{2}$ as described by $\mathrm{R} 2$ and $\mathrm{R} 3$. The facile decomposition of $\mathrm{CH}_{3} \mathrm{CHOH}$ yielding $\mathrm{CH}_{3}$ and $\mathrm{HCHO}$ is consistent with the observation of $\mathrm{HCHO}$ as a by-product of ethanol oxidation. Hence, for ethanol, R3 represents a plausible source of nitromethane formation.

Prabhu et al [18] recently reported that addition of small concentrations of NO (0-500 ppm) significantly altered 1-pentene oxidation $\left(325\right.$ to $\left.525^{\circ} \mathrm{C}\right)$ as a result of competition between its promoting effect through reaction with $\mathrm{HO}_{2}$ radicals (R4) and its retarding effect through reaction with $\mathrm{OH}$ radicals (R5):

$$
\begin{aligned}
& \mathrm{NO}+\mathrm{HO}_{2}-\rightarrow->\mathrm{NO}_{2}+\mathrm{OH} \\
& \mathrm{NO}+\mathrm{OH}+\mathrm{M} \rightarrow-->\mathrm{HONO}+\mathrm{M} .
\end{aligned}
$$

This effect is a function of temperature, the underlying fuel oxidation chemistry which generates $\mathrm{HO}_{2}$ and $\mathrm{OH}$ radicals, and the concentration of the NO added.

Molecular oxygen and hydroperoxy radicals are believed to be the key initiating species for the intermediate-temperature conversion of methanol and ethanol to formaldehyde and ethene and acetaldehyde, respectively [16]. To a first approximation, our experiments appear to be consistent with the observations of Prabhu et al [18]. The competition between $\mathrm{OH}$ attack on the fuel and intermediate products and the reaction of $\mathrm{OH}$ with NO may partially explain the observed changes in byproduct distributions with NO addition. For example, under all conditions, fuel consumption is promoted with $\mathrm{NO}$ addition. The promotional influence of $\mathrm{NO}$ on the oxidation of methanol and ethanol results largely from the ability of NO to convert hydroperoxy radicals to more reactive $\mathrm{OH}$ radicals. The potential inhibitory effect of R5 is not observed because of the much faster reaction rates of $\mathrm{OH}$ radicals with both methanol and ethanol [17]. For example, at $500^{\circ} \mathrm{C}$, the rate coefficient for the reaction of $\mathrm{OH}$ with methanol and ethanol is $2.79 \times 10^{12} \mathrm{~cm}^{3} / \mathrm{mol}-\mathrm{s}$ and $4.42 \mathrm{x}$ $10^{12} \mathrm{~cm}^{3} / \mathrm{mol}-\mathrm{s}$, respectively [17]. This compares with the rate coefficient for R5 of $\sim 3 \times 10^{12}$ $\mathrm{cm}^{3} / \mathrm{mol}-\mathrm{s}$ [3]. This competition favors methanol and ethanol even more at higher temperatures due to the negative temperature dependence of R5 [19]. Alternatively, the consumption of ethene was inhibited by NO addition under certain conditions (cf. Figure 14 and 16). The reaction of $\mathrm{OH}$ radicals with ethene is considerably slower than with NO. For example, at $500^{\circ} \mathrm{C}$, the rate coefficient for the reaction of $\mathrm{OH}$ with ethene is $4.09 \times 10^{11} \mathrm{~cm}^{3} / \mathrm{mol}-\mathrm{s}$ [16]. This is a factor of 7.3 slower than the rate coefficient for R5. This results suggests that, unless NO is rapidly consumed in the initial stages of the reaction, R5 becomes a significant inhibitory effect under these conditions. 


\section{Conclusions and Recommendations}

Experiments of the $\mathrm{NO}_{x}$ perturbed oxidation of methanol, M85, ethanol, E85, natural gas, and LP gas have been completed for temperatures ranging from 500 to $1075^{\circ} \mathrm{C}$. The results are summarized as follows:

1. At mild temperatures, NO addition results in enhanced fuel conversion for the alcohol fuels.

2. At elevated temperatures, an inhibitory effect was observed through increased vields of both partial oxidation and pyrolysis-type reaction products.

3. Changes in the concentrations of initiator radicals, i.e. $\mathrm{HO}_{2}$ and $\mathrm{OH}$ radicals, are proposed to account for the experimental observations.

4. The addition of $\mathrm{NO}_{\text {or }} \mathrm{NO}_{2}$ had no effect on high-temperature product distributions for natural gas and LP gas.

5. The addition of $\mathrm{NO}_{2}$ had no effect on product distributions for methanol and ethanol. For M85 and E85, however, reductions in concentrations of the hydrocarbon components of the fuels were observed with $\mathrm{NO}_{2}$ addition.

6. Products unique to studies conducted in the presence of NO included nitromethane (methanol, ethanol). hydrogen cyanide (methanol), isobutene (M85), dimethyl ether (ethanol. E85), 1.2pentadiene (E85) and n-heptane (E85).

We have previously shown [20] that comparison of flow reactor product distributions with vehicle results generally indicated improved comparisons when NO was added to the fuel. This improvement is an indication of the importance of post-cylinder reactions of residual fuel and NO. Previous experiments were conducted in the absence of NO [11,12]. These reactions result in additional conversion of residual fuel and the formation of partially oxidized intermediates and elevated levels of light hydrocarbon pyrolysis products. Even with the presence of NO accounted for, differences in product distributions betweeen laboratory flow reactor and vehicle tests remain. These differences may be due to failure mode mechanisms described in the introduction of this report that have yet to be examined. However. a more plausible explanation is thermal degradaton of lubricants that are not present in the laboratory studies.

\section{References}

1. Hori, M. 1986. 21st Symp. (Int.) on Combustion, p. 1181, The Combustion Institute.

2. Bromly, J. H., Barnes, F. J. and Little, L. 1988. H. J. Inst. Energy, 61: 89.

3. Bromly, J. H., Barnes, F. J., Mandyczewski, R., Edwards, T. J., and Haynes, B. S. 1992. 24th Symp. (Int.) on Combustion, p. 899, The Combustion Institute.

4. Hori, M., Matsunaga, N., Malte, P. C. and Marinov, N. M. 1992. 24th Symp. (Int.) on Combustion, The Combustion Institute, p. 909.

5. Doughty, A., Barnes, F.J., Bromly, J.H., and Haynes, B.S. 1996. 26th Symp. (Int.) on Combustion, p. 589, The Combustion Institute. 
6. Bromly, J. H., Barnes, F.J., Muris, S., You, X. and Haynes, B.S. 1996. Combust. Sci. Technol., 115: 259.

7. Johnson, G. M. and Smith, M. Y. 1978. Combust. Sci. Technol., 19: 67

8. Yano, T. and Ito, K. 1983. Bull. JSME, 26: 94.

9. ibid 1983. Bull. JSME, 26: 213.

10. Lyon, R. K., Cole, J. A., Kramlich, J. C., and Chen, S. L. 1990. Combust. Flame, 81: 30.

11. Zamansky, V. M., Ho, L., Maly, P. M., and Seeker, W. R. 1996. Combust. Sci. Technol., 120: 255

12. Shanbhag, S., Taylor, P. H., Rubey, W. A., and Dellinger, B. 1998. "Speciation of Organic Pollutants from the Thermal Degradation of Alternative Fuels," J. Air. \& Waste Manage. Assoc., in press.

13. Taylor, P. H., Cheng, L., and Dellinger, B. 1996. in "Alternative Fuel: Composition, Performance, Engines, and Systems," \#961088, SAE Technical Paper Series, Warrendale, PA.

14. Nelson, P. F. and Haynes, B. S. 1994. Twenty-Fifth Symp. (Int.) on Combustion, p. 1003, The Combustion Institute.

15. Seinfeld, J.H. 1986. "Atmospheric Chemistry and Physics of Air Pollution," John Wiley \& Sons, New York.

16. Norton, T.S. and Dryer, F.L. 1990. Twenty-Third Symp. (Int.) on Combustion, p. 179, The Combustion Institute.

17. Atkinson, R. 1989. J. Phys. Chem. Ref. Data, Monograph 1.

18. Prabhu, S.K., Bhat, R.K., Miller, D.L., and Cernansky, N.P. 1996. Combust. Flame, 104.

19. Atkinson, R., Baulch, D.L., Cox, R.A., Hampson, Jr., R.F., Kerr, J.A., and Troe, J. 1992. J. Phys. Chem. Ref. Data, 21, 1125.

20. Taylor, P. H., Cheng, L., Rubey, W. A., Striebich, R. C., Sidhu, S. S. and Dellinger, B. 1997. "The Origin and Fate of Organic Pollutants from the Combustion of Alternative Fuels: Phase IV Report," National Renewable Energy Laboratory SR-540-23145. 


\section{Task14 - Low Temperature, Surface Catalyzed and Gas Phase Pollutant Formation}

\section{Introduction}

The reactions occurring in the exhaust system greatly impact overall engine emissions. The threeway catalyst in the exhaust system mitigates NO, CO and hydrocarbon emissions, however, some organics like nitro-PAHs are also known to form in the exhaust system [1]. The extent of pollutant destruction and formation depends on temperature, residence time and the composition of the gas stream that enters the exhaust system from the exhaust port. This project is a continuation of our preliminary surface-catalysis study (Task 9) where we constructed our own three-way catalyst $(\mathrm{Pd} / \mathrm{Rh}$ in ratio 10:1) and conducted experiments in stoichiometric oxygen at a fixed residence time $(200 \mathrm{~ms})$ with and without $500 \mathrm{ppm}$ NO. In the preliminary study, we observed a number of partially oxidized reaction products (i.e., methyl formate, acetic acid, methyl acetate, etc.) that have not been previously reported in vehicle tests $[2,3]$ or post-combustion, laboratory-scale, gas-phase studies.[4-6] The results of that study have raised questions about the effect of some fundamental parameters, e.g. NO concentration, time and temperature distributions throughout the catalyst and catalyst formulation, on pollutant formation in engine exhaust systems.

To resolve differences in product distributions obtained from our previous study and vehicle emission test data, we conducted the present study using a commercial Pd/Rh (Degussa) catalyst under conditions characteristic of cold start, part load engine operation. This meant shorter residence time $(150 \mathrm{~ms})$ and higher NO concentrations $(1500 \mathrm{ppm})$. This NO concentration is based on representative engine exhaust mixture used in various laboratory studies as reported in literature.[7] The Degussa catalyst is a two brick system (dimensions of each brick are 3.15 in $\mathrm{x}$ 4.75 in $\times 2.0$ in) with a ceramic (Corning) substrate and a cell density of 400 cells/in ${ }^{2}$. The surface area of the catalyst is $52 \mathrm{~cm}^{2}$ with a substrate volume of $51.04 \mathrm{in}^{3}$. This Degussa threeway catalyst (TWC) has a $\mathrm{Pd} / \mathrm{Rh}$ ratio of $12: 1$ and a catalyst (metal) loading of $35 \mathrm{~g} / \mathrm{ft}^{3}$ which is very similar to the loading of our own catalyst used in the previous task. This should provide an accurate comparison between our laboratory catalyst and a commercially developed catalyst.

\section{Experimental Approach}

The experimental data for this task were obtained using the advanced thermal reactor system (ATRS). A schematic diagram of the ATRS is given in Figure 20. The ATRS consists of a dualchannel sample inlet system connected to a cylindrical quartz reactor vessel, and a heated exhaust line. For this project both inlet and exhaust lines were maintained at $100^{\circ} \mathrm{C}$. The ATRS is designed to give a nearly plug-flow residence time distribution. The quartz reactor vessel was 8 $\mathrm{cm}$ long with a $1 \mathrm{~cm}$ i.d. and contained a $5 \mathrm{~cm}$ long Degussa TWC plug which was obtained by boring Degussa catalyst brick. The catalytic reactor was then characterized to obtain total catalyst surface area and bulk density.

For this project, a split line was added to the reactor exhaust line because of the high gas flow rate (short residence time ) and large quantities of reactants injected. The sample trapping and analysis system of ATRS is located downstream of the exhaust split line. The cryogenic trap is cooled to $-140^{\circ} \mathrm{C}$ to collect the reactor effluent. Once the effluent collection process is complete, the trap is rapidly heated to $300^{\circ} \mathrm{C}$, releasing the collected material to an in-line gas chromatograph (GC)-mass selective detector (MSD)-hydrogen flame ionization detector (HFID) for analysis. 


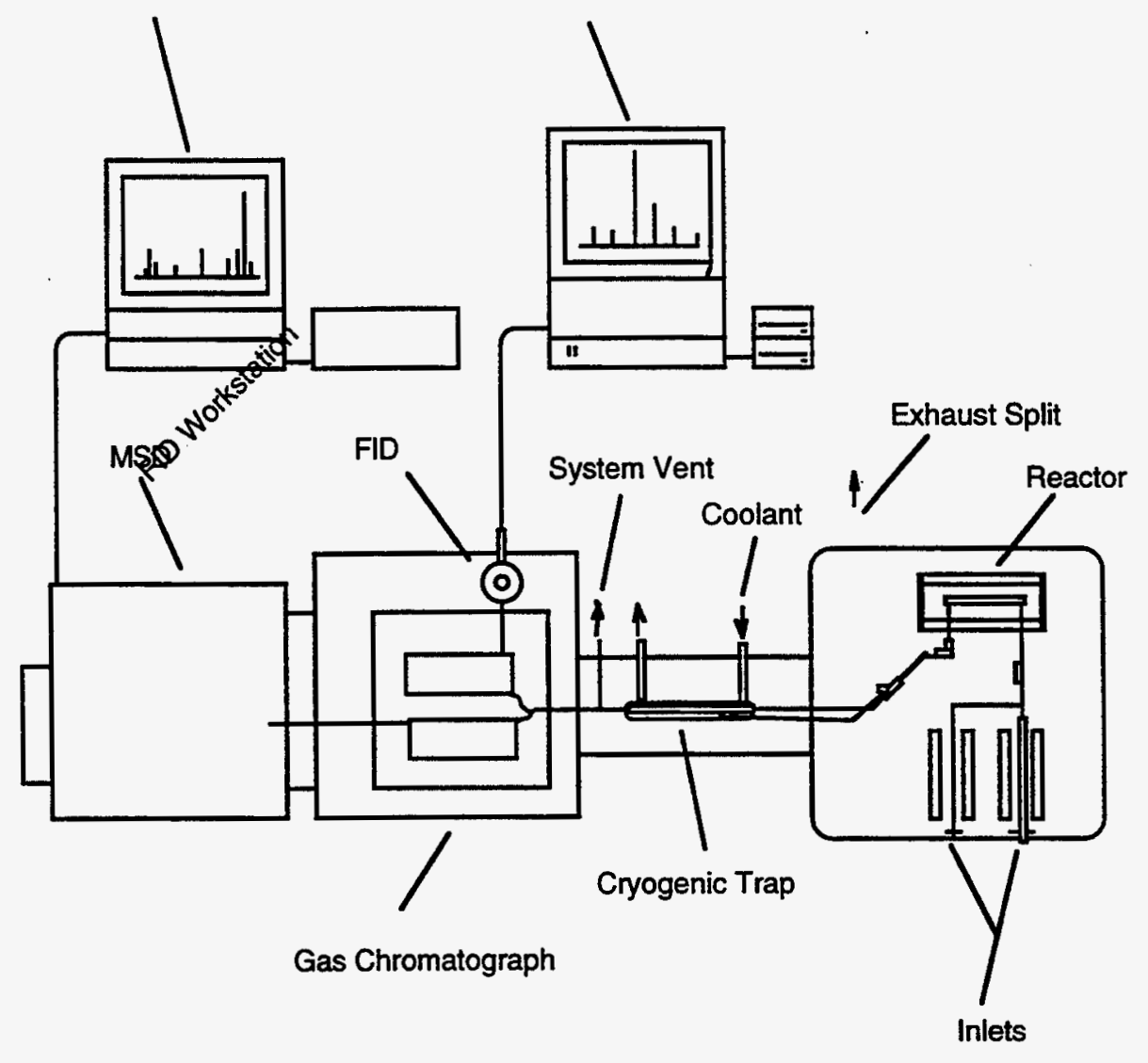

Figure 20. Schematic Diagram of Advanced Thermal Reactor System.

Experiments were conducted under fuel-lean conditions. A fuel concentration of $1000 \mathrm{ppmv}$ was maintained in all experiments to represent the unburnt fuel entering the automobile exhaust zone. A fuel - water mixture (to give $10 \% \mathrm{H}_{2} \mathrm{O}$ by volume in the reactor) was prepared and premixed in $3 \mathrm{~cm}^{3}$ Pyrex@ sample vials and injected into the insertion chamber using a calibrated syringe pump. Since M85 and E85 are not miscible in water, these two samples were prepared in a fine suspension using an ultrasonic shaker before injection into the reactor chamber. This technique was judged successful based on $a \pm 10 \%$ repeatability criterion. The reactor gas for these experiments consisted of $1 \% \mathrm{O}_{2}, 0.1 \% \mathrm{CO}$, and $1500 \mathrm{ppm} \mathrm{NO}$ in helium to emulate the postcombustion effluent. Four different fuels were tested: methanol, ethanol, M85 and E85. Experiments were conducted at temperatures of $100^{\circ} \mathrm{C}$ to $400^{\circ} \mathrm{C}$ in $50^{\circ} \mathrm{C}$ intervals. Experiments were conducted at reactor residence times of $150 \mathrm{~ms}$ which corresponds to a space velocity of $24,000 \mathrm{~h}^{-1}$. The time and temperatures were chosen to emulate the conditions in an exhaust system under cold start, part load operation.

For each experiment, the reactor effluent was collected in a cryogenic sampling system and subsequently analyzed. The analytical system of the ATRS is a programmed temperature GC (Hewlett-Packard, Model 5890) coupled to a HFID and MSD (Hewlett-Packard, Model 5970), the latter operating in the scanning mode ( $12 \mathrm{AMU}$ to $250 \mathrm{AMU}$ ). For this project, the HFID channel was fitted with a $15 \mathrm{~m}$ long DB-1 (J\&W Scientific) column with a $0.25 \mu \mathrm{m}$ film thickness. The MSD channel was fitted with a $2 \mathrm{~m}$ long DB-1 (J\&W Scientific) column with a $0.4 \mu \mathrm{m}$ film thickness. Both channels were connected to a common inlet fitted with 4:1 inlet splitter. For each analysis, the GC was temperature programmed from $-80^{\circ} \mathrm{C}$ (initial hold of $2 \mathrm{~min}$.) to $5^{\circ} \mathrm{C}$ at rate of $10^{\circ} \mathrm{C} / \mathrm{min}$ and then to $260^{\circ} \mathrm{C}$ (final temperature hold of $10 \mathrm{~min}$.) at a rate of $20^{\circ} \mathrm{C} / \mathrm{min}$. 
Identifications were accomplished using the mass spectral data and subsequently confirmed using analytical standards. Compound quantification was achieved using prepared standards of known concentration. In cases where standards were not available, structurally similar materials were used for product quantification.

\section{Results and Discussion}

The oxidation of methanol, ethanol, M85 and E85 was studied over a Degussa, Pd/Rh three-way catalyst under fuel-lean conditions. Experiments covered a temperature range of 100 to $400^{\circ} \mathrm{C}$, at an interval of $50^{\circ} \mathrm{C}$. No organic products were found above $300^{\circ} \mathrm{C}$ for any of the four fuels.

Weight percent product yields of all four fuels at $100^{\circ} \mathrm{C}, 200^{\circ} \mathrm{C}$, and $300^{\circ} \mathrm{C}$ are given in Figure 21 . For methanol and ethanol, we also conducted experiments in the absence of water with stoichiometric oxygen and varying NO concentration $(0$ and $500 \mathrm{ppm})$. These experiments were conducted to compare performance of the Degussa three way catalyst with the laboratory three way catalyst used in our previous study (task 9). Detailed experimental results for each fuel are given below.
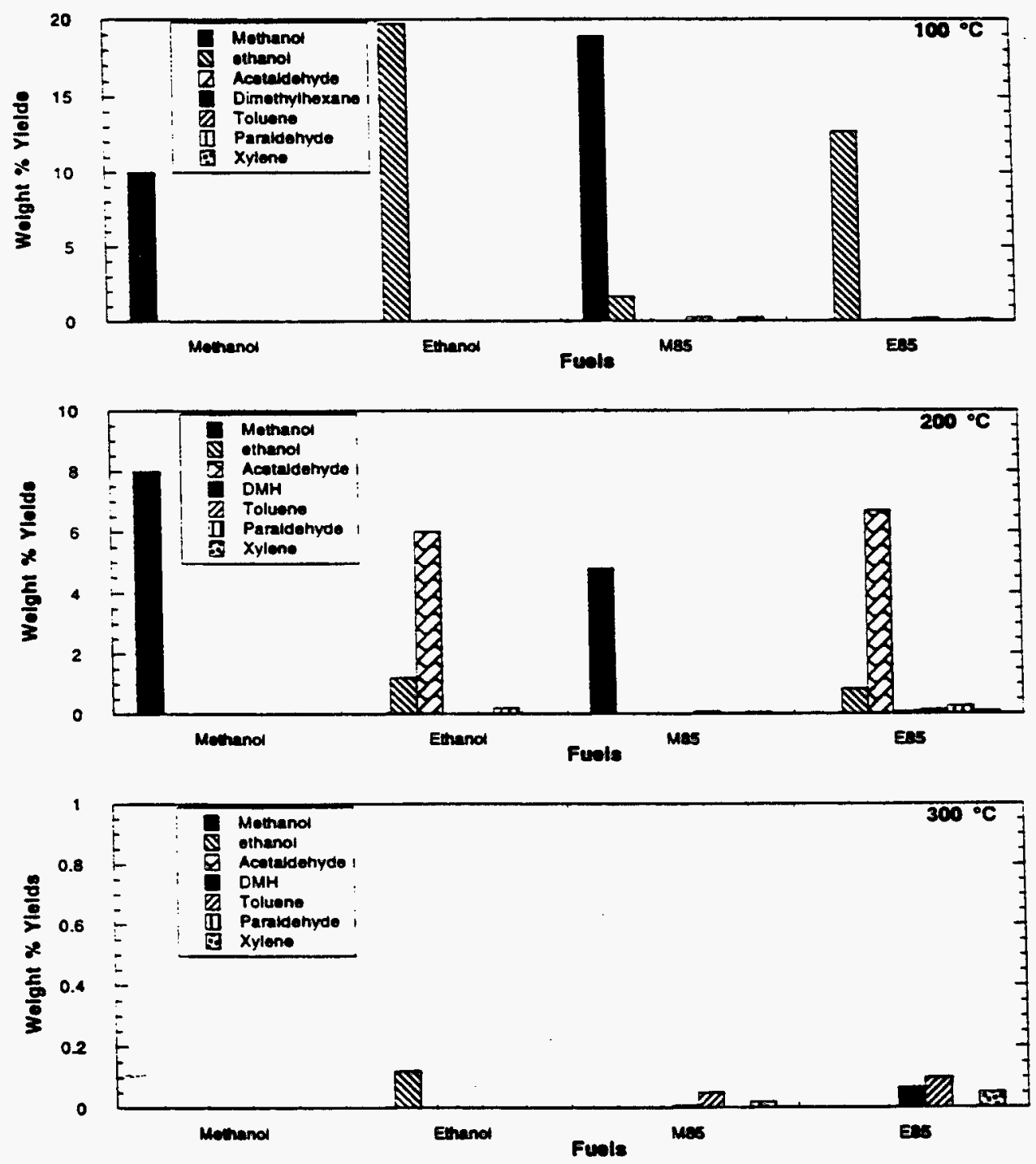

Figure 21. Product yields from four different fuels at 100,200 , and $300^{\circ} \mathrm{C}$. All fuels were passed over $\mathrm{Pd} / \mathrm{Rh}$ catalyst with a carrier gas containing $0.1 \% \mathrm{CO}, 1 \% \mathrm{O}_{2}, 10 \% \mathrm{H}_{2} \mathrm{O}$, and $1500 \mathrm{ppm}$ NO. Residence time $=150 \mathrm{~ms}$. Space velocity $=24,000 \mathrm{~h}^{-1}$. 


\section{Methanol}

GC-HFID traces at $100^{\circ} \mathrm{C}, 200^{\circ} \mathrm{C}$, and $300^{\circ} \mathrm{C}$ for the oxidation of $1000 \mathrm{ppm}$ of methanol in $10 \%$ $\mathrm{H}_{2} \mathrm{O}, 1 \% \mathrm{O}_{2}, 0.1 \% \mathrm{CO}$ and $1500 \mathrm{ppm} N \mathrm{NO}$ over a Degussa $\mathrm{Pd} / \mathrm{Rh}$ three-way catalyst are shown in Figure 22. Methanol conversion was greater than $99 \%$ by $250^{\circ} \mathrm{C}$. Methyl nitrite was the only organic product observed. However, we were concerned that methyl nitrite might be a sampling artifact based on earlier studies of engine emissions from methanol fueled vehicles [8-10]. To check our sampling system we removed the catalytic reactor and repeated the experiment keeping the transfer lines at room temperature. Methyl nitrite was still observed. From these results, we concluded that unconverted methanol reacted with NO in the transfer lines downstream of the catalytic reactor to form methyl nitrite. This is consistent with findings of Morikawa and Ito [8] that secondary formation (at room temperature after the catalytic converter) was a major contributor to methyl nitrite emissions. As a result, methyl nitrite is reported as unconverted methanol in this report.
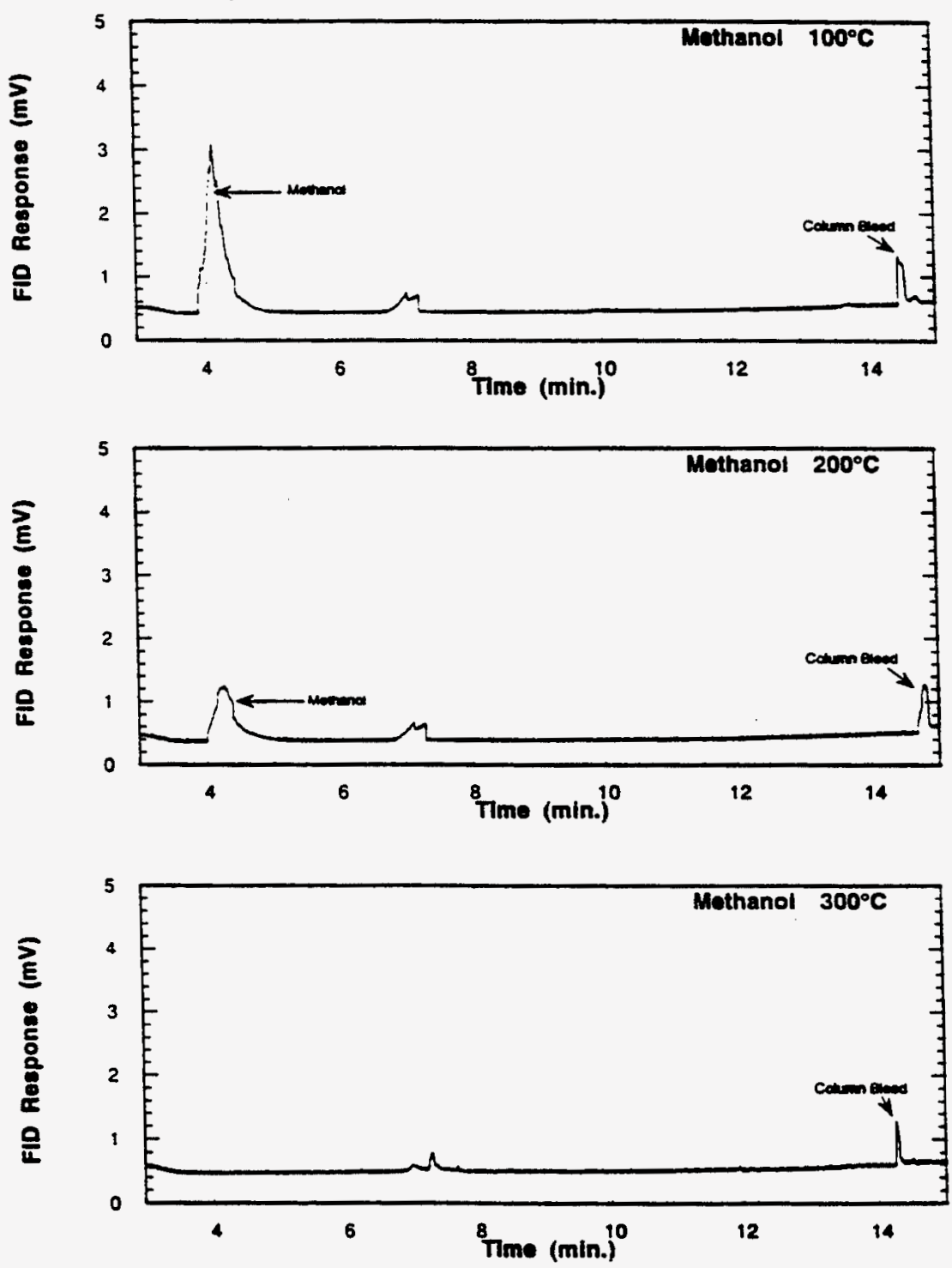

Figure 22. GC-FID traces for $1000 \mathrm{ppm}$ methanol over $\mathrm{Pd} / \mathrm{Rh}$ catalyst in carrier gas containing $0.1 \% \mathrm{CO}, 1 \% \mathrm{O}_{2}, 10 \% \mathrm{H}_{2} \mathrm{O}$, and $1500 \mathrm{ppm}$ NO. Residence time $=150 \mathrm{~ms}$. Space velocity $=24,000 \mathrm{~h}^{-1}$. 
We also conducted experiments with $1000 \mathrm{ppm}$ of methanol in stoichiometric oxygen in the absence of NO and then in stoichiometric oxygen with $500 \mathrm{ppm}$ of NO over a Degussa $\mathrm{Pd} / \mathrm{Rh}$ three-way catalyst at $100^{\circ} \mathrm{C}$. Methanol conversion for three $100^{\circ} \mathrm{C}$ experiments (cf. Figure 23) ranged from 87 to $90 \%$ and no organic products were observed. These three methanol experiments produced identical results within the limits of experimental uncertainty. This lead us to conclude that methanol conversion is not dependent on oxygen, NO or water concentration at a space velocity of $24,000 \mathrm{~h}^{-1}$. In our previous study, we observed that in absence of NO, methanol was completely converted and methyl formate was the major product from the oxidation of $1000 \mathrm{ppm}$ of methanol in stoichiometric oxygen at $100^{\circ} \mathrm{C}$. When $500 \mathrm{ppm}$ of NO was added to the reaction mix, methanol conversion decreased but methyl formate was still the major product. We believe that difference in product distributions between our two studies is mainly due to differences in catalyst formulation.
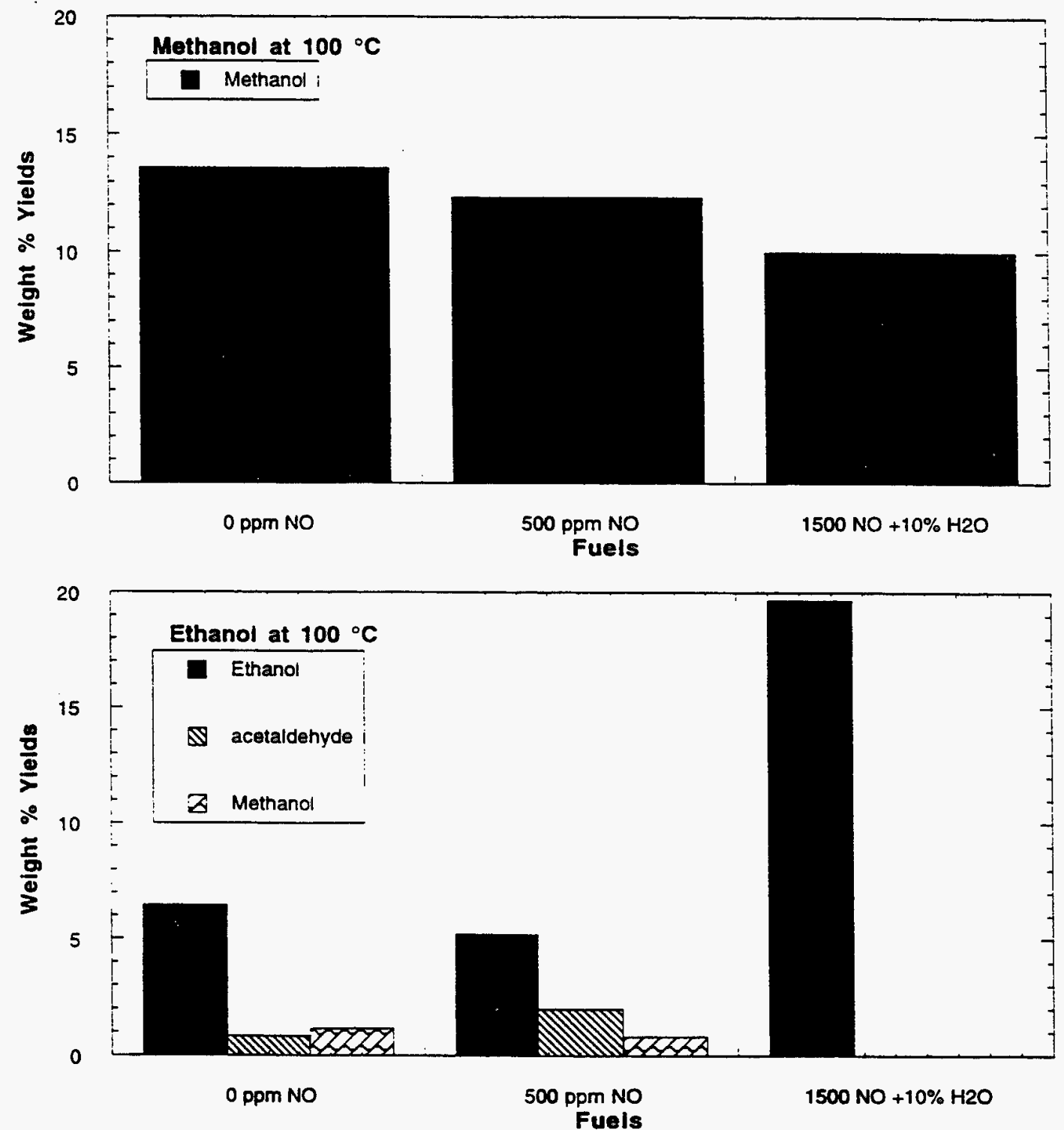

Figure 23. Effect of NO concentration on conversion of methanol and ethanol over $\mathrm{Pd} / \mathrm{Rh}$ catalyst at $100^{\circ} \mathrm{C}$. Experiments with 0 and $500 \mathrm{ppm}$ NO were conducted under stoichiometric conditions; experiments with 1500 ppm NO were conducted under fuel-lean conditions. 


\section{Ethanol}

GC-HFID traces at $100^{\circ} \mathrm{C}, 200^{\circ} \mathrm{C}$, and $300^{\circ} \mathrm{C}$ for oxidation of $1000 \mathrm{ppm}$ of ethanol in $10 \% \mathrm{H}_{2} \mathrm{O}$, $1 \% \mathrm{O}_{2}, 0.1 \% \mathrm{CO}$ and $1500 \mathrm{ppm}$ NO over a Degussa Pd/Rh three-way catalyst are shown in Figure 24 . Ethanol conversion was greater than $99 \%$ by $300^{\circ} \mathrm{C}$. Ethyl nitrite, acetaldehyde, and paraldehyde were the only organic products observed. To check if ethyl nitrite might also be a sampling artifact like methyl nitrite we again removed catalytic reactor and repeated the experiment keeping the transfer lines at room temperature. Once again we observed ethyl nitrite. From these results we concluded that like methanol, unconverted ethanol also reacted with NO in the transfer lines downstream of catalytic reactor to form ethyl nitrite. Hence, we have reported ethyl nitrite as unconverted ethanol in this report.
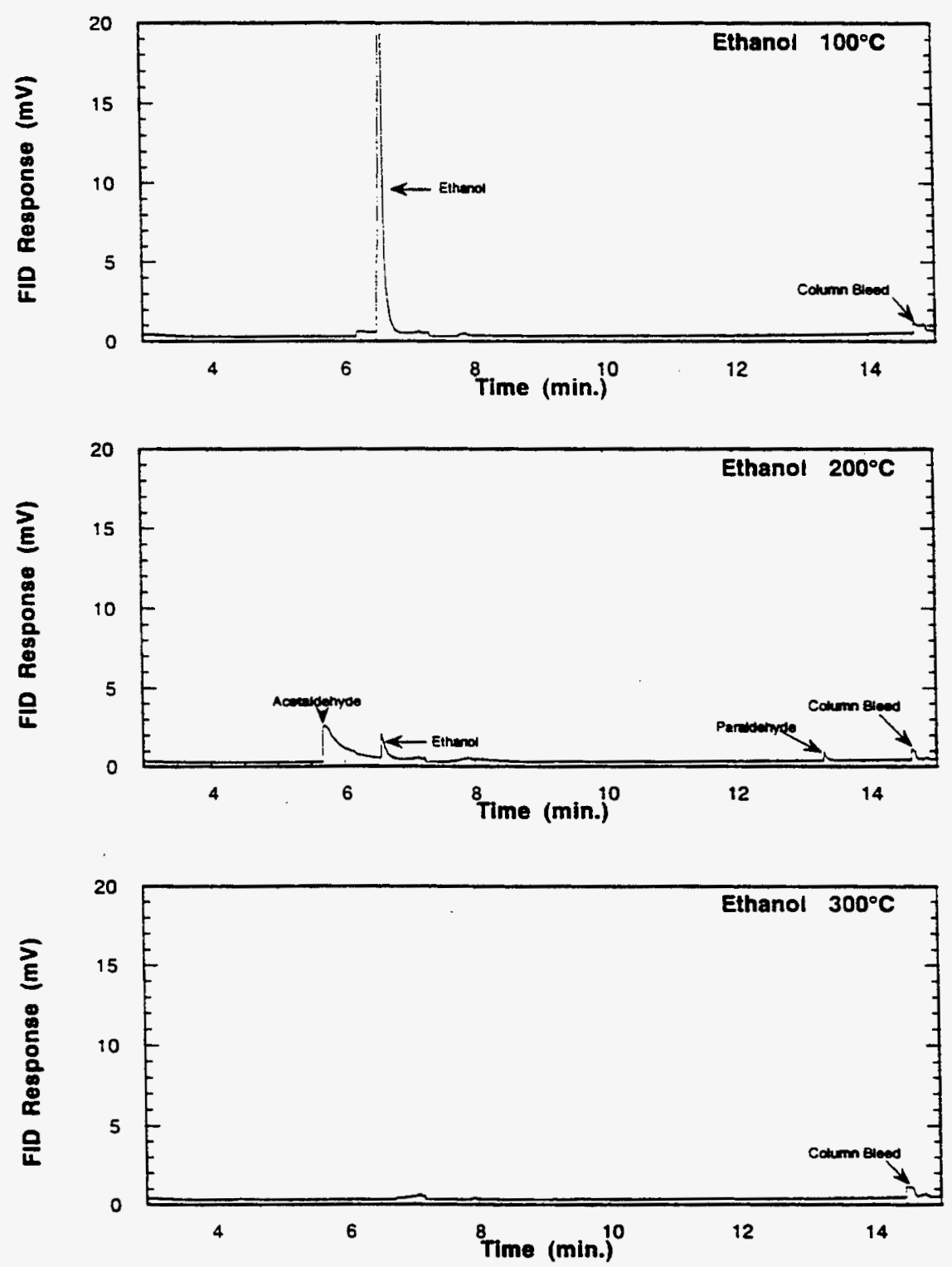

Figure 24. GC-FID traces for $1000 \mathrm{ppm}$ ethanol over $\mathrm{Pd} / \mathrm{Rh}$ catalyst in carrier gas containing $0.1 \% \mathrm{CO}, 1 \% \mathrm{O}_{2}, 10 \% \mathrm{H}_{2} \mathrm{O}$, and $1500 \mathrm{ppm}$ NO. Residence time $=150 \mathrm{~ms}$. Space velocity $=24,000 \mathrm{~h}^{-1}$. 
Acetaldehyde was the main organic product of the ethanol experiments. Acetaldehyde was first observed at $150^{\circ} \mathrm{C}$ and was below detection limits by $300^{\circ} \mathrm{C}$. Paraldehyde was also observed at $150^{\circ} \mathrm{C}$ and $200^{\circ} \mathrm{C}$. These are the temperatures at which acetaldehyde conversion was approximately 6 weight percent of the inlet ethanol concentration. This led us to consider that paraldehyde, a polymer of acetaldehyde, might be formed downstream of the catalytic reactor. To verify this hypothesis we ran acetaldehyde standards without the reactor and found that paraldehyde was indeed formed in the transfer lines. However, since paraldehyde is a minor product $(<0.3 \mathrm{wt} \%)$ and we did not measure the rate of conversion of acetaldehyde to paraldehyde, we will report paraldehyde as paraldehyde in this report.

We also conducted experiments with $1000 \mathrm{ppm}$ of ethanol in stoichiometric oxygen without NO and then in stoichiometric oxygen with $500 \mathrm{ppm}$ of NO over a Degussa $\mathrm{Pd} / \mathrm{Rh}$ three-way catalyst at $100^{\circ} \mathrm{C}$. Ethanol conversion for these three $100^{\circ} \mathrm{C}$ experiments (cf. Figure 23) ranged from 80 to $95 \%$. Ethanol conversion increased from $93 \%$ to $95.5 \%$ when NO concentration was increased from 0 to $500 \mathrm{ppm}$. In these experiments acetaldehyde yield also increased from 0.8 to $2 \%$. However, the ethanol conversion dropped to $80 \%$ in reactor gas that contained $10 \% \mathrm{H}_{2} \mathrm{O}, 0.1 \%$ $\mathrm{CO}$ and $1500 \mathrm{ppm}$ of NO under fuel-lean conditions $\left(1 \% \mathrm{O}_{2}\right)$. This result is consistent with the findings of Bart et al. where under fuel-lean conditions hydrocarbon conversion over a Pt/Rh catalyst was reduced by the addition of water [11]. This happens because in excess oxygen steam reforming cannot occur and hydrocarbon conversion is mainly due to oxidation which is inhibited by water. These ethanol results are in apparent contradiction to our methanol results where it was observed that methanol conversion was not dependent on oxygen, NO or steam concentration at space velocity of $24,000 \mathrm{~h}^{-1}$. This difference in ethanol and methanol conversion can be explained by acetaldehyde formation from ethanol. Acetaldehyde is the major product from ethanol oxidation over the Degussa catalyst, and is formed by R5:

$$
\mathrm{C}_{2} \mathrm{H}_{5} \mathrm{OH}+0.5 \mathrm{O}_{2} \rightarrow \mathrm{CH}_{3} \mathrm{CHO}+\mathrm{H}_{2} \mathrm{O}
$$

By introducing water, we are shifting equilibrium towards ethanol and away from acetaldehyde formation, thus, inhibiting ethanol conversion. In case of methanol oxidation formaldehyde is formed but it is too fragile to survive these reaction condition (it is not observed in our experiments) and not available to shift the equilibrium towards methanol.

We have also compared the results of this study with the results of our previous study. Ethanol was not completely converted in either study. However, in our previous study we observed ethyl acetate, methyl acetate, acetone, acetic acid and vinyl acetate along with acetaldehyde from oxidation $1000 \mathrm{ppm}$ of ethanol in stoichiometric air at $100^{\circ} \mathrm{C}$ with 0 and $500 \mathrm{ppm}$ of NO. With exception of acetaldehyde, none of these products were observed in this study or in engine tests. The differences in product yields could be due to differences in residence time $(200 \mathrm{~ms})$ or catalyst formulation used in the previous study.

\section{M85}

GC-HFID traces at $100^{\circ} \mathrm{C}, 200^{\circ} \mathrm{C}$, and $300^{\circ} \mathrm{C}$ for oxidation of $1000 \mathrm{ppm}$ of $\mathrm{M} 85$ in $10 \% \mathrm{H}_{2} \mathrm{O}, 1 \%$ $\mathrm{O}_{2}, 0.1 \% \mathrm{CO}$ and $1500 \mathrm{ppm}$ NO over a Degussa Pd/Rh three-way catalyst are shown in Figure 25. M85 conversion was greater than $99 \%$ by $350^{\circ} \mathrm{C}$. Products observed from M85 experiments were methyl nitrite, ethyl nitrite, dimethylhexane, toluene and xylene. Based on our methanol and ethanol experiments, we have reported ethyl and methyl nitrite as unconverted ethanol and methanol. Ethanol is observed because it is a known impurity in M85. Toluene, dimethylhexane and xylene are major components of the gasoline fraction. Methanol in M85 did not produce any detectable organic products; this is consistent with methanol experiments. 

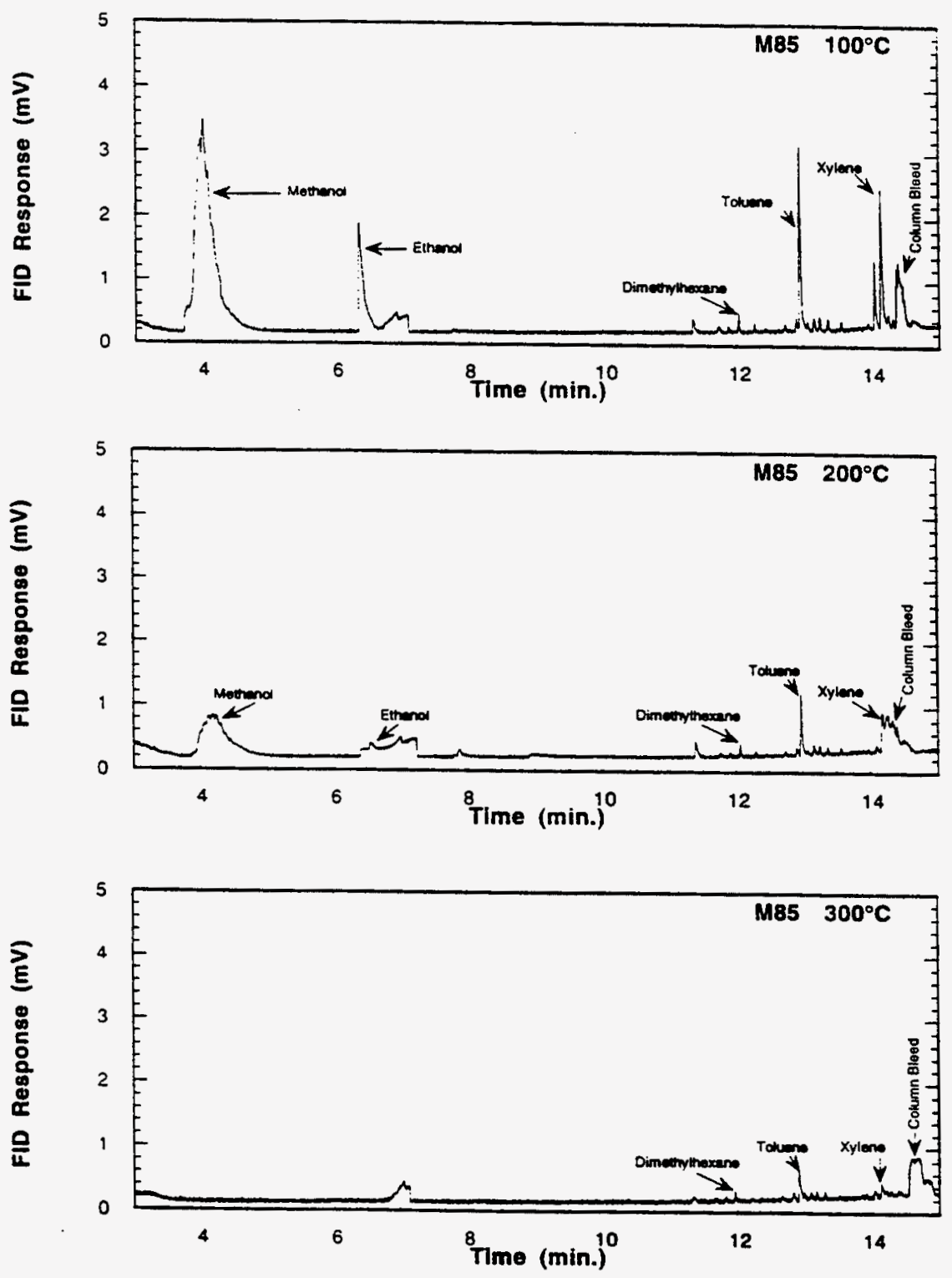

Figure 25. GC-FID traces for $1000 \mathrm{ppm} \mathrm{M85}$ over $\mathrm{Pd} / \mathrm{Rh}$ catalyst in carrier gas containing $0.1 \%$ $\mathrm{CO}, 1 \% \mathrm{O}_{2}, 10 \% \mathrm{H}_{2} \mathrm{O}$, and $1500 \mathrm{ppm}$ NO. Residence time $=150 \mathrm{~ms}$. Space velocity $=24,000 \mathrm{~h}^{-1}$. 


\section{E85}

GC-HFID traces at $100^{\circ} \mathrm{C}, 200^{\circ} \mathrm{C}$, and $300^{\circ} \mathrm{C}$ for oxidation of $1000 \mathrm{ppm}$ of $\mathrm{E} 85$ in $10 \% \mathrm{H}_{2} \mathrm{O}, 1 \%$ $\mathrm{O}_{2}, 0.1 \% \mathrm{CO}$ and $1500 \mathrm{ppm}$ NO over Degussa $\mathrm{Pd} / \mathrm{Rh}$ three way catalyst are shown in Figure 26. Like M85, E85 was also $99 \%$ converted by $350^{\circ} \mathrm{C}$. Products observed from E85 experiments were methyl nitrite, ethyl nitrite, acetaldehyde, paraldehyde, dimethylhexane, toluene, and xylene. Based on our methanol and ethanol experiments, we have reported ethyl and methyl nitrite as unconverted ethanol and methanol. Toluene, dimethylhexane and xylene are major components of the gasoline fraction. Like the ethanol experiments, acetaldehyde was first observed at $150^{\circ} \mathrm{C}$ and below detection limits by $300^{\circ} \mathrm{C}$. Paraldehyde was also observed at $150^{\circ} \mathrm{C}$ and $200^{\circ} \mathrm{C}$.
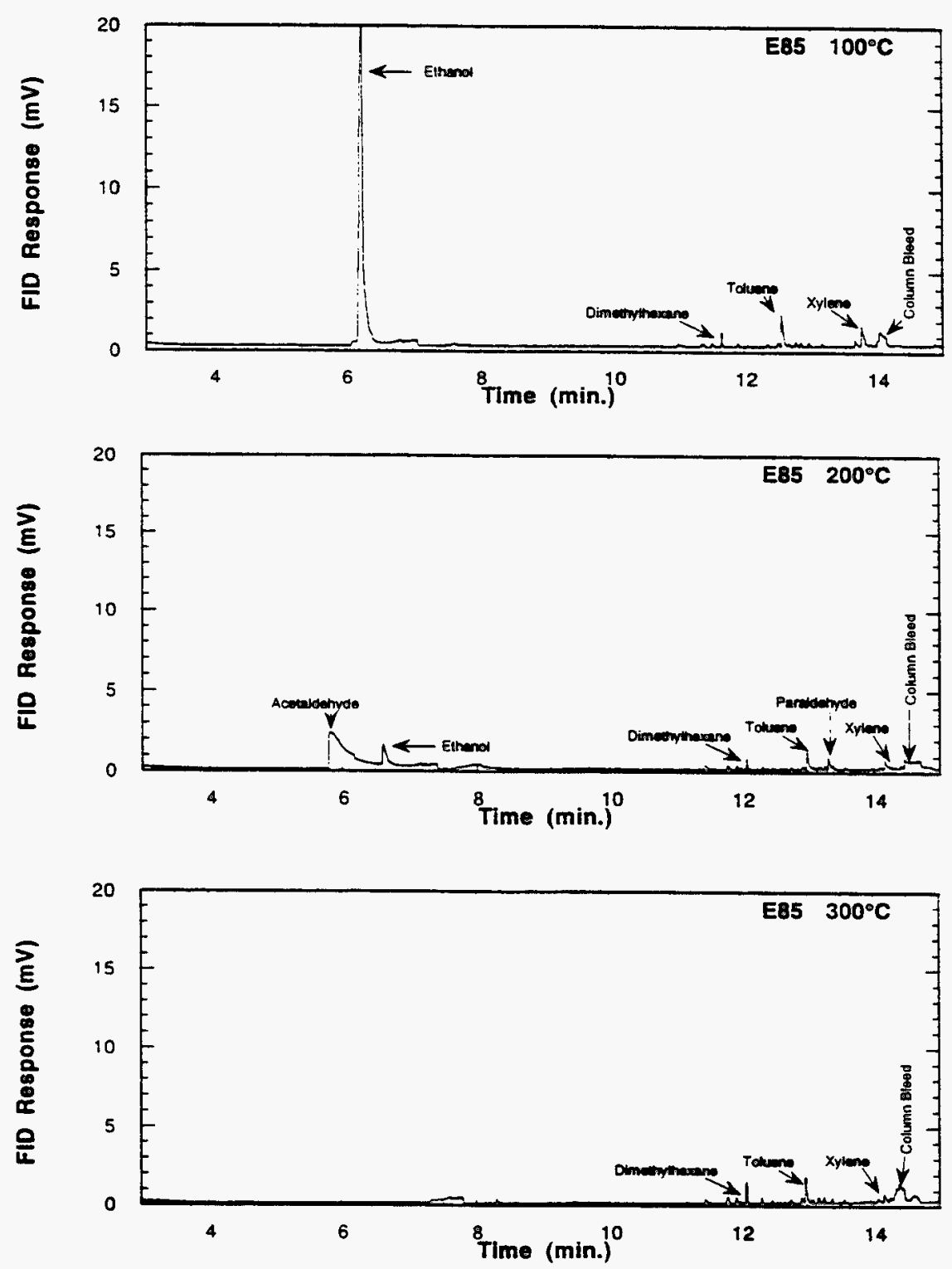

Figure 26. GC-FID traces for $1000 \mathrm{ppm}$ E85 over Pd/Rh catalyst in carrier gas containing $0.1 \%$ $\mathrm{CO}, 1 \% \mathrm{O}_{2}, 10 \% \mathrm{H}_{2} \mathrm{O}$, and $1500 \mathrm{ppm} \mathrm{NO}$. Residence time $=150 \mathrm{~ms}$. Space velocity $=24,000 \mathrm{~h}^{-1}$. 


\section{Conclusions and Recommendations}

Laboratory experiments were conducted simulating cold start of four alternative fuels using a commercial Degussa $\mathrm{Pd} / \mathrm{Rh}$ three-way catalyst under fuel-lean conditions. The results are summarized as follows:

1. Methanol and ethanol were $>99 \%$ converted at $300^{\circ} \mathrm{C}$; for $\mathrm{M} 85$, and E85, conversion was $\geq 99 \%$ at $350^{\circ} \mathrm{C}$.

2. Under fuel-lean conditions, the addition of steam inhibited conversion of ethanol and promoted formation of acetaldehyde.

3. The products observed in this study were similar to those observed in engine tests except we did not observe formaldehyde from methanol oxidation. This discrepancy could be because formaldehyde yields were below detection limits because of the fuel lean condition in the cold start temperature range.

4. The products observed in this study were different than our previous study. This difference in product distribution is likely due to a more efficient catalyst. The Degussa catalyst used in this study is a monolithic, honeycomb catalyst with far more surface area than the in-house catalyst (packed bed) used in the previous study.

5. Emissions from M85 and E85 were similar to methanol and ethanol emissions except for the formation of toluene, xylene, and dimethylhexane. These hydrocarbons are major components of the gasoline fraction and were apparently not readily oxidized with this catalyst under fuel-lean conditions.

These results are consistent with previous studies where 80 to $90 \%$ of the observed organic emissions occurred during the cold start temperature range of ambient to $450^{\circ} \mathrm{C}[2,3,6]$. However, a notable difference in this study was that emissions were observed under fuel-lean conditions as opposed to fuel-rich conditions considered more typical of cold start. This suggests that a significant factor in pollutant formation in catalytic converters may be low temperature and to a lesser extent variable stoichiometry. This further suggests that pollutant control technologies should focus on maintaining high temperatures rather than increasing the available oxygen concentration.

\section{References}

1. Schuetzle, D., and Perez, J.M. 1983. J. Air Poll. Cont. Assoc.. 33, 751.

2. Whitney, K.A. 1995. "Determination of Alternative Fuels Combustion Products," NREL/TP425-7528, Golden, CO: National Renewable Energy Laboratory.

3. Whitney, K.A. 1996. "Determination of Alternative Fuels Combustion Products," NREL/TP425-xxxx, Golden, CO: National Renewable Energy Laboratory.

4. Taylor, P.H., Shanbhag, S., and Dellinger, B. 1994. in Progress in Emission Control Technologies (SP-1053). SAE Technical Paper Series \#941904, p. 39, Warrendale, PA.

5. Shanbhag, S., Taylor, P.H., and Dellinger, B. 1996. "The Origin and Fate of Organic Pollutants from the Combustion of Alternative Fuels," presented at the 11th International Symposium on Alcohol Fuels, Sun City, South Africa. 
6. Taylor, P.H., Cheng, L., and Dellinger, B. 1996. in Alternative Fuel: Composition. Performance, Engines, and Systems (SP-1181), SAE Technical Paper Series \#961088, p. 269, Warrendale, PA.

7. Taylor, K.C. 1984. "Automobile Catalytic Converters," Springer-Verlag, New York.

8. Morikawa, T. and Ito K. 1996., "Formation of Methyl Nitrite in a Garage and Tunnel from Methanol Vehicle Exhaust Gases", Proceedings of the 11th International Symposium on Alcohol Fuels, Sun City, South Africa, p. 862.

9. Smith, L.R., Urban, C.M., and Baines, T.M. 1982. Proceeding of West Coast International Meeting, San Francisco, CA, SAE Technical Paper Series \#820967, Warrendale, PA.

10. Jonsson, A. and Bertilsson, B.M. 1982. Environ. Sci. Technol., 16, 106.

11. Bart, J.M., Pentenero, A., and Prigent, M., in Silver, R.G., Sawyer, J.E. and Summers, J.C. (Editors) 1992. Catalytic Control of Air Pollution, Mobile and Stationary Sources, ACS Symp. Series, Vol. 495, Am. Chem. Soc., Washington, p.42. 


\section{REPORT DOCUMENTATION PAGE}

Form Approved OMB NO. 07040188

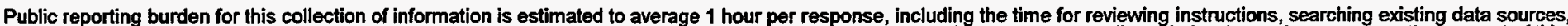

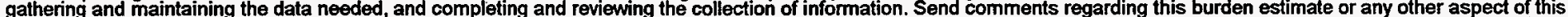

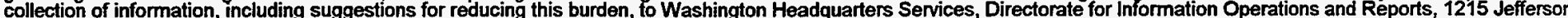

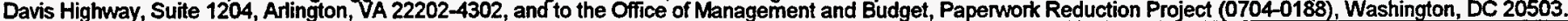
1. AGENCY USE ONLY (Leave blank)
2. REPORT DATE
3. REPORT TYPE AND DATES COVERED
May 1998
Subcontract report

\section{TITLE AND SUBTITLE}

The Origin of Organic Pollutants from the Combustion of Alternative Fuels: Phase VNVI Report

6. AUTHOR(S)

S. Sidhu, J. Graham, P. Taylor, and B. Dellinger

7. PERFORMING ORGANIZATION NAME(S) AND ADDRESS(ES)

University of Dayton Research Institute

Environmental Sciences and Engineering Group

300 College Park

Dayton, $\mathrm{OH} \quad 45469-0132$

\section{SPONSORING/MONITORING AGENCY NAME(S) AND ADDRESS(ES)}

National Renewable Energy Laboratory

1617 Cole Boulevard

Golden, CO 80401-3393

FUNDING NUMBERS

(C) XAU-3-12228-02

(TA) FU803230

\section{SUPPLEMENTARY NOTES}

12a. DISTRIBUTION/AVAILABILITY STATEMENT

National Technical Information Service

U.S. Department of Commerce

5285 Port Royal Road

Springfield, VA 22161

\section{ABSTRACT (Maximum 200 words)}

As part of the U.S. Department of Energy/National Renewable Energy Laboratory program on altemative automotive fuels, the subcontractor has been conducting studies on the origin and fate of organic pollutants from the combustion of alternative fuels. Laboratory experiments were conducted simulating cold start of four alternative fuels using a commercial three-way catalyst under fuel-lean conditions. This report summarizes the results of these experiments.
15. NUMBER OF PAGES 44

16. PRICE CODE

19. SECURITY CLASSIFICATION OF ABSTRACT
. PERFORMING ORGANIZATION REPORT NUMBER

0. SPONSORING/MONITORING AGENCY REPORT NUMBER

NRELSR-540-24134

12b. DISTRIBUTION CODE

UC-1504

\author{
17. SECURITY CLASSIFICATION \\ OF REPORT
}

18. SECURITY CLASSIFICATION OF THIS PAGE

\section{LIMITATION OF ABSTRACT}


Report Number (14)_NREL/SR $-540-24134$

Publ. Date (11)

Sponsor Code (18)

199805

UC Category (19)

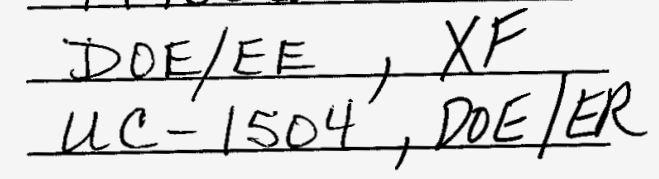

\section{6}

